Illinois State University

ISU ReD: Research and eData

Theses and Dissertations

5-18-2016

\title{
Effects Of A Self-Advocacy Intervention On The Ability Of High School Students With High Incidence Disabilities To Advocate For Academic Accommodations
}

Nancy J. Lopez

Illinois State University, nlopez418@aol.com

Follow this and additional works at: https://ir.library.illinoisstate.edu/etd

Part of the Special Education Administration Commons, and the Special Education and Teaching Commons

\section{Recommended Citation}

Lopez, Nancy J., "Effects Of A Self-Advocacy Intervention On The Ability Of High School Students With High Incidence Disabilities To Advocate For Academic Accommodations" (2016). Theses and Dissertations. 582.

https://ir.library.illinoisstate.edu/etd/582

This Dissertation is brought to you for free and open access by ISU ReD: Research and eData. It has been accepted for inclusion in Theses and Dissertations by an authorized administrator of ISU ReD: Research and eData. For more information, please contact ISUReD@ilstu.edu. 


\title{
EFFECTS OF A SELF-ADVOCACY INTERVENTION ON THE ABILITY OF HIGH SCHOOL STUDENTS WITH HIGH INCIDENCE DISABILITIES TO ADVOCATE FOR ACADEMIC ACCOMMODATIONS
}

\author{
Nancy J. Lopez \\ 207 Pages \\ One factor that may contribute to the success of students with disabilities in \\ postsecondary educational settings may be their ability to advocate for academic \\ accommodations (Garrison-Wade, 2012; Getzel \& Thoma, 2008). By incorporating self- \\ determination practices into the curriculum and transition process during high school, \\ students with disabilities may acquire the self-advocacy skills to be successful in \\ postsecondary settings. The purpose of this study was to examine the effects of a self- \\ advocacy intervention on the ability of five high school students with high incidence \\ disabilities to request academic accommodations in a high school general education \\ course. Specifically, this study was a systematic replication of Walker and Test (2011) \\ that focused on the impact of the Self-Advocacy and Conflict Resolution (SACR) \\ training program on the ability of students to request academic accommodations. This \\ study extended the research of Walker and Test by including (a) high school students \\ with disabilities as participants, (b) a disability awareness lesson that incorporated
}


information from each student's IEP, and (c) student self-evaluations of their video recorded role-plays. A multiple probe design across participants was employed to evaluate the effects of the SACR on 14-targeted behaviors. Findings indicated a functional relation between the SACR and the ability of students to request accommodations. As a result of instruction using the SACR, students acquired and maintained the self-advocacy skills, and then generalized the skills to the general education setting. Students and teachers also validated the importance of the goals, procedures, and effects of the intervention. Findings from this study are discussed along with limitations, suggestions for future research, and implications for educational practice.

KEYWORDS: Accommodations, High incidence disabilities, Self-advocacy, Selfdetermination. 
EFFECTS OF A SELF-ADVOCACY INTERVENTION ON THE ABILITY OF HIGH SCHOOL STUDENTS WITH HIGH INCIDENCE DISABILITIES

TO ADVOCATE FOR ACADEMIC ACCOMMODATIONS

NANCY J. LOPEZ

\begin{abstract}
A Dissertation Submitted in Partial Fulfillment of the Requirements for the Degree of DOCTOR OF EDUCATION Department of Special Education ILLINOIS STATE UNIVERSITY
\end{abstract}


(C) 2016 Nancy J. Lopez 
EFFECTS OF A SELF-ADVOCACY INTERVENTION ON THE ABILITY OF HIGH SCHOOL STUDENTS WITH HIGH INCIDENCE DISABILITIES

TO ADVOCATE FOR ACADEMIC ACCOMMODATIONS

NANCY J. LOPEZ

COMMITTEE MEMBERS:

Nicole M. Uphold, Chair

Karen H. Douglas

Shaqwana M. Freeman-Green 


\section{ACKNOWLEDGMENTS}

My dissertation journey has been bittersweet. Whenever I would catch a glimpse of the finish line, feelings of uncertainty would sometimes surface. Yet, somewhere along the way, I became empowered by the most amazing people, and I accomplished what I set out to do. To those of you who have guided me, supported me, mentored me, and encouraged me on my journey, I would like to express my sincerest appreciation.

I would like to begin by thanking my family for their unwavering love, constant support, and endless patience. Your support gave me the strength to finish.

Next, I would like to acknowledge my committee for sharing their scholarly knowledge, insightful feedback, and genuine enthusiasm for seeing others succeed. To my chair, Dr. Nicole Uphold, thank you for guiding me on my journey and teaching me to breathe along the way. To Dr. Karen Douglas, thank you for always seeing in me what I sometimes did not see in myself. To Dr. Shaqwana Freeman-Green, thank you for providing valuable insight and encouragement. I consider myself fortunate for having had the opportunity to work alongside the three of you.

Further, I would like to thank the members of the Chicago cohort. Together, we shared our experiences, supported each another, and enjoyed ourselves along the way.

Lastly, I would like to thank Ann and the rest of my Thunderbird family. This study would not have been possible without each and everyone of you. You guys rock!

N. J. L. 


\section{CONTENTS}

\section{Page}

ACKNOWLEDGMENTS

CONTENTS

TABLES vii

FIGURES viii

\section{CHAPTER}

I. THE PROBLEM AND ITS BACKGROUND 1

Introduction 1

Statement of the Problem $\quad 10$

Purpose of the Study $\quad 14$

Research Questions $\quad 15$

Definitions of Terms $\quad 15$

II. REVIEW OF RELATED LITERATURE 19

History of the Self-Advocacy Movement 19

Self-Advocacy and the Relatedness to Self-Determination and

Transition $\quad 24$

Definition of Self-Advocacy 24

Conceptual Framework of Self-Advocacy 26

Knowledge of self $\quad 27$

Knowledge of rights 28

Communication $\quad 29$

Leadership 30

Relationship Between Self-Advocacy and Self-Determination 31

Relationship Between Self-Advocacy and Transition 33

Findings from Major Reviews on Self-Advocacy Interventions 36 
Self-Advocacy Practices that Enhance the Transition Process

Interventions to Teach Students with Disabilities to Request

Requesting Accommodations in Postsecondary Education Settings

Requesting Accommodations in High School

Importance of Understanding Rights and Responsibilities

Components of Effective Interventions for Requesting

Accommodations

Lack of Diversity in Study Samples

Summary of Research on Requesting Accommodations

Chapter Summary and Synthesis

III. METHOD

Participants

Monique

Sasha

John

65

Todd

Setting

Materials

The Self-Advocacy \& Conflict Resolution Training (SACR):

Strategies for the Classroom Accommodation Request

SACR Template

Disability Awareness Graphic Organizer 68

IEP at a Glance

Student Binder

SACR Poster

Student Reflection Poster

Technology Tools

Data Collection Procedures

Interventionist

Data Collector

Dependent Variable 
Social Validity

Experimental Design $\quad 75$

$\begin{array}{ll}\text { Procedures } & 78\end{array}$

$\begin{array}{ll}\text { Pregeneralization Probe } & 79\end{array}$

Baseline Procedures $\quad 80$

Intervention Procedures $\quad 81$

$\begin{array}{ll}\text { Session } 1 & 82\end{array}$

Session 2

Session $3 \quad 84$

Session $4 \quad 85$

Session 5

Session $6 \quad 86$

Session $7 \quad 86$

Session $8 \quad 87$

$\begin{array}{ll}\text { Session } 9 & 87\end{array}$

$\begin{array}{ll}\text { Session } 10 & 87\end{array}$

$\begin{array}{ll}\text { Intervention booster sessions } & 88\end{array}$

Postgeneralization Probe $\quad 89$

Maintenance Procedures 90

IV. RESULTS 92

Interobserver Reliability $\quad 92$

Procedural Fidelity $\quad 93$

Effect of the SACR on the Dependent Variable 94

Requesting Accommodations in Role-Play Simulations 94

Monique $\quad 95$

La'Shay $\quad 97$

Sasha 98

John 99

Todd 100

Requesting Accommodations in the General Education Classroom

Monique 101

La'Shay $\quad 102$

$\begin{array}{ll}\text { Sasha } & 103\end{array}$

John 103 
Social Validity

Student Perceptions

Chapter Summary

V. DISCUSSION

Major Findings and Relevance to Extant Literature

Effect of the SACR on Student Outcomes

Providing explicit instruction

Promoting effective communication skills

Intervention Modifications

Disability awareness lesson

Student role-play self-analyses

Serendipitous Findings

Student Perceptions of the Intervention

Teacher Perceptions of the Intervention

Limitations and Future Research

APPENDIX B: SACR Student Lesson Templates

$\begin{array}{lll}\text { APPENDIX D: } & \text { SACR Poster } & 158\end{array}$

APPENDIX E: Student Reflection Poster 159

APPENDIX F: Target Behaviors for Requesting Accommodations 160 
APPENDIX G: Interobserver Reliability for Requesting Accommodations

APPENDIX H: Definition of Target Behaviors

APPENDIX I: $\quad$ Baseline and Maintenance Procedural Reliability Checklist

APPENDIX J: Intervention Procedural Reliability Checklist

APPENDIX K: Student Social Validity Survey

APPENDIX L: Teacher Social Validity Survey

APPENDIX M: Modified SACR Lesson Plans 


\section{TABLES}

Table $\quad$ Page

1. Requesting Accommodations Studies 58

2. Descriptive Characteristics of Participants 63

3. IOA Data Collection Results by Condition and Participant 93

4. Students' Perceptions of the SACR 106

5. General Education Teachers' Perceptions of the SACR 108 


\section{FIGURES}

Figure $\quad$ Page

1. Number of Target Behaviors Demonstrated During Role-Plays 96 


\section{CHAPTER I}

\section{THE PROBLEM AND ITS BACKGROUND}

\section{Introduction}

Preparing our youth to become productive citizens is recognized as a primary goal of education. This transition to adulthood can be daunting for all students, but particularly students with disabilities. When students with disabilities leave high school, they are not as resourceful as students without disabilities to face the challenges they may encounter when transitioning to postschool settings (Mazzotti, Rowe, Cameto, Test, \& Morningstar, 2013). Although outcomes for young adults with disabilities have been improving in the areas of employment, postsecondary programs, and independent living, same-age peers without disabilities are still experiencing better outcomes (Newman et al., 2011). For example, results from the National Longitudinal Transition Survey 2 (NLTS2) for young adults with disabilities indicated that only $60 \%$ of young adults with disabilities enrolled in postsecondary programs in comparison to $67 \%$ of peers in the general population. Additionally, postsecondary completion rates for students with disabilities were lower than rates for peers without disabilities. Only $41 \%$ of students with disabilities completed postsecondary programs, while $52 \%$ of the youth without disabilities did. In terms of employment, young adults with disabilities earned a lower wage than their peers without disabilities. On average, young adults without disabilities 
earned $\$ 11.40$ per hour, whereas those individuals with disabilities earned $\$ 10.40$ per hour. Furthermore, only $45 \%$ of youth with disabilities lived independently compared to $59 \%$ of their peers in the general population. These data provided by Newman et al. (2011) substantiate the importance of continually seeking to provide students with disabilities with the supports to successfully transition to postsecondary settings. As outcomes for students with disabilities improve, the gap between students with and without disabilities may continue to narrow.

As a result of the noted discrepancies in postschool outcomes between students with and without disabilities that first became apparent in the 1980s, more effective transition services became warranted (Landmark, Ju, \& Zhang, 2010). To address this charge, the Individuals With Disabilities Education Act (IDEA) of 1990 mandated the inclusion of transition services in the Individualized Education Programs (IEPs) of students with disabilities. Subsequent reauthorizations of IDEA in 1997 and 2004 more stringently identified the role of secondary special education personnel in planning and promoting the effective transition to postschool settings for students with disabilities (Mazzotti et al., 2013). Specifically, IDEA 2004 required measurable postsecondary goals in the areas of education, employment, training, and independent living based on the identification of students' strengths, preferences, interests and needs (Konrad, Walker, Fowler, Test, \& Wood, 2008; Morningstar et al., 2010). To facilitate this movement from school to postsecondary settings, researchers have identified evidencebased practices and predictors (Mazzotti et al., 2013; Test, Fowler, et al., 2009; Test, Mazzotti, et al., 2009) and transition best practices (Landmark et al., 2010). 
The promotion of self-determination is highly regarded as an evidence-based practice that will foster more positive postschool outcomes in students with disabilities (Wehmeyer, 2014). Incorporating self-determination practices into the curriculum and transition process empowers students with disabilities to take more control of their lives and the decisions that may impact their lives. According to Field, Martin, Miller, Ward, and Wehmeyer (1998), self-determination is "a combination of skills, knowledge, and beliefs that enables a person to engage in goal directed, self-regulated, autonomous behavior" (p. 2). Furthermore, researchers have recognized self-determination as a multifaceted construct comprised of component elements that must be addressed through instruction if students with disabilities are going to develop the skills to exhibit selfdetermined behavior (Wehmeyer, Agran, \& Hughes, 1998; Wehmeyer, Palmer, Soukup, Garner, \& Lawrence, 2007; Wood, Karvonen, Test, Browder, \& Algozzine, 2004). Considering self-determination skills may take years to develop, researchers have recommended that students have continuing opportunities to enhance these skills from the time they enter school and continue throughout their educational paths (e.g., Webb, Patterson, Syverud, \& Seabrooks-Blackmore, 2008; Wehmeyer, Sands, Doll, \& Palmer, 1997). In a study to determine the factors that most significantly impacted the development of self-determination during the school years, adults with physical disabilities identified the availability of on-going opportunities to practice selfdetermination skills as the most important variable fostering their self-determination (Angell, Stoner, \& Fulk, 2010). Participants acknowledged that experiencing both positive and negative outcomes promote the growth of self-determination. Consequently, repeated opportunities to develop and practice self-determination skills are necessary if 
we expect students with disabilities to acquire the skills that will enable them to become active participants in their lives.

To conceptualize self-determination, Wehmeyer et al. (1998) identified 12 interrelated component skills necessary for self-determined behavior. These component skills include (a) choice making; (b) decision making; (c) problem solving; (d) goal setting and attainment; (e) independence, risk taking, and safety skills; (f) selfobservation, evaluation, and reinforcement skills; (g) self-instruction; (h) self-advocacy and leadership skills; (i) internal locus of control; (j) positive attributes of efficacy and outcome expectancy; (k) self-awareness; and (1) self-knowledge. Wehmeyer (1999) declared that the identification of these component skills provide the foundation for developing instructional activities, strategies, and materials that may promote the enhancement of self-determination skills in students with disabilities. He further contended that instruction to promote self-determination occurs at the component level. Additionally, based on the component skills of self-determination, Wehmeyer, Agran, and Hughes (2000) identified seven instructional domains: (a) choice making, (b) decision making, (c) problem solving, (d) goal setting and attainment, (e) self-advocacy, (f) self-management and self-regulation, and (g) self-awareness and self-knowledge. Instructional domains are the self-determination skill areas that can be explicitly taught and addressed in the school setting to increase student capacity in self-determination.

One of the instructional domains recognized as both a critical component of selfdetermination and a skill that should be explicitly taught in schools is self-advocacy (Fiedler \& Danneker, 2007; Roberts, Ju, \& Zhang, 2014; Schreiner, 2007). Although definitions of self-advocacy abound the literature, "self-advocacy refers, literally, "to 
advocating on one's own behalf. To advocate means to speak up or defend a cause or person" (Field et al., 1998). Self-advocacy, like self-determination, is a complex concept comprised of multiple skills. Test, Fowler, Wood, Brewer, and Eddy (2005) identified knowledge of self, knowledge of rights, communication, and leadership as components of self-advocacy. Schreiner (2007) contended that self-advocacy requires students to have self-knowledge and the communication skills to convey this information to others. Furthermore, self-advocacy is recognized as a critical component of the transition process (Getzel \& Thoma, 2008).

The IDEA (2004) requires educators to use evidence-based practices derived from scientifically based research (Test \& Cease-Cook, 2012). Evidenced-based practices in transition are established when the effects of a strategy or intervention on a behavior in experimental studies are examined and validated (Mazzotti et al., 2013). Wehmeyer (2014) claimed the enhancement of self-determination skills in students with disabilities to promote school and postschool outcomes began as an untested hypothesis and is now recognized as an evidence-based practice. In a review of literature of experimental studies to identify levels of causal inference, Test, Fowler, et al. (2009) identified 32 evidence-based practices in secondary transition. Only practices with strong, moderate, or potential evidence based on the National Secondary Transition Technical Assistance Center's Decision Rules for Determining Levels of Evidence were included. Affirming Wehmeyer's assertion, results supported instruction in self-advocacy and selfdetermination, with each being assessed as having a moderate level of evidence. Moreover, results from a literature review of secondary transition and correlational literature conducted by Test, Mazzotti, et al. (2009) identified 16 evidence-based in- 
school predictors of postschool outcomes in the areas of education, employment, and/or independent living. Further supporting Wehmeyer's contention, self-advocacy/selfdetermination was recognized as an evidence-based predictor category that correlated with postschool outcomes in the areas of education and employment. Self-advocacy and self-determination were found to have a potential level of evidence. A potential level of evidence indicates promising research that does not have the evidence to reach moderate levels, and as a result, additional research is warranted. Moreover, in a literature review of special education studies that measured global self-determination, Chambers et al. (2007) found that students with higher levels of self-determination were more likely to achieve positive adult outcomes in the areas of employment, postsecondary education, and independent living.

In addition to evidence-based practices and predictors that lead to improved postschool outcomes for students with disabilities, best practices in transition have been identified. In a review of transitional literature by Landmark et al. (2010), eight practices linked to positive postschool outcomes were recognized as substantiated best practices in transition. Substantiated practices were defined as transition practices that were empirically validated. These practices included paid or unpaid work experience, employment preparation, family involvement, general education inclusion, social skills training, daily living skills training, self-determination skills training, and community or agency collaboration. Of these eight practices, enhancing the self-determination skills in students with disabilities is also regarded as "critically important for students with disabilities" (Wehmeyer, 2014, p. 1). Researchers strongly support fostering selfdetermination practices in the school setting (Fiedler \& Danneker, 2007; Roberts et al., 
2014) as a means to reducing the outcomes gap between students with and without disabilities by equipping students with the skills that may promote positive postschool outcomes (Landmark et al., 2010; Wehmeyer, 2014). Findings from reviews on evidence-based practices, evidence-based predictors, and substantiated best practices in transition clearly strengthen the research base and support the instruction of selfdetermination practices (e.g., learning to self-advocate) as a means to helping students effectively transition to postschool settings and possibly achieve more positive postschool outcomes.

Many students with disabilities do not inherently acquire self-advocacy skills, thus, they may require direct instruction to learn the skills (Fiedler \& Danneker, 2007; Schreiner, 2007). Yet, incorporating self-advocacy skills into instruction challenges many teachers. In a study by Cho, Wehmeyer, and Kingston (2011), the researchers sought to identify obstacles that impede the promotion of self-determination by general and special educators. Three of the top barriers were insufficient time, students having more urgent needs in other areas, and lack of training or knowledge. The most prevalent barrier cited by $52 \%$ of general educators and $60 \%$ of special educators was students having more urgent needs in other areas. Carter, Lane, Pierson, and Stang (2008) also surmised that competing instructional priorities might account for the differences between the value that educators assign to self-determination and the amount of time they spend promoting self-determination. Carter et al. based their supposition on results from previous survey research (e.g., Agran, Snow, \& Swaner, 1999; Wehmeyer, Agran, et al., 2000). 
Having multiple opportunities to practice self-advocacy skills in the school environment is paramount to enhancing these skills in students with disabilities (Roberts et al., 2014). Although research indicates opportunities for the enhancement of selfdetermination and self-advocacy skills are improving, a gap still exists between current practices and desired outcomes (i.e., Carter et al., 2008). In the earliest studies evaluating teachers' perceptions and practices regarding self-determination skill instruction, teachers viewed the teaching of self-advocacy as an important instructional component; however, their practices did not reflect their beliefs (i.e., Agran et al., 1999; Wehmeyer, Agran, et al., 2000). Findings indicated a lack of instructional practices promoting selfdetermination in addition to minimal emphasis on self-determination goals in their students' Individualized Education Programs (IEPs). For example, 55\% of the teachers in the Agran et al. (1999) study declared that self-determination goals were either not in their students' IEPs or included in only some of them. In the Wehmeyer, Agran, et al. (2000) study, $31 \%$ of the teachers did not write self-determination goals in their students' IEPs and, only $22 \%$ of the teachers confirmed that all of their students had selfdetermination goals in their IEPs.

More recently, Carter et al. (2008) surveyed 340 general and special education high school teachers to determine the importance teachers assigned to teaching selfdetermination skills, the extent that these teachers provide this instruction, and the differences in views and practices that may exist between general and special educators. As increasing number of students with disabilities continue to be included in the general education setting, these researchers contended that the views of general educators are critical. By analyzing the similarities and differences in the perspectives between general 
and special educators, researchers and practitioners may gain valuable information to further promote self-determination skill instruction across the curriculum (Carter et al., 2008). Results from Carter et al. substantiated that educators overall assigned moderate to high levels of importance to the component elements of self-determination with special educators' ratings being slightly higher. Positive correlations were also noted between the ratings educators assigned to the skill areas and the amount of instructional time used to address those skills.

When comparing the findings from Carter et al. (2008) with the Agran et al. (1999) and Wehmeyer, Agran, et al. (2000) studies, teachers in all three studies valued the inclusion of self-determination as an instructional priority. Yet, in contrast to those studies, Carter et al. identified positive correlations between ratings of importance for component skills of self-determination and the amount of instructional time they actually used for instruction in these skill areas. The findings from Carter et al. suggested that educators are more frequently addressing some of the components of self-determination through instruction. Though these researchers noted opportunities for teaching certain component skills of self-determination (i.e., problem solving, self-management, and decision making) have been increasing in schools, their results also indicated that general education teachers and special education teachers differed on the amount of instructional time allocated for several component skills. For example, general educators rated selfadvocacy and self- awareness (i.e., knowledge of self) as being less important and requiring less instructional time. Additionally, both general and special educators reported that they taught self-advocacy/leadership much less frequently that any other self-determination domain. Hence, if the views of these educators are representative of 
secondary educators, a renewed emphasis on self-advocacy research and instruction may be warranted.

\section{Statement of the Problem}

According to the U.S. Department of Education (2010), increasing numbers of students with disabilities are transitioning to postsecondary education settings, and this trend is expected to continue for decades to come. Consequently, now more than ever, high school students must be equipped with tools to address the challenges that they may face (Gil, 2007). Besides preparing students academically for postsecondary settings, researchers have maintained the importance of self-advocating in these settings (Finn, Getzel, \& McManus, 2008; Garrison-Wade, 2012; Getzel \& Thoma, 2008; Gil, 2007; Hadley, 2006; Morningstar et al., 2010; Shaw, Madaus, \& Banerjee, 2009; Skinner, 2004). Particularly, Getzel and Thoma (2008) asserted, "students with disabilities need self-determination skills to successfully transition to, adjust to, and remain in college" (p. 78). Since college graduation, not just matriculation, is the ultimate goal for these students, they must become more aware of their changing roles and the new responsibilities that accompany these roles once they leave high school and transition to college or other postsecondary settings. At the postsecondary educational level, students are expected to self-disclose (i.e., identify themselves as having a disability) to receive accommodations, provide documentation to substantiate the need for accommodations, and communicate with college faculty to receive those accommodations (Getzel \& Thoma, 2008). Self-disclosing requires students to utilize their knowledge of their disabilities and the impact that their disabilities have on their learning to self-advocate for essential accommodations. Effective self-advocates have an awareness of themselves 
and their rights, in addition to the ability to communicate this information. Although knowledge of self and knowledge of rights are considered the building blocks of selfadvocacy, acquiring the communication skills to assertively request and/or negotiate supports cannot be overlooked (Test, Fowler, Wood, et al., 2005). Results from Getzel and Thoma support this assertion. These researchers utilized focus group interviews with 34 college students who had self-disclosed to specifically identify the skills that effective self-advocates use to persist in college and obtain supports. Initially, many of these students had not self-disclosed and failed. Subsequently, these students felt compelled to disclose their disabilities and seek supports. All 34 participants acknowledged that knowing about themselves and their disabilities enabled them to remain in college. Without a clear understanding of their disabilities and the impact of those disabilities on their learning, students would be challenged to effectively articulate their needs.

Even though research clearly substantiates the importance of self-determination and self-advocacy skills in the transition process, Bangser (2008) noted that high school programs often do not equip students with disabilities with the skills to be successful in postsecondary environments. Results from a qualitative case study by Garrison-Wade (2012) suggested that students with disabilities might not be arriving on college campuses with the self-advocacy skills to actively seek effective accommodations. Students and disability coordinators in this study identified a lack of students' awareness of their disabilities and the effective accommodations to address their needs as barriers. Accordingly, participants voiced that students must have the self-advocacy and selfawareness skills to request accommodations in postsecondary educational settings. 
Skinner (2004) contended that a lack of disability awareness would most likely lead to academic failure in postsecondary institutions.

As previously stated, barriers have been identified that challenge the ability of teachers to provide self-determination or self-advocacy instruction in the high school setting. Besides the lack of instructional time afforded to systematically provide selfadvocacy instruction and the emphasis on competing instructional demands (e.g., highstakes testing and standards-based reform), researchers have purported that enabling support provided by teachers at the secondary level is a factor that may potentially limit the progress of students becoming their own advocates (Ankeny \& Lehmann, 2011; Roberts et al., 2014). Ankeny and Lehmann (2011) specifically identified too much attention and assistance as impeding the growth of self-determination in students with disabilities. During high school these students often become passive recipients of supports from well-intentioned teachers and parents. This overdependence on others may prevent these students from developing the self-advocacy skills that will enable them to speak up for themselves and acquire needed supports and services in postsecondary environments. To combat this dependency, there needs to be a balance between the supports that teachers provide for students and the repeated opportunities for these students to become the change agents in their lives. To better prepare our students for life after high school, emphasis should be placed on students advocating for themselves instead of teachers and parents advocating on behalf of the students. Mishna, Muskat, Farnia, and Wiener (2011) suggested that teachers and parents should assume the role of advisor, supporter, or consultant as opposed to that of the decision-maker. GarrisonWade (2012) recommended empowering students with the skills to become their own 
advocates to prepare them to manage the new challenges and responsibilities that they will face in postsecondary environments. Achieving successful postschool outcomes will require students with disabilities to acquire the self-advocacy skills that will enable them to capitalize on their strengths, identify their needs, and seek supports to address those needs. Particularly, if students with disabilities are going to succeed in postsecondary educational settings, they will need to fully understand how their disabilities impact their learning and how to advocate for the academic accommodations to address their needs. Thus, the role of secondary educators will be to prepare students to take charge of their learning and their lives.

Effective practices promoting the enhancement of self-advocacy skills in preparation for the transition to postsecondary settings include teaching high school students to actively participate in and lead IEP meetings (e.g., Test et al., 2004; Woods, Martin, \& Humphrey, 2013) and to advocate for accommodations (e.g., Durlak, Rose, \& Bursuck, 1994; Prater, Redman, Anderson, \& Gibb, 2014). Although the latter has been recognized as a critical component of the transition process, only a limited number of empirical studies have evaluated the effects of instructional interventions on the ability of students with disabilities to advocate for accommodations. Four empirical studies were identified that taught college students to advocate for accommodations (Palmer \& Roessler, 2000; Roessler, Brown, \& Rumrill, 1998; Walker \& Test, 2011; White \& Vo, 2006), and only two empirical studies that taught high school students with disabilities to acquire the knowledge to request accommodations (Wood, Kelly, Test, \& Fowler, 2010) or demonstrate the skills to advocate for accommodations (Durlak et al., 1994) were located. Research supports that students with disabilities will need to advocate for 
themselves in postsecondary settings (i.e., Finn et al., 2008; Getzel \& Thoma, 2008; Gil, 2007; Hadley, 2006; Morningstar et al., 2010; Shaw et al., 2009); however, effective practices to specifically prepare high school students with the skills to advocate for their accommodations before they enter college are lacking.

This current gap in literature should be addressed if we expect students with disabilities to be prepared to disclose their disabilities and self-advocate as they matriculate to college. Thus, seeking input from students with disabilities in postsecondary settings is integral to identifying the skills and strategies that will enable future students to be successful in these settings (e.g., Garrison-Wade, 2012; Skinner, 2004; Thoma \& Getzel, 2005); however, evaluating the effectiveness of instructional interventions to prepare students with disabilities with these skills is paramount to establishing practices that may enhance desired postschool outcomes.

\section{Purpose of the Study}

The purpose of the present study was to determine if a self-advocacy intervention resulted in five high school students with high incidence disabilities acquiring the skills to request academic accommodations and then generalizing those skills in a high school general education course. This study was a systematic replication of Walker and Test (2011) that focused on the impact of the Self-Advocacy and Conflict Resolution (SACR) training program on the ability of high school students to request academic accommodations. It differed from the Walker and Test study in the following ways: (a) ages, grade levels, and functioning levels of the participants; (b) investigator; (c) setting; (d) addition of student self-evaluations of their video recorded role-plays; (e) the inclusion of a self-awareness and disability awareness component; and (f) additional 
modifications of the SACR. The studies are similar in regards to the independent (i.e., the SACR) and dependent (i.e., the ability of students to advocate for accommodations) variables. This proposed study will add to the paucity of research on the impact of selfadvocacy interventions on the ability of high school students with high incidence disabilities to self-advocate for their accommodations.

\section{Research Questions}

1. Does instruction using the SACR increase the ability of high school students with high incidence disabilities to independently request academic accommodations in role-play simulations?

2. Does instruction using the SACR increase the ability of high school students with disabilities to independently request academic accommodations in the natural academic classroom?

3. Do high school students with high incidence disabilities believe the SACR had a positive effect on their ability to identify their learning needs and the accommodations to address those needs?

4. Do high school students with high incidence disabilities believe the SACR had a positive effect on their ability to independently request academic accommodations?

5. Do general education teachers believe the SACR had a positive effect on the ability of high school students to request academic accommodations?

\section{Definitions of Terms}

Academic Accommodations. "Changes in the format, response mode, setting, or scheduling that will enable a student with one or more disabilities to complete the general 
curriculum" (Overton, 2011, p. 151). Academic accommodations level the playing field for students with disabilities by providing them with the supports to compensate for their areas of difficulties. Common examples of accommodations include extended time on assignments, projects, and assessments; copies of notes or a note-taker; oral exams; a scribe or recorder for tests or assignments; electronic copies of readings and texts; recording devices; screen-readers; adaptive software and hardware for computers; and alternate settings.

High incidence disabilities. High incidence disabilities, or mild disabilities, generally occur most often in the population, and may include mild or moderate mental retardation, emotional disturbance, or specific learning disabilities (Edyburn, 2006). At the high school level, students with high incidence disabilities are often included in the general education setting for core and/or elective courses.

Explicit instruction. Direct and systematic instruction that often includes (a) the purpose of the lesson, (b) modeling, (c) guided practice with feedback, and (d) independent practice. The use of role-play simulations (e.g., Durlak et al., 1994) is a common component of explicit instruction when teaching students to self-advocate.

Self-advocacy. The ability of an individual "to speak up or defend a cause or a person" (Wehmeyer et al., 1998, p. 20). Self-advocacy skills are recognized as being critical to the transition from school to postschool settings.

Self-awareness. "A basic understanding of one's strengths, weaknesses, abilities, and limitations as well as knowledge about how to utilize these unique attributions to beneficially influence one's quality of life" (Wehmeyer et al., 1998, p. 23). Selfknowledge is often used synonymously with self-awareness. 
Self-determination. "A combination of skills, knowledge, and beliefs that enables a person to engage in goal directed, self-regulated, autonomous behavior. An understanding of one's strengths and limitations together with a belief in oneself as capable and effective are essential to self-determination. When acting on the basis of these skills and attitudes, individuals have greater ability to take control of their lives and assume the role of successful adults in society" (Field et al., 1998, p. 2).

Self-disclosure. Identifying oneself as an individual with a disability in order to receive accommodations and supports (Getzel \& Thoma, 2008). Self-disclosure is necessary if students with disabilities seek accommodations in a postsecondary educational setting. Students with disabilities must initiate this process in postsecondary settings.

Postschool outcomes. Experiences of students with disabilities after leaving high school. Outcome areas include postsecondary education enrollment and completion; gainful employment, residential independence, social and community involvement; and productive engagement in school, work, or preparation for work (Newman et al., 2011).

Transition Services. " A coordinated set of activities for a child with a disability that is: (a) designed to be within a results-oriented process, that is focused on improving the academic and functional achievement of the child with a disability to facilitate the child's movement from school to post-school activities, including postsecondary education, vocational education, integrated employment (including supported employment); continuing and adult education, adult services, independent living, or community participation; (b) based on the individual child's needs, taking into account the child's strengths, preferences, and interests; and (c) included instruction, related 
services, community experiences, the development of employment and other postschool adult living objectives, and, and if appropriate, acquisition of daily living skills and functional vocational evaluation" [IDEA: 34CFR 300.43(a)] [20 U.S.C. 1401(34)]. 


\section{CHAPTER II}

\section{REVIEW OF RELATED LITERATURE}

This chapter presents an overview of the literature that substantiates the importance of promoting self-advocacy practices for students with disabilities to enhance their transition to and success in postsecondary settings. To accomplish this task, the review begins by tracing the history of the self-advocacy movement to identify factors that prompted the growth of the movement and led to the promotion of self-determination. Next, the concept of self-advocacy is operationalized and conceptualized in relation to selfdetermination and transition. Findings from major reviews of self-advocacy intervention studies are then discussed to identify evidence-based practices that promote selfadvocacy. Further, the current state of research on requesting academic accommodations is presented and analyzed. Finally, the research is summarized and synthesized to expose the gaps in self-advocacy literature that would warrant future research.

\section{History of the Self-Advocacy Movement}

The self-advocacy movement has been regarded as a civil rights movement for individuals with disabilities (Williams \& Stoultz, 1982). The origins of the self-advocacy movement have been greatly influenced by the changing perceptions about individuals with intellectual disabilities and the impact that those new perceptions had on the lives of people with disabilities. Following World War II, as the U.S. birthrate significantly rose, 
the number of babies born with developmental disabilities also increased (Bersani, 1996). Simultaneously, advancements in science and medicine led to a new understanding of people with disabilities, which resulted in the enhancement of life expectancies for those with disabilities (Wehmeyer, Bersani, \& Gagne, 2000). Consequently, parents of children with disabilities, especially those with intellectual disabilities and cerebral palsy, began to advocate for their rights as well as the rights of their children. Writings of renowned professionals in the field of disability, such as Gunnar Dybwald, Burton Blatt, and Wolf Wolfensberger, also provided a humanitarian effort that supported parents in their endeavors (Bersani, 1996). Influenced by the works of Bengt Nirje of Sweden and his normalization principle, Wolf Wolfensberger promulgated this principle throughout the United States by exposing inhumane conditions in institutions and proposing community integration for individuals with disabilities. The normalization principle, which prompted deinstitutionalization (i.e., community integration), provided guidance to promote services that "create conditions through which a handicapped person experiences the normal respect to which any human being is entitled" (Nirje, 1972, p. 177). Nirje's words referenced the necessity of people with intellectual disabilities to become selfdetermined and take charge of their own lives (Wehmeyer, Bersani, et al., 2000).

From the 1950s to the 1970s, parents not only became the voices for their children and young adults with disabilities, but they also emerged as leaders in a disability movement that would gradually transform into what is now known as the self-advocacy movement (Wehmeyer, Bersani, et al., 2000). This transformation occurred when parents and professionals recognized the need for people with intellectual disabilities to have their own voices. As a result of parent advocacy, organizations such as the National 
Association for Retarded Children (now ARC) and the United Cerebral Palsy Association were formed, and services and legislation such as the Developmental Disabilities Act of 1970 were enacted (Bersani, 1996). Interestingly, the services resulted from the needs and experiences of the families, not from professional literature (Bersani, 1996).

In the early 1970s, people with intellectual disabilities, with support from their families and other allies, organized a grassroots movement and formed their own selfadvocacy organizations (Bersani, 1996). This self-advocacy movement was influenced by the civil rights movement of the 1960s (Bersani, 1996) and the social clubs designed by Bengt Nirje of Sweden in 1969 that allowed individuals with intellectual disabilities to practice self-determined behaviors (Perske, 1996). People First, the first self-advocacy organization in the U.S., originated in Salem, Oregon in January of 1974 by former residents of a state institution who wanted to speak for themselves and make others aware that they wanted to be treated like everyone else. To them, it was about having a voice and being heard by others. Later that year the first self-advocacy convention occurred in Otter Crest, Oregon. Within five years of development, People First in Oregon grew to over 1000 members (Schaaf \& Bersani, 1996). According to Dybwad (1996), the movement continued to expand across the U.S., and in 1990, 400 people from 38 states and two Canadian provinces convened at the North American People First Conference in Estes Park, Colorado. An outcome of this conference was the eventual establishment of a national organization, Self-Advocates Becoming Empowered. By the late 1990s, there were over 700 self-advocacy groups across the U.S. (Wehmeyer, Bersani, et al., 2000). These groups provided a "forum for individuals with disabilities and a means by which to advocate for individual and group rights" (Test, Fowler, Wood, Brewer, \& Eddy, 2005, 
p. 43). In summation regarding the self-advocacy movement from the 1970 s to the 1990s, Dybwad asserted, "people with intellectual impairments have ... gone from 'feebleminded patients' to empowered agents of social change" (1996, p. 16).

As the emergence of organizations across the United States propelled the selfadvocacy movement, legislation both promoted and supported the efforts of these advocates. Specifically, the Americans with Disabilities Act (ADA) was signed in 1990. This act was viewed as a "gateway to full citizenship" for self-advocates and other persons with disabilities (Perske, 1996, p. 31). This landmark civil rights bill prohibited discrimination against persons with disabilities by guaranteeing them access to public services, transportation, employment, and telecommunications. The ADA removed barriers and opened doors that had previously been closed for people with disabilities.

The self-advocacy movement continued to expand both nationally and internationally in the 1990s, and the promotion of self-determination was moved to the educational forefront of the disability movement. A self-determination initiative emerged when individuals with disabilities, their families, educators, and service providers questioned the passive roles often assigned to persons with disabilities (Hoffman \& Field, 1995). This evolving self-determination movement was the result of federal policies related to disability and a 1988 initiative from the U.S. Department of Education, Office of Special Education and Rehabilitative Services (OSERS). Monumental to this initiative was the National Conference on Self-Determination that occurred in January of 1989 when more than half of the attendees were people with disabilities. Results of the conference included 29 recommendations for promoting self-determination across federal agencies (Ward, 2005). To specifically address the development of self-determination 
programs, a grant competition ensued in September of 1989. By 1990, this initiative funded 26 model demonstration projects that promoted the identification and instruction of self-determination skills in youth with disabilities (Ward, 2005). The selfdetermination initiative shifted the focus from an emphasis on legislative and political advocacy to the enhancement of skills that would enable individuals with disabilities to become self-determined (Wehmeyer, 1999).

Initially, legislation provided the impetus for equality, advocacy, activism, and accessibility. Section 504 of the Rehabilitation Act of 1973 prohibited discrimination on the basis of disability. The Education for All Handicapped Children Act of 1975 provided a free and appropriate education in the least restrictive environment for students with disabilities. The ADA was then enacted to protect the civil rights of individuals with disabilities by mandating accessibility. However, the intent of legislation gradually began to change. The pendulum had swung, whereas, preparing individuals with disabilities with the skills to become productive citizens became as important as prohibiting discrimination and providing access. Thus, legislation clearly fostered the growth and development of the self-advocacy and self-determination movements.

The self-determination initiative concurrently emerged with changes in federal legislation regarding transition mandates (Wehmeyer et al., 2007). The evolution of legislation prompted an emphasis on the involvement of individuals with disabilities in the transition process. The reauthorization of the Individuals with Disabilities Education Act (IDEA) in 1990 added transition-related requirements that mandated the inclusion of transition services in the Individual Education Plans (IEPs) for students who were at least 16 years of age, or younger if a state elected to do so. The 1992 Rehabilitation Act 
Amendments required individuals with disabilities to be actively involved in their rehabilitation programs. As active participants, individuals make informed choices about their vocational goals and vocational rehabilitation services. The IDEA of 1997 required children with disabilities to actively participate in their IEP and transition planning meetings. The primary goal of the 1997 Amendments to the IDEA was to continue to strengthen and improve the education of students with disabilities. With this goal in mind, Congress added the requirement that students with disabilities would have access to the general curriculum and should be involved in and progress in the general curriculum. Finally, the reauthorization of the IDEA in 2004 emphasized the importance of identifying students' strengths, needs, preferences, and interests to enhance the transition process for students with disabilities. As a result of both the legislative and self-determination initiatives, curricula were developed (e.g., Halpern et al., 1997; Wehmeyer \& Lawrence, 1995); assessments were created (e.g., Wehmeyer \& Kelchner, 1995; Wolman, Campeau, Dubois, Mithaug, \& Stolarski, 1994); and research to support the impact and importance of self-determination in students with disabilities, specifically during the transition process (e.g., Getzel \& Thoma, 2008; Thoma \& Getzel, 2005) surfaced.

\section{Self-Advocacy and the Relatedness to Self-Determination and Transition}

\section{Definition of Self-Advocacy}

Self-advocacy has been identified as a critical skill to achieve successful school and postschool outcomes for individuals with varying disabilities (Fiedler \& Danneker, 2007; Test, Fowler, Brewer, \& Wood, 2005; Wehmeyer, 2014). In order to self-advocate effectively, students must understand their disability, recognize the impact their disability 
has on their lives and their learning, and determine what supports they will need in order to be successful. Scholars and self-advocates have contended that self-advocacy is an educational construct that should be taught and practiced in schools (Roberts et al., 2014). Throughout the years, researchers have defined self-advocacy and identified component skills associated with this construct; yet, there is not a universally accepted definition of self-advocacy. Field (1996) stated that self-advocacy is "used almost interchangeably with self-determination" and referred to self-advocacy as "taking action on one's own behalf; acts of self-advocacy lead to greater self-determination" (p. 42). Wehmeyer and Schwartz (1997) asserted, "self-advocacy skills include learning how to be assertive but not aggressive; how to negotiate, compromise and use persuasion; how to be an effective leader and team member" (p. 253). Merchant and Gajar (1997) identified skills associated with self-advocacy that included an understanding of one's disability (i.e., strengths and weaknesses), knowledge of individual rights under the law, accommodations needed, and effective communication skills. Wehmeyer et al. (1998) defined self-advocacy as "skills individuals need to speak up or defend a cause" (p. 20). To conceptualize self-advocacy, Test, Fowler, Wood et al. (2005) compiled and analyzed 26 definitions of self-advocacy. Results of this analysis identified skills associated with self-advocacy. Some of those skills included in the literature were understanding self, identifying needs and interests, responding assertively, being able to negotiate, effectively communicating, being aware of and standing up for rights, and leading. These researchers concluded that self-advocacy is a combination of knowledge and skills that “can occur at various levels of complexity throughout an individual's life" (p. 51). In support of this conclusion, Hadley (2006) identified self-advocacy as a "life skill" (p. 16). 
Finally, Schreiner (2007) stated students with disabilities must have an accurate awareness of themselves and be able to appropriately apply that knowledge if they want to effectively advocate. Although the numerous definitions of self-advocacy offer differing perspectives about the construct and the skills associated with self-advocacy, commonalities exist. Therefore, based on the aforementioned definitions and descriptions, a collective definition of self-advocacy would include the ability of an individual to recognize his/her strengths and needs, to identify supports to address his/her needs, and to seek those supports in educational, vocational, and community settings by effectively communicating this knowledge to others. Effective self-advocates may also acquire the skills to lead others and support the causes they believe to be important.

\section{Conceptual Framework of Self-Advocacy}

Test, Fowler, Wood et al. (2005) recognized that one way to narrow the research to practice gap between self-advocacy and instructional practices was to create a framework to guide instructional planning, design curriculum and assessment, and further the self-advocacy research agenda. Using the definitions of self-advocacy as a starting point, Test, Fowler, Wood et al. synthesized self-advocacy literature to develop a conceptual framework. This self-advocacy framework was primarily derived from a literature review that identified 26 self-advocacy definitions and 20 intervention studies published from 1972 through 2003 that included individuals with disabilities as participants and promoted self-advocacy or identified components of self-advocacy. Furthermore, input was requested from 30 stakeholders on the working drafts of the framework, of which seven provided feedback. Stakeholders included two selfadvocates, three researchers, and two adult self-advocacy training organizations. 
Based on the analysis and synthesis of research and input from stakeholders, Test, Fowler, Wood et al. identified four components in their framework. These components included knowledge of self, knowledge of rights, communication, and leadership. These researchers recognized knowledge of self and knowledge of rights as the foundation of self-advocacy since students must be aware of their strengths, needs, and rights before they can communicate this information to others.

Knowledge of self. Test, Fowler, Wood et al. (2005) identified knowledge of self as the initial step for self-advocacy. Schreiner (2007) reaffirmed that "self-knowledge is a prerequisite for eventual self-advocacy" (p. 302). Abernathy and Taylor (2009) contended that when self-awareness is lacking, the ability to self-advocate would be diminished. One must be aware of who they are as an individual with a disability before they can communicate this information and advocate for supports. Based on the framework, subcomponents of knowledge of self may include strengths, preferences, interests, goals, learning styles, disability awareness, and needs. In the two most recent reviews of literature on self-advocacy intervention studies (Roberts et al., 2014; Test, Fowler, Brewer, et al., 2005), 32 of the 43 (74\%) studies measured the impact of an intervention on self-knowledge or self-awareness, which reinforces the importance of self-knowledge when promoting the development of self-advocacy in students with disabilities. For example, in a qualitative study by Kotzer and Margalit (2007), 111 middle school students with learning disabilities made significant gains in self-awareness. In a mixed-methods study by Campbell-Whatley (2008), middle school students with disabilities increased their self-esteem by learning to explain their disability, identifying their needs, and requesting assistance. Mishna et al. (2011) evaluated the impact of a 
school-based intervention on the self-reported self-advocacy of 68 middle school students with learning disabilities. Students were placed in either an immediate-intervention condition or a withheld-intervention condition. Findings denoted that students in both groups significantly increased their self-reported self-advocacy knowledge as a result of a self-advocacy intervention.

Knowledge of rights. Knowledge of rights is the second component of the selfadvocacy framework. Knowledge of rights includes rights as a citizen, rights as an individual with a disability, and rights in school and employment settings (Test, Fowler, Wood, et al., 2005). This component enables individuals to seek necessary supports, services, and accommodations for which they are entitled (Fiedler \& Danneker, 2007). The underpinnings of legislation clearly substantiate the rights of individuals with disabilities; however, individuals must have an awareness of those rights and the skills to communicate that knowledge to others. Numerous studies have examined the impact of an intervention on an individual's knowledge of their rights (Campbell-Whatley, 2008; Mason, McGahee-Kovac, Johnson, \& Stillerman, 2002; Powers et al., 2001; Rothman, Maldonado, \& Rothman, 2008; White, Summers, Zhang, \& Renault, 2014; White \& Vo, 2006; Wood et al., 2010). For example, Wood et al. (2010) taught students with disabilities their rights and responsibilities for requesting accommodations in postsecondary education guaranteed by Section 504 of the Rehabilitation Act of 1973 and the ADA. Results indicated students gained knowledge of their rights and responsibilities and were able to generalize this knowledge to a new situation. Findings from this study extended the findings of White and Vo (2006) who utilized a selfadvocacy training package to teach college students to request accommodations and to 
improve their knowledge regarding ADA rights and responsibilities. All three participants in White and Vo increased their ADA-related knowledge to $100 \%$ after training.

Communication. Communication is the third component of the framework. Test, Fowler, Wood, et al. (2005) stipulated that knowledge of self and knowledge of rights must be communicated effectively in order to receive needed supports. Communication development can be used as a means to promote self-advocacy. Subcomponents of the communication component of the framework include asserting oneself, negotiating, persuading, listening, articulating, and compromising. In the Roberts et al. (2014) and Test, Fowler, Brewer, et al. (2005) reviews, 38 (88\%) of the 43 intervention studies included effective communication skill development to enhance self-advocacy. For example, Neale and Test (2010) evaluated the effects of a communication strategy (i.e., I Can Use Effort) on verbal contributions and IEP participation of elementary students with high incidence disabilities. Results indicated all students improved their ability to express their learning preferences and contribute information in an IEP meeting. Thus, this study enhanced the students' self-awareness skills as demonstrated by more effective communication skills. More recently, in a single subject design study by Cuenca-Carlino and Mustian (2013), the researchers employed the self-regulated strategy development model of writing instruction to teach middle school students with emotional and behavior disorders how to persuasively advocate their needs. In addition to gains in written communication skills, the researchers noted significant improvements in the selfdetermination perceptions and knowledge of the students. 
Leadership. The final component of the framework is leadership. Test, Fowler, Wood et al. (2005) defined leadership as "learning the roles and dynamics of a group and the skill to function in a group" (p. 50). Subcomponents of leadership include learning group dynamics and roles, as well as learning to advocate for others and causes.

Leadership may include skills involved in leading an IEP meeting as well as advocating for groups (Fiedler and Danneker, 2007). Leadership research generally revolves around the development of IEPs and transition plans. Test, Fowler, Wood et al. acknowledged that leadership is a component of self-advocacy but not a necessity to self-advocacy. Moreover, leadership is recognized as the "least explored and understood aspect of selfdetermination among individuals with disabilities" (Carter, Swedeen, Walter, Moss, \& Hsin, 2011, p. 58), as evidenced by only 14 (33\%) of the 43 studies in the Test, Fowler, Brewer, et al. (2005) and Roberts et al. (2014) reviews that included interventions to promote leadership development skills. A study by Ankeny and Lehmann (2011) reported that students identified the IEP meeting as a tool for building leadership skills while still in high school. In a more recent study by Cease-Cook, Test, and Scroggins (2013), findings indicated that students with mild disabilities learned to increase the number of quality contributions during mock IEP meetings. Skills were also generalized to the students' actual IEP meetings. Additionally, the Youth Leadership Forum model has been used to promote self-advocacy and leadership skills in students with disabilities (Grenwelge, Zhang, \& Landmark, 2010). Grenwelge and Zhang (2012) evaluated the effects of one such training, the Texas Youth Leadership Forum. Findings suggested that youth with disabilities could improve their self-advocacy and leadership skills in a short amount of time with intense training. 
In summary, the self-advocacy framework provides researchers with a tool from which to evaluate research, develop instructional practices, and design curricula. This framework also provides educators with a better understanding of the concept of selfadvocacy and the specific skills that can be addressed in instruction from elementary school through high school. When educators understand the knowledge and skills associated with self-advocacy, they may then be able to develop strategies and practices to enhance these skills. The framework merely provides the basis for that instruction (Test, Fowler, Wood, et al., 2005). Ultimately, knowing oneself, knowing one's rights, and communicating this knowledge are important life skills for all students that can and should be enriched through instruction. Although leadership is recognized as a component of self-advocacy, and students with disabilities would benefit from leadership training, it is not necessarily a prerequisite to becoming an effective self-advocate.

\section{Relationship Between Self-Advocacy and Self-Determination}

Self-determination, a critical concept in the field of special education, remains at the forefront of educational research (Denney \& Daviso, 2012). The emphasis on selfdetermination in literature has significantly influenced the emergence of research on selfadvocacy. Although the self-advocacy movement in the 1970s preceded the selfdetermination movement, the influence of legislation and the self-determination initiative in the 1990s provided the impetus for the promotion of self-advocacy in all students with disabilities. Often used synonymously with self-determination, self-advocacy is generally recognized as a component of self-determination (Roberts et al., 2014; Test, Fowler, Wood et al., 2005) or a concept related to self-determination (Test et al., 2004). Abernathy and Taylor (2009) stated that self-advocacy is often viewed in the lens of self- 
determination studies, which adds to the difficulty of discerning the two concepts. Regardless of the differences between the terms, Sebag (2010) proposed that selfdetermination and self-advocacy both have a common goal: "to move the students from the passenger seat to the driver's seat of life" (p. 23). Wehmeyer (2014) reinforced this idea by stating that self-determination should be equated with "making things happen in one's life and being the causal agent in one's life" (p. 2). According to Wehmeyer and Schwartz (1997), self-determination and self-advocacy skills improve the opportunity for students with disabilities to take more responsibility of their lives and transition more effectively.

There are many definitions of self-determination in the literature, but one offered by Field et al. (1998) encompasses the essence of the term. Field et al. defined selfdetermination as "a combination of skills, knowledge, and beliefs that enable a person to engage in goal directed, self-regulated, autonomous behavior. An understanding of one's strengths and limitations together with a belief in oneself as capable and effective are essential to self-determination" (p. 2). Central to this definition is the importance of recognizing one's strengths and limitations, which are subcomponents of knowledge of self, a component of the self-advocacy framework. While self-determination is considered a multi-faceted construct and will likely improve the opportunity for positive adult outcomes (Chambers et al., 2007), self-advocacy clearly has been identified as being critical to postsecondary success for students with disabilities (Mazzotti et al., 2013).

Enhancing self-determination and self-advocacy skills in students with disabilities is regarded as an educational best practice. Yet, researchers have contended that students 
with disabilities are not inherently equipped with self-advocacy and self-determination skills; therefore, these skills must be explicitly taught (Fiedler \& Danneker, 2007; Pocock et al., 2002; Schreiner, 2007). To teach these skills, Wehmeyer, Agran et al. (2000) identified seven instructional domains derived from component elements of selfdetermination. These domains include (a) choice making (i.e., selecting between several alternatives), (b) decision making (i.e., using choice making to determine the best course of action to address a problem), (c) problem solving (i.e., identifying a situation that requires a solution), (d) goal setting and attainment (i.e., identifying goals and a plan to achieve them), (e) self-advocacy (i.e., speaking up for oneself), (f) self-management and self-regulation (i.e., monitoring one's behavior), and (g) self-awareness and selfknowledge (i.e., knowing one's strengths, needs, and interests). Self-determination instruction should focus on promoting the development of the skills in each of these domains. The beliefs that must accompany these skills should also be emphasized in instruction (Wehmeyer \& Schwartz, 1997).

\section{Relationship Between Self-Advocacy and Transition}

Self-advocacy skills are instrumental to the transition process from high school to postsecondary settings in the areas of education, employment, and community involvement (Fiedler \& Danneker, 2007). Kline and Kurz (2014) specifically identified disability awareness, which includes the knowledge of the impact that strengths and limitations have on performance, as necessary for the transition to future education and employment. Transition services have been defined as coordinated activities for students with disabilities designed within a results-oriented process to promote movement from school to postschool activities including postsecondary education, vocational training, 
integrated employment (including supported employment), and independent living (IDEA, 2004). If students with disabilities are expected to achieve positive outcomes in school and postschool settings, they must take charge of their lives and become their own advocates. "Students taught appropriate self-determination related strategies, learn to serve as their own support system, while having greater control over their choices, behavior, and lives" (Campbell-Whatley, 2008, p. 137).

Enhancing the development of self-advocacy should occur throughout one's life. Promoting practices to develop self-advocacy skills early in a student's educational career may increase the potential for stronger school and postschool outcomes (Hart \& Brehm, 2013). In a study by Rosetti and Henderson (2013), students with disabilities identified self-advocacy as a crucial tool that must be developed over time. Historically, parents, teachers, and other professionals have made decisions for students with disabilities and advocated for their rights and services; consequently, students with disabilities often lack self-determination and self-advocacy skills (Arndt, Konrad, \& Test, 2006). Improving outcomes for students with disabilities is recognized as "the ultimate goal of transition" (Mazzotti et al., 2013, p. 146), thus, practices that enhance the development of self-determination and self-advocacy are necessary.

A strong evidence base supports self-advocacy and self-determination instruction as an effective transition-related practice that promotes positive school and postschool outcomes (Wehmeyer, 2014). By enhancing self-determination or self-advocacy skills in students, improvements have been noted in academic performance (Konrad, Fowler, Walker, Test, \& Wood, 2007), behavior management (Sebag, 2010), postsecondary education (Getzel \& Thoma, 2008), employment (Wehmeyer \& Palmer, 2003; 
Wehmeyer \& Schwartz, 1997), and improved quality of life (Lachapelle et al., 2005; McDougall, Evans, \& Baldwin, 2010). Wehmeyer and Schwartz (1997) found that students with higher levels of self-determination were more likely to be employed after high school and earn a higher wage. Wehmeyer and Palmer (2003) noted that selfdetermination skills in high school predicted success in postschool education and independent living. McDougall et al. (2010) proposed that the promotion of selfdetermination was associated with improved postschool and quality of life outcomes.

Besides looking at how self-advocacy and self-determination enhance postschool outcomes, researchers have identified the lack of self-advocacy and self-determination as a school-to-work barrier for students with disabilities (Riesen, Morgan, Schultz, \& Kupferman, 2014). In this study researchers acknowledged a lack of self-advocacy and self-determination skills was a high impact barrier for transition students. These researchers concluded the primary goal of transition should be to enhance these skills in students to enable them to be successful in postsecondary employment and educational settings. Madaus, Gerber, and Price (2008) asserted that students with learning disabilities must be aware of their strengths and needs and the compensatory strategies to address those needs prior to entering the workforce. Additionally, college students with disabilities have identified the importance of self-advocating in postsecondary educational settings and the implications if these skills are lacking (Finn et al., 2008; Getzel \& Thoma, 2008; Gil, 2007; Hadley, 2006; Morningstar et al., 2010; Shaw et al., 2009). Finally, as a result of a systematic review of secondary transition correlational research, Test, Mazzotti et al. (2009) identified higher levels of self-determination and 
self-advocacy skills in students with disabilities as predictors of engagement in postsecondary education and employment.

\section{Findings from Major Reviews on Self-Advocacy Interventions}

The extant research base on effective self-advocacy interventions has been reviewed three times. The initial review by Merchant and Gajar (1997) evaluated the literature on self-advocacy programs related to transition from secondary to postsecondary education for students with learning disabilities. The researchers identified seven programs that included at least one of four skills associated with selfadvocacy. These skills included understanding one's own disability, knowledge of individual rights under the law, accommodations needed, and effective communication skills. Only one study (i.e., Durlak et al., 1994) identified a specific experimental design (i.e., single-subject). Role-play and direct instruction methodologies were common components of the programs. Role-play was used to provide students with opportunities to practice the skills they would need to explain their disabilities to a professor in order to acquire needed accommodations. Direct instruction provided an explicit procedure for acquiring the identified skills. Specifically, each of the seven programs included roleplay as an instructional method, and four of the programs utilized direct instruction to teach self-advocacy skills (Barretti, 1993; Brinkerhoff, 1994; Dalke, 1991; Durlak et al., 1994). Of the seven programs, only four reported empirically based outcomes (Aune, 1991; Barretti, 1993; Dalke, 1993; Durlak et al., 1994). Researchers concluded that additional empirical research was needed to determine the effectiveness of self-advocacy interventions on transition. At the time of this review, the importance of teaching 
students the skills to enhance their transition to postsecondary settings was only in the beginning stages.

As a result of the limited scope of self-advocacy interventions in the Merchant and Gajar (1997) review, Test, Fowler, Brewer et al. (2005) completed a content and methodological review of empirically validated self-advocacy intervention studies that included individuals of varying ages and disabilities. Consequently, 25 studies (i.e., 11 single-case, 11 group experimental, and 3 qualitative) were located and evaluated. Each study was examined based on the self-advocacy components measured or taught. For this evaluation the components from the Test, Fowler, Wood et al. (2005) framework (i.e., knowledge of self, knowledge of rights, communication, and leadership) were referenced. Findings from this review indicated that researcher-developed interventions, published curricula (e.g., the Self-Advocacy Strategy, Van Reusen, Bos, Schumaker, \& Deshler, 1994), and role-play were effective strategies for teaching self-advocacy skills. These results substantiated findings from Merchant and Gajar regarding effective self-advocacy strategies. Furthermore, each of the researcher-based interventions and the interventions that utilized published curricula positively impacted the self-advocacy skills of students with disabilities. Unique to this review was the recommendation that teachers should use the IEP process as an instructional strategy to promote self-advocacy. Ten studies were identified that evaluated the effects of teaching students to participate in their IEP or transition meetings, and improvements in self-advocacy behaviors were noted in those studies (e.g., Lancaster, Schumaker, \& Deshler, 2002; Test \& Neale, 2004; Van Reusen \& Bos, 1994). Additionally, two studies (Durlak et al., 1994; Roessler et al., 1998) 
evaluated the effects of teaching students to advocate for accommodations, and results indicated students acquired the associated skills.

More recently, Roberts et al. (2014) provided an up-to-date review on selfadvocacy interventions. The researchers evaluated empirical studies published after the Test, Fowler, Brewer et al. (2005) study. Eighteen empirical studies (i.e., four singlecase, seven group experimental, one quasi-experimental with pre-post evaluation, one mixed-method, and three qualitative) were identified and assessed. The Test, Fowler, Wood et al. (2005) self-advocacy framework was again referenced to ascertain which components of self-advocacy were being promoted in each study. Roberts et al. evaluated the content and the quality of the intervention studies. As documented in previous reviews as well as in this review, effective instructional practices for teaching self-advocacy skills included direct instruction, published curricula, role-play, and researcher-developed interventions. Four additional empirically validated studies used the IEP to promote self-advocacy were included (e.g., Martin et al., 2006; Neale \& Test, 2010). No new studies were identified that specifically taught students the skills to request accommodations.

Based on the aforementioned reviews, effective practices for teaching selfadvocacy skills include using published curricula or researcher-designed interventions, incorporating direct instruction and role-play into the intervention practices, and teaching students to lead their IEP and transition meetings. Two empirical studies (i.e., Durlak et al., 1994; Roessler et al., 1998) that evaluated interventions to teach students to request accommodations also provided evidence of an effective practice for enhancing the transition skills of students with disabilities. By identifying effective practices, 
researchers have a starting point from which to develop future studies, and educators are exposed to strategies that may promote enhanced postschool outcomes while continuing to narrow the research to practice gap.

\section{Self-Advocacy Practices that Enhance the Transition Process}

Examples of best practices that specifically promote self-advocacy as a skill to enhance the transition process have generally emphasized teaching students to actively participate in IEP and transition meetings and to request accommodations (Pocock et al., 2002; Test et al., 2004; Wehmeyer et al., 2007). Involving students in their IEP and transition planning meetings is one way to significantly improve self-determination and self-advocacy skills by providing opportunities to practice these skills (Test et al., 2004). Specifically, researchers have noted improvements in self-advocacy when students are actively engaged in their IEP and/or transition meetings (Arndt et al., 2006; Woods et al., 2013). Test et al. (2004) posited that if students mastered the skills to run their own IEP meetings and participated actively, they could become their own self-advocates in preparation for postsecondary environments. Woods et al. (2013) investigated the impact of instruction using the Self-Directed IEP (Martin, Marshall, Maxson, \& Jerman, 1997) on two consecutive annual IEP meetings for a high school student with a learning disability. Results indicated the student took a more active leadership role by dramatically increasing the amount of time and number of words she spoke, more clearly identifying her postschool goals and dreams, and demonstrating additional examples of increased self-advocacy during the second meeting. When students understand their strengths and needs, actively participate in the selection of postschool goals which are based on their identified preferences and interests, and are given ample opportunities to 
practice self-determined behaviors, they have the potential to become their own advocates.

Teaching students with disabilities to request accommodations is another means to promoting self-advocacy to bridge the gap between high school and postsecondary settings for students with disabilities. Accommodations offer the potential to reduce disability-related barriers in school and postschool settings (Kline and Kurz, 2014); therefore, teaching students to request accommodations enables them to function more independently. Davison, O'Leary, Schlosberg, and Bing (2009) determined that individuals who had previously requested accommodations were more likely to request future accommodations. Based on this finding by Davison et al., high school students who are taught to request accommodations and practice this skill while in high school may continue to request accommodations in postschool settings. Students with disabilities who require accommodations in school usually acquire them with support from teachers and parents. In postsecondary settings, students are expected to disclose their disabilities and independently request accommodations; yet, they are not always equipped with the self-advocacy skills to do this. Section 504 of the Rehabilitation Act and the ADA protect students against discrimination in the workplace and other postschool settings and entitle them to reasonable accommodations; however, students must initiate the request for any accommodations or services they may need. Impeding the access to these accommodations is often the inability of students to identify and effectively request accommodations or the anxiety that results within a student when having to request or negotiate that accommodation. As a result, students benefit from 
explicit instruction that not only teaches them to request accommodations, but provides opportunities for repeated practice to obtain the skills (Durlak, et al., 1994).

If students are going to request accommodations in postsecondary settings, they will need to acquire and practice these skills before they leave the secondary school setting. The continued emphasis on placing students with disabilities in general education classes substantiates the importance of students being able to independently seek supports based on their identified needs. Furthermore, by increasing students' placements in the general education settings, on-going opportunities will become available for students to practice advocating for accommodations in preparation for postsecondary settings. The most recent reviews of self-advocacy literature (i.e., Roberts et al., 2014; Test, Fowler, Brewer et al., 2005) identified only two empirical studies that utilized an intervention to specifically teach high school students between the ages of 15 and 20 the skills to advocate for accommodations. Consequently, a thorough analysis of the current state of research on requesting accommodations in preparation for the transition to postsecondary settings was completed.

To summarize literature on requesting accommodations, I completed an electronic search through the ERIC, Psych Info, Academic Search Complete, Education Full Text, and Sage Journals databases using various combinations of the following search terms: self-advocacy, self-determination, requesting accommodations, accommodations, students with disabilities, learning disability, emotional disability, behavior disorder, other health impairment, postschool settings, postsecondary education, employment, independent living, outcomes, and interventions. I also completed ancestral searches to identify any additional intervention studies that were not retrieved from the database. 
Criteria for inclusion were as follows: (a) published between 1990 (when the selfdetermination initiative commenced and the IDEA 1990 was enacted) and 2015, (b) published in a peer-reviewed journal in English, and (c) focused on an instructional intervention from an empirical study that taught students with high incidence disabilities to request accommodations.

After critical review of the literature and a search of the references from intervention studies, I identified 6 articles that met the inclusion criteria. Two additional articles were located but not included in this review. Prater et al. (2014) was not an empirical study, and White et al. (2014) evaluated the effects of a training program (i.e., Access to Success) that primarily addressed the negotiation aspect of requesting accommodations.

\section{Interventions to Teach Students with Disabilities to Request Accommodations}

If students with disabilities are going to successfully transition to and succeed in postsecondary settings, they will need to fully understand how their disabilities impact their learning and how to advocate for the accommodations to address their needs. Even though literature supports the importance of teaching students with disabilities to request accommodations in all settings, individuals with disabilities generally request accommodations more in postsecondary educational settings than in postsecondary employment settings (Madaus et al., 2008). To support this claim, Madaus et al. noted that $100 \%$ of the respondents in his study disclosed their disabilities in college, and $75 \%$ stated that their learning disability impacted their work in some way; however, only 55\% disclosed their disabilities in the workplace. Of that $55 \%$, only $12 \%$ requested accommodations. Therefore, reviewing the literature regarding advocating for 
accommodations in educational settings as opposed to employment settings is more feasible at the current time. Identifying and evaluating the research on accommodations in educational settings may potentially promote the enhancement of requesting accommodations in other postschool settings (i.e., community settings and employment settings) in the future. For this reason, empirical studies in which college students and high school students with disabilities were taught the skills and/or knowledge to request accommodations were reviewed. The studies were analyzed to identify effective components of interventions that promoted the enhancement of these skills, limitations in previous research, and existing gaps in the literature. See Table 1 for an overview of the purpose, participants, research methodologies, interventions, main findings, and implications of each study.

\section{Requesting Accommodations in Postsecondary Education Settings}

Interviews with college students with disabilities have substantiated the importance of self-advocacy skills in postsecondary settings and that advocating for accommodations is a critical component to academic success for these students. While literature supports that college students recognize the importance of acquiring selfadvocacy skills (Finn et al., 2008; Getzel \& Thoma, 2008; Gil, 2007; Hadley, 2006; Morningstar et al., 2010; Shaw et al., 2009), only four experimental studies were located that demonstrated the effectiveness of instructional interventions to assist college students in the acquisition of self-advocacy skills to request academic accommodations (Palmer \& Roessler, 2000; Roessler et al., 1998; Walker \& Test, 2011; White \& Vo, 2006).

To begin with, Roessler et al. (1998) evaluated the impact of an instructional training program, Self-advocacy Training (Rumrill, Roessler, \& Brown, 1994), on the 
preparedness of three college students with disabilities to self-advocate for accommodations. The researchers utilized a multiple baseline design with replication. Eight sessions were presented, with each lasting 90 minutes. The first session included pretesting and an introduction to self-advocacy. Each self-advocacy lesson followed a standard format (i.e., defining the lesson topic, explaining the importance of the selfadvocacy skill, presenting target behaviors, practicing and role-playing the skills, and summarizing the targeted skills). The intervention included 17-targeted behaviors. Results suggested that the students acquired, maintained, and generalized the skills. A continual ascent in percentile scores of target behaviors on direct test role-plays was observed from the introduction of the self-advocacy lessons through posttest assessments, as evidenced by an increase in the demonstration of target behaviors from $12 \%$ to $41 \%$ on pretest measures and $80 \%$ to $100 \%$ on posttests. Direct test role-plays specifically targeted accommodations in English and algebra classes. Similar results were noted on generalization role-plays, which reflected a steady ascent in scores and culminated in posttest scores of $77 \%$ to $100 \%$ on minimal generalization tests and $80 \%$ to $90 \%$ on extended generalization tests. Minimal generalization role-plays required students to request accommodations from the trainers in courses that were not included in the training lessons (i.e., physical science and communications class). During extended generalization role-plays, students advocated for accommodations in another subject (i.e., a social science course) with a staff member not involved in the training. Skills were maintained up to 20 days after the training ended. Although the students generalized the skills to other courses with someone other than the trainer, this study did not include any type of in-vivo assessment with the students' actual professors. 
In another study, Palmer and Roessler (2000) enhanced the instructional training program used in Roessler et al. (1998) by combining a conflict resolution module with the established self-advocacy module. Using an experimental design with control and treatment groups, the authors evaluated the effects of the Self-Advocacy and Conflict Resolution (SACR; Rumrill, Palmer, Roessler, \& Brown, 1999) training program on 50 students with disabilities who were enrolled in two and four-year postsecondary settings. Students were randomly assigned to either the treatment (i.e., 24 students) or control groups (i.e., 26 students). Training occurred in small groups. Role-play ratings of selfadvocacy and conflict resolution skill acquisition were primarily used to determine the effectiveness of the intervention; however, paper and pencil measures were administered and analyzed to identify differences between the groups in the areas of self-efficacy and knowledge of academic accommodation rights and responsibilities. Results indicated statistically significant differences between the control and treatment groups in general knowledge of accommodation rights and responsibilities. Further, the self-efficacy of the treatment group increased significantly compared to the control group. The treatment group was much more confident in their ability to advocate for accommodations and resolve conflicts. Lastly, the treatment group displayed a significantly higher number of targeted self-advocacy and conflict resolution behaviors than the control group. Specifically, the mean number of self-advocacy behaviors for the treatment group was 8.83 compared to 3.87 for the control group. As was noted in the previous study (i.e., Roessler et al.), the skills were not generalized to the natural environment with one of the students' instructors. A limitation of this study is that students only requested 
accommodations during role-plays and not with their own instructors in the natural environment.

White and Vo (2006) also investigated the impact of a training package to teach college students with disabilities how to self-advocate for accommodations by employing a multiple-baseline design across seven behaviors and three students. Instruction occurred in a one-to-one setting. Unique to this study was the infusion of ADA-related knowledge in the training program. Additionally, this study included a negotiation component to prepare college students to effectively negotiate accommodations requests that may be denied. Thirty-eight different scenarios for requesting accommodations were utilized in the study. Overall, students participated in three training sessions in addition to baseline and follow-up sessions. Each training session lasted from 90 to 120 minutes. Role-plays were used to assess the accommodations advocating skills. Four role-plays were assessed in each session. Direct and systematic instruction (e.g., reviewing skills, providing examples, modeling skills, and role-playing practice) was provided in the training sessions to teach seven classes of behaviors (i.e., opening a meeting, making the request, asking for suggestions, asking for a referral, planning future actions, summarizing the meeting, and closing the meeting). A functional relation was established between the training program and the participants ADA knowledge and accommodationrequesting skills. Findings showed that all participants made substantial gains in knowledge regarding their rights to reasonable accommodations and the ability to request those accommodations. All participants increased their ADA knowledge and accommodation-requesting skills to $100 \%$. Furthermore, the participants confirmed that they would use the acquired skills to request accommodations in the future. Several 
limitations were identified. For example, in this study students did not generalize the accommodation-requesting skills to natural settings with their actual teachers, and the majority of the practice scenarios were not related to the student's individual disability.

Lastly, Walker and Test (2011) extended the literature base by using a modified version of the SACR to evaluate the effects of this intervention on the ability of three African American college students to request academic accommodations during roleplays. The dependent variable was the number of correctly demonstrated target behaviors during a role-play probe. Thirteen target behaviors were identified, of which eleven (i.e., identify disability status, explain needs functionally, mention previous accommodations, explain benefits of past accommodations, identify resources and how they help, explain what you will do, ask for agreement, affirm agreement, restate accommodations, clarify your role or the instructor's role) were required for data collection. The intervention consisted of two parts. First, the student viewed a video that focused on the differences between high school and postsecondary education and the journey to become a self-advocate. After viewing the video, each student had a meeting with the researcher to identify an accommodation that the student would request from one of his instructors. During the second part of the intervention, the seven self-advocacy lessons of the SACR were presented. Each SACR lesson followed the same format and included a skill description, goal of the skill, skill examples, opportunities for the researcher to model, opportunities to role-play, and a summary of the lesson. Instruction for each lesson lasted 15 minutes. Lessons 1 through 3 were taught the first day. Lessons 4 and 5 were taught on the second day. Lessons 6 and 7 were taught on the third day. Role-play probes were administered after lessons 3 and 7. Additional probes were 
administered until the student demonstrated mastery (i.e., $100 \%$ of the target behaviors on two consecutive days). As a result of the intervention, a functional relation was demonstrated between the SACR and the participants' ability to request accommodations. Mastery attainment for the three participants occurred within 3 days of the introduction of the intervention. During a 1-week maintenance check, two of the participants performed $91 \%$ of the identified behaviors, and one student performed $73 \%$ of the behaviors. All three students demonstrated between 7 and 11 of the target behaviors during an in vivo generalization probe. Generalization occurred with the student's instructor. Social validity data from student questionnaires indicated that they believed the intervention enhanced their ability to self-advocate for academic accommodations. Several limitations were noted in this study. First, the intervention occurred in a one-to-one setting, so the intervention may not have the same results in a group setting. Next, it was challenging for the researcher to collect the generalization data if an instructor was not able to identify the behaviors the student demonstrated when requesting accommodations. Lastly, the targeted behaviors were very specific skills and may have been challenging for the students to remember to include in a conversation.

\section{Requesting Accommodations in High School}

Research on evaluating the effects of instructional interventions on the ability of high school students with disabilities to advocate for academic accommodations is sparse. For this review only two empirical studies were located in which high school students were either evaluated on their ability to self-advocate for instructional accommodations (Durlak et al., 1994) or their knowledge of accommodations and the procedures to request those accommodations in college (Wood et al., 2010). In an early study that 
employed a multiple baseline design across behaviors, Durlak et al. (1994) developed and applied a direct instructional training program to teach self-determination skills to eight high school students with learning disabilities. The intervention targeted seven selfadvocacy and self-awareness skills (e.g., asking for clarification of lecture material, telling a teacher that one has a learning disability, or making an appointment with a teacher to discuss needs and /or accommodations). Videotaped role-plays were used to assess the targeted skills. Prior to group training, each student met individually with the trainer and resource teacher to discuss the impact that his or her disability had on learning and to identify potentially effective accommodations. Each student was required to verbalize this information before he or she could enter training. Training was provided in groups of four students and included a direct instructional format comprised of seven steps (i.e., describing target behavior, demonstrating the behavior, allowing students to ask questions, having students practice skills, providing immediate feedback, repeating task until mastery, and generalizing to natural environment). After completing the training tasks, students performed five generalization tasks. Findings indicated all participants acquired skills in self-advocacy and self-awareness. All students reached criterion for each of the seven tasks in two to five instructional trials, completed a maintenance check with a $100 \%$ performance rate one week after training ended, and completed 4.38 out of 5 generalization tasks within one to two weeks after the maintenance check. Several limitations were noted in this study. First, during maintenance checks students wrote or stated the steps of a task instead of role-playing the steps. Next, skill acquisition was determined by performing the skills in the resource 
room and not the general education setting. Finally, the selected target skills did not fully represent the construct of self-determination.

Utilizing a simultaneous-treatments design with an initial baseline and final best treatment, Wood et al. (2010) extended the research of White and Vo (2006) by incorporating instruction about the ADA and Section 504 rights and responsibilities to teach four high school students with mild disabilities how to request accommodations. The primary purpose of the research was to determine if audio-supported text or explicit instruction on students' knowledge of their rights and accommodations in postsecondary settings was a more effective delivery of instruction. The study began with a pretest that included mock interviews with students to determine their knowledge regarding their rights and responsibilities for requesting accommodations in postsecondary education settings. Students were then randomly assigned to a content area (i.e., accommodations or rights and responsibilities) and condition (i.e., audio support or explicit instruction) after five baseline probes. After training with audio support, students individually answered probe questions that were digitally recorded and scored. During explicit instruction, a model-lead-test procedure was used. The experimenter followed a scripted lesson plan, and student responses were digitally recorded. The experimenter used error correction to address incorrect student responses. The student entered best treatment when he or she reached $80 \%$ mastery across two consecutive probes in either content area. Additional instruction was provided using the best treatment phase on the content area not mastered during instruction. For the posttest, students were then videotaped in a mock interview. Results indicated a functional relation and higher scores with explicit instruction compared to the audio-supported text. Students were able to generalize the 
skills to the mock interview. Findings also supported the outcomes of previous research (i.e., Durlak et al., 1994) that explicit instruction enhanced self-advocacy skills, even though the emphasis was placed on acquiring the knowledge of accommodations (i.e., being able to identify the needed accommodations and identify steps to request an accommodation) as opposed to acquiring the target behaviors associated with the skill. Social validity data from students in Wood et al. also supported the efficacy of the training in regards to understating their disabilities better and learning to request accommodations. One-to-one instruction was cited as a limitation because teachers may not have the time to explicitly teach these skills to students individually. Furthermore, the repetition of probe questions was identified as a possibly limitation.

\section{Importance of Understanding Rights and Responsibilities}

To effectively transition from school to postschool settings and address barriers in those settings, students with disabilities must be aware of accommodation rights and responsibilities. Three of the studies incorporated instruction to address students' knowledge of their civil rights related to accommodations (Palmer \& Roessler, 2000; White \& Vo, 2006; Wood et al., 2010) since civil rights acts for individuals with disabilities mandate reasonable accommodations in postsecondary settings. The interventions in these studies incorporated training materials comprised of information regarding the rights guaranteed to students with disabilities under the ADA and Section 504. As a result of the interventions in each study, students with disabilities improved their knowledge of accommodation rights and responsibilities. While Palmer and Roessler (2000) and White and Vo (2006) provided training to postsecondary education students, Wood et al. (2010) evaluated the outcomes of training on high school students 
transitioning to college. Nonetheless, students benefit from having knowledge of their rights and responsibilities if they will be expected to self-advocate and request accommodations in postschool settings.

\section{Components of Effective Interventions for Requesting Accommodations}

All six of the studies utilized direct and systematic instructional practices to teach students to request accommodations (Durlak et al., 1994; Palmer \& Roessler, 2000; Roessler et al., 1998; Walker \& Test, 2011; White \& Vo, 2006; Wood et al, 2010). Features of direct instruction may include an array of skills (e.g., identification of target behaviors, role-playing, modeling, feedback, and repeated practice). Not all of these skills were included in all of the reviewed studies. For example, every study except Wood et al. (2010) included a description of target behaviors, models of target behaviors, repeated practices, and role-play opportunities. Wood et al. evaluated students' knowledge of accommodations and rights and responsibilities using oral questioning probes instead of evaluating role-play situations. However, in Wood et al. explicit instruction was determined to be more effective than audio-supported text. Durlak et al. was the only study that videotaped training sessions and viewed them to promote group discussion and provide feedback. The addition of videotaping, while still providing direct instruction, allowed students to analyze their role-plays and self-correct based on the feedback they received. All studies except Wood et al. incorporated immediate and specific feedback into the trainings. Both positive feedback and corrective feedback were provided in most studies.

Single subject methodologies were also used in all of the studies except for Palmer and Roessler (2000). As a result, effective interventions included one-to-one 
instruction (Roessler et al, 1998; Walker \& Test, 2011; White \& Vo, 2006; Wood et al, 2010) and small group (Durlak et al., 1994) instruction when teaching students specific target skills to request accommodations. Explicit instructional practices were feasible because of the one-to-one and small group settings.

A generalization probe or component was included in every study except for Palmer and Roessler (2000). Yet, only Walker and Test (2011) included a generalization probe in the natural setting where students requested accommodations from their actual instructors. Not generalizing the skills to the natural setting with the appropriate personnel was identified as a limitation in several of the studies (e.g., Roessler et al., 1998; White \& Vo, 2006). Being able to generalize the acquired skills and effectively advocate for accommodations in the natural setting was identified as a desired outcome of an effective intervention.

\section{Lack of Diversity in Study Samples}

Students from culturally diverse backgrounds were not well represented in the samples of the studies in this review. Although not every study identified the racial background of all of the participants, in the five studies that did specify the ethnicity, 45 out of 60 total participants were Caucasian. Of the remaining 15 participants, one was Hispanic, eight were Native American, and six were African American. Walker and Test (2011) and Wood et al. (2010) included participants who were African American, but only Walker and Test implemented an instructional intervention to specifically teach diverse students to request accommodations that was evaluated through direct observation of skill performance. The Wood et al. study focused on increasing the students' knowledge of accommodations and rights and responsibilities for requesting 
accommodations in postsecondary settings rather than explicitly teaching them to request accommodations. As a result, no studies were identified that specifically focused on teaching high school students with disabilities from culturally diverse backgrounds to request accommodations.

\section{Summary of Research on Requesting Accommodations}

Requesting accommodations in school and postschool settings is, and will continue to be, a necessity for students with disabilities. While in school, increasing numbers of students with disabilities continue to be placed in general education classrooms and will require the self-advocacy skills to request their IEP accommodations to promote success in those environments (Hart \& Brehm, 2013). High school students with disabilities experience an environmental shift when they transition from a highly supportive high school environment to a college environment, work environment, or living environment in which they must function more independently. When transitioning from high school to postschool settings, students with disabilities are expected to take a more active role in their learning and their lives (Hadley, 2006). Hence, we must provide instruction that will promote the attainment of self-advocacy skills while students are enrolled in high school if we expect them to advocate for themselves in postsecondary settings (Hatch, Shelton, \& Monk, 2009). After all, a lack of effective training to develop self-advocacy skills in students with disabilities may result in negative postschool outcomes (Fiedler \& Danneker, 2007).

Five of the studies identified in the extant research explicitly taught students to request accommodations (Durlak et al., 1994; Palmer \& Roessler, 2000; Roessler et al., 1998; Walker \& Test, 2011; White \& Vo, 2006), and one study focused primarily on 
improving student's knowledge of their rights and responsibilities for requesting accommodations (Wood et al., 2010). Of those six studies, only two (Durlak et al., 1994; Wood et al., 2010) implemented an intervention with high school students. This paucity in research to teach high school students with disabilities the skills to effectively advocate for accommodations warrants additional research in this area.

Based on the analysis of the 6 studies, evidence supports utilizing direct instructional practices (i.e., identification of target behaviors, modeling, role-playing, repeated practice, and feedback) in one-to-one or small group settings for teaching students how to request accommodations. Specifically, using role-play to simulate the natural environment prepares students to generalize the skills they are learning; however, effective interventions should incorporate a generalization component in the natural setting. Incorporating video recording also provides participants an opportunity to analyze their behavior and determine if they are effectively displaying the target behaviors. Self-reflection and self-analysis can provide insight that feedback from others may not generate. Additionally, the SACR was utilized in three studies with college students, (Palmer \& Roessler, 2000; Roessler et al, 1998; Walker \& Test, 2011), and findings indicated improvements in the students' abilities to request accommodations. Consequently, this intervention may also be effective with high school students. Lastly, most of the studies included participants who were primarily Caucasian; therefore, future research may want to include participants from more diverse backgrounds.

\section{Chapter Summary and Synthesis}

The self-advocacy movement began as a result of the parents of children with disabilities advocating for their rights as well as those of their children. Simultaneously, 
writings of professionals in the field of disability supported the parents' efforts. By the early 1970's, individuals with intellectual disabilities, along with support from their allies (e.g., parents and other advocates), began to form self-advocacy organizations that enabled them to speak for themselves and their cause. These organizations continued to expand both nationally and internationally into the 1990s. This movement progressed as a result of legislative changes (e.g., the ADA and Section 504) and a self-determination initiative funded by the U.S. Department of Education. Consequently, the promotion of self-determination became a critical component in the education of students with disabilities.

Self-advocacy, a component of self-determination, has been recognized as a vital skill that students with disabilities must acquire in order to achieve successful postschool outcomes (Fiedler \& Danneker, 2007; Test, Fowler, Brewer et al., 2005; Wehmeyer, 2014). In order to self-advocate effectively, students must understand their disability and the impact their disability has on their learning and their lives, determine the supports they will need to be successful, and communicate effectively for those supports (Test, Fowler, Wood, et al., 2005). Since many students with disabilities are not inherently equipped with self-advocacy skills, these skills must be explicitly taught to them (Fiedler \& Danneker, 2007; Pocock et al., 2002; Schreiner, 2007). Reviews of self-advocacy studies (i.e., Test, Fowler, Brewer, et al., 2005; Roberts et al, 2014) support the effectiveness of interventions that utilize direct and systematic instruction to teach components of self-advocacy (i.e., knowledge of self, knowledge of rights, communication, and leadership). 
Teaching students to actively participate in IEP and transition meetings and to request accommodations have been identified as best practices to promote the transition of students with disabilities to postsecondary settings (Pocock et al., 2002; Test et al., 2004; Wehmeyer et al., 2007). Further, college students with disabilities have identified self-advocacy skills (e.g., knowing how their disability impacts them, requesting accommodations, and communicating effectively) in postsecondary educational settings as being instrumental to their success (Angell et al., 2010; Finn et al., 2008; Getzel \& Thoma, 2008; Gil, 2007; Hadley, 2006; Morningstar et al., 2010; Shaw et al., 2009). In conclusion, research supports that self-advocating in school and postsecondary settings is a critical life skill for students with disabilities, and direct instruction promoting these skills must be instituted early and continually reinforced throughout students' educational paths. Nevertheless, limited studies have explicitly taught students to self-advocate for supports that may promote successful outcomes in postsecondary settings. Specifically, only one empirical study was located for this review that utilized an intervention to teach high school students how to request accommodations in the general education setting to prepare them with the skills to request accommodations in postsecondary educational settings (i.e., Durlak et al., 1994). As a result, a definitive gap exists and additional research is warranted in this area. Students with disabilities may be initially resistant to becoming more aware of their disabilities, discussing their disabilities with others, and taking responsibility for future decisions regarding their lives; however, by employing interventions that promote the development of self-advocacy skills, they may become the strongest advocates for the development of self-determination skills (Karvonen, Test, Wood, Browder, \& Algozzine, 2004). 


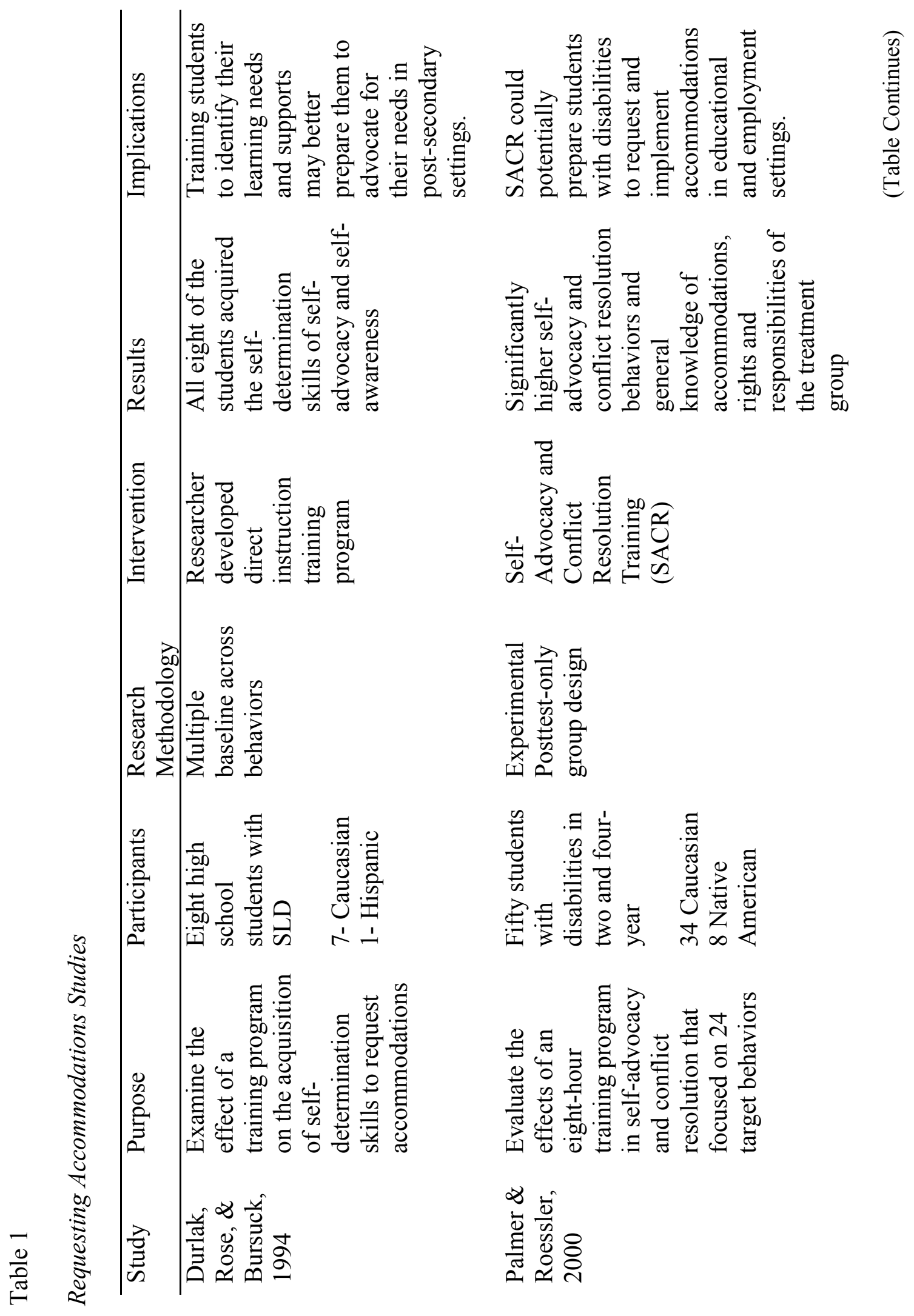




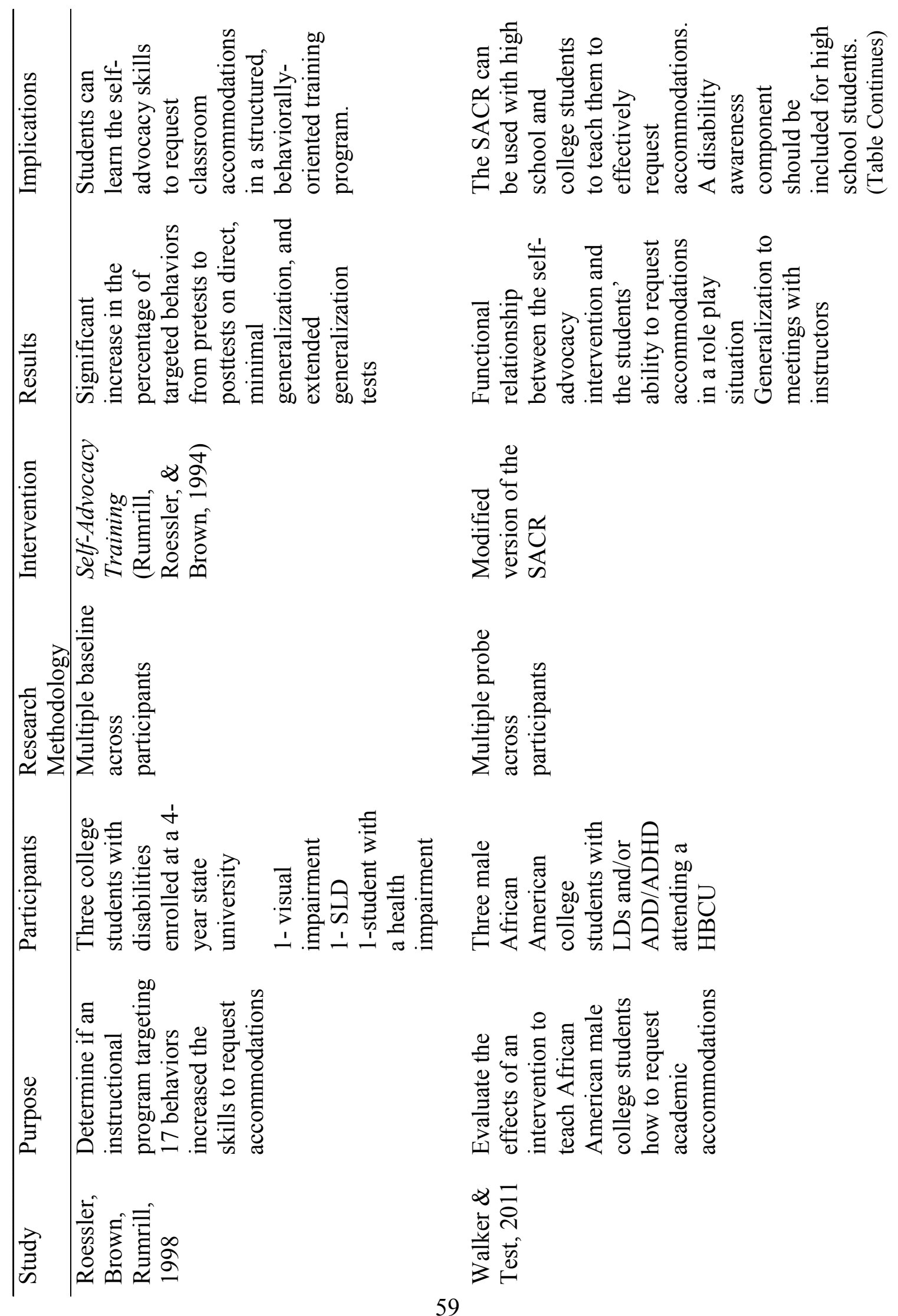




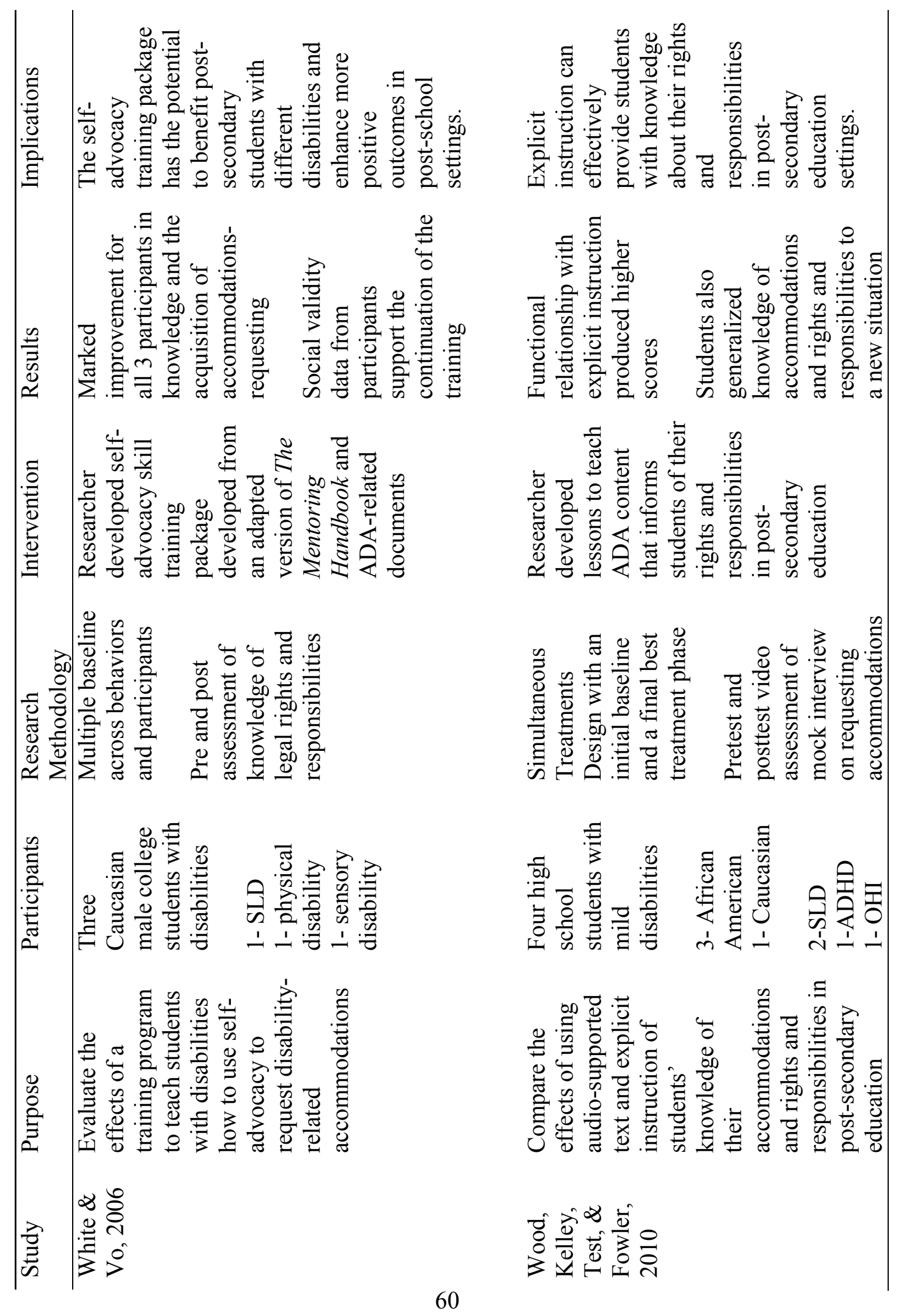




\section{CHAPTER III}

\section{METHOD}

This chapter begins by presenting the participants, setting, materials, and data collection procedures. Next, the experimental design is discussed. Lastly, pregeneralization, baseline, intervention, postgeneralization, and maintenance procedures are discussed.

\section{Participants}

Five high school students with high incidence disabilities (i.e., specific learning disability and other health impairment) participated in this study. All five of these students attended their most recent IEP meeting and have a transition plan in their IEP. Additional criteria for inclusion were (a) current status as a $9^{\text {th }}, 10^{\text {th }}$, or $11^{\text {th }}$ grade student; (b) enrollment in at least one general education course without a co-teacher, excluding physical education; (c) enrollment in a Learning Skills classroom; (d) postsecondary education goal in the student's transition plan that indicated the student will be attending college; (e) accommodations identified in the IEP; (f) attendance rate of $90 \%$ or better; and $(\mathrm{g})$ no prior experience self-advocating for accommodations. Students enrolled in a Learning Skills classroom receive daily assistance for their content area classes and support to develop and practice strategies to build academic and functional skill deficits. Additionally, a primary purpose of the Learning Skills classroom is to address students' needs based on their IEP and postsecondary goals; therefore, preparing students with the 
skills to advocate for their accommodations addresses their postsecondary educational goals. Participant selection began by identifying students in the Learning Skills classroom who met the grade-level criteria. Next, IEPs of students were reviewed to ascertain the disability area, the presence of a postsecondary education goal for college, and recommended accommodations. I then obtained a copy of the students' schedules to determine which students met the general education course enrollment criteria. I also interviewed each potential participant to determine if any of them had any previous experience requesting accommodations. Lastly, I analyzed attendance records to identify students who met the attendance criteria. A school administrator provided copies of the students' IEPs, schedules and attendance records for review. The specific course and general educator for that course were determined after participant selection. Students were permitted to choose the general education teacher from whom they would be requesting their accommodations. Speaking with a teacher for the first time about one's disability might be daunting for a student, so students were allowed to select a teacher they would feel comfortable with while having this conversation.

Informed consent for student participants was garnered from parents and assent was obtained from students prior to the start of the study. Each student was assigned a pseudonym to maintain confidentiality. Consent was also received from the teachers from whom the students would be requesting their accommodations. Descriptive characteristics identifying each student's grade in school, disability classification, full scale IQ, course in which the student requested the accommodations, and the accommodations that were being requested are provided in Table 2. A brief synopsis of each of the students and his or her functional needs, accommodations, postsecondary 
educational goals, general education courses, and individual strengths is provided below.

Table 2

Descriptive Characteristics of Participants

\begin{tabular}{|c|c|c|c|c|c|}
\hline Name & Grade & $\begin{array}{l}\text { Disability } \\
\text { Classification } \\
\end{array}$ & IQ & $\begin{array}{l}\text { Course } \\
\text { Enrollment }\end{array}$ & $\begin{array}{l}\text { Accommodation(s) } \\
\text { Request }\end{array}$ \\
\hline Monique & 11 & $\begin{array}{l}\text { Specific Learning } \\
\text { Disability }\end{array}$ & $67^{\mathrm{a}}$ & AVID & $\begin{array}{l}\text { Extra time and } \\
\text { smaller setting for } \\
\text { tests, graphic } \\
\text { organizers, more } \\
\text { detailed explanations }\end{array}$ \\
\hline La'Shay & 9 & $\begin{array}{l}\text { Specific Learning } \\
\text { Disability }\end{array}$ & $87^{\mathrm{a}}$ & Reading & $\begin{array}{l}\text { Extra time and } \\
\text { smaller setting for } \\
\text { tests, study guides }\end{array}$ \\
\hline Sasha & 10 & $\begin{array}{l}\text { Specific Learning } \\
\text { Disability }\end{array}$ & $73^{b}$ & Spanish & $\begin{array}{l}\text { Extra time and } \\
\text { smaller setting for } \\
\text { tests, study supports }\end{array}$ \\
\hline John & 9 & $\begin{array}{l}\text { Other Health } \\
\text { Impairment } \\
(\mathrm{ADHD})\end{array}$ & $122^{\mathrm{b}}$ & English & $\begin{array}{l}\text { Extra time and } \\
\text { smaller setting for } \\
\text { tests; motor breaks }\end{array}$ \\
\hline Todd & 9 & $\begin{array}{l}\text { Specific Learning } \\
\text { Disability }\end{array}$ & $78^{\mathrm{b}}$ & PreAlgebra & $\begin{array}{l}\text { Extra time for tests, } \\
\text { copies of notes }\end{array}$ \\
\hline
\end{tabular}

Note. ${ }^{\mathrm{a}}$ WASI-IV, ${ }^{\text {bB }}$ IT-II

Monique. Monique is a 17-year-old African American female. She was first evaluated and diagnosed with a learning disability as a sophomore in high school. Her speed in which she processes information impairs her ability to respond in a timely and efficient manner and understand course content. Her learning disability impacts her educational performance primarily in the areas of reading comprehension and math reasoning. Accommodations in her IEP include additional time for tests and assignments, a smaller setting (i.e., the resource room) for tests, and graphic organizers for course content. Monique is currently enrolled in one general education class (i.e., AVID, an 
elective class that enhances students' writing, inquiry, reading, and organizational skills to prepare them for college). According to her postsecondary transition goal for education, she will attend college and study nursing. In the classroom setting, Monique strives to do well and asks for assistance regularly.

La'Shay. La'Shay is a 14-year-old African American female. She was evaluated and diagnosed with a learning disability during or prior to $5^{\text {th }}$ grade. Her records were incomplete and did not indicate the grade in which she became eligible for services. La'Shay's learning disability specifically impacts her educational performance in the areas of basic reading, reading comprehension, vocabulary development, and math reasoning. Current accommodations in her IEP include additional time for tests and assignments, a smaller setting (i.e., the resource room) for testing, and study guides and advanced organizers to assist her with processing course content. La'Shay is currently enrolled in five general education classes, of which four of them have a special education co-teacher in the class (i.e., Algebra, Biology, Education and Career Tech, and English). La'Shay does not have a co-teacher in her general education Reading class. According to her postsecondary transition goal for education, she will attend college and pursue a degree in education. In the classroom setting, La'Shay displays a strong work ethic, strives to do well, and works well with others.

Sasha. Sasha is a 16-year-old African American female. She was evaluated and diagnosed with a learning disability in $6^{\text {th }}$ grade. Prior to this diagnosis, Sasha was eligible for services under the other health impairment category. Her learning disability specifically impacts her educational performance in the areas of reading comprehension, math calculation, and math reasoning. Current accommodations in her IEP include 
additional time for tests and assignments, a smaller setting (i.e., the resource room) for testing, and study guides and advanced organizers to assist her with processing course content. Sasha is currently enrolled in five general education classes, of which three of them have a special education co-teacher in the classroom (i.e., English, Economics, and Chemistry). Sasha does not have a co-teacher in her Spanish and Physical Education classes. According to her postsecondary transition goal for education, she will attend college and would like to eventually become a child advocate. In the classroom setting, Sasha strives to do well and is becoming more confident in her abilities. She is learning to work through her academic frustrations by not giving up.

John. John is a 14-year-old African American male. He was first evaluated and diagnosed with an other health impairment (i.e., ADHD) in $1^{\text {st }}$ grade. His ADHD specifically affects his organizational skills and ability to maintain focus and attend to tasks. Current accommodations in his IEP include additional time for tests and assignments, a smaller setting (i.e., the resource room) for testing, and self-management supports (i.e., motor breaks and support to maintain focus). John is currently enrolled in all general education classes except for his Learning Skills class. John does not have coteachers in any of his classes. Furthermore, three of his general education classes are honors classes (i.e., Reading, Algebra, and Biology). According to his postsecondary transition goal for education, he will attend college and study engineering. In the classroom setting, John exhibits a strong work ethic, demonstrates strength in his core subjects (i.e., English, math, science) and a keen interest in science, and displays respect to his teachers as well as his peers. Motor breaks benefit him when he is having difficulty attending to tasks or getting restless from sitting for extended periods of time. 
Todd. Todd is a 15-year-old African American male. He was first evaluated and diagnosed with a learning disability in $4^{\text {th }}$ grade. His learning disability specifically impacts his educational performance in the areas of basic reading, reading fluency, reading comprehension, and written expression. Current accommodations in his IEP include additional time for tests and assignments, a smaller setting (i.e., the resource room) for testing, and study guides and copies of class notes. Todd is currently enrolled in five general education classes, and three of the classes have a special education coteacher in the classroom (i.e., Ancient World History, Biology, and English). Todd does not have a co-teacher in his Reading and PreAlgebra classes. According to his postsecondary transition goal for education, he will attend college and study law enforcement. In the classroom setting, Todd is a well-mannered, respectful student who sometimes becomes distracted and may become frustrated as reading tasks become more challenging. Todd benefits from praise, support, and redirection.

\section{Setting}

This study took place in a suburban, public high school in the Midwestern part of the United States that had an approximate enrollment of 2,000 students in grades 9-12, of which about 300 were students with disabilities. The racial/ethnic background of the high school was 90.5\% Black, 1.8\% White, and 5.8\% Hispanic. Students from lowincome households comprised almost $68 \%$ of the school population.

All preintervention role-plays, instruction, role-play assessments during intervention, and maintenance probes occurred in a conference room located in the lower level of the library of the high school. The conference room offered a private setting that included a computer and desk, two bookcases, an easel, and two rectangular tables with 
six chairs. Additional space was available in this room if students chose to stand to perform their role-plays. Two posters created by the researcher hung in the conference room during intervention sessions. A SACR poster included the 14 target skills that the students would be displaying when requesting accommodations. Only the target skills from the lessons that had been presented were displayed on the poster. A student reflection poster was also visible when students analyzed their role-plays and wrote their reflections. Students were able to reference this poster if they needed ideas to assist them when writing their reflections. Pregeneralization and postgeneralization data were collected in the classrooms of the general educators from whom the participants requested their accommodations.

\section{Materials}

\section{The Self-Advocacy \& Conflict Resolution Training (SACR): Strategies for the}

\section{Classroom Accommodation Request}

The SACR (Rumrill et al., 1999) is a training program that was developed to prepare postsecondary students with disabilities to appropriately self-advocate with their instructors for their academic accommodations and effectively negotiate compromises when necessary. The SACR is comprised of two modules: a self-advocacy phase and a conflict resolution phase. The training was developed for college students with disabilities; however, it has also been recommended for use with high school students (Walker \& Test, 2011). For purposes of the current study, a modified version of the first module of the SACR was implemented along with an author-created disability awareness component. The modified SACR module consisted of seven skill lessons. These lessons included the following skills: Introduction, Disclosure, Solution, Resources, Agreement, 
Summary, and Closure. In each of the seven skill lessons, specific target behaviors were taught. The number of target behaviors in each lesson varied. For example, during the Introduction lesson, students demonstrated two target behaviors: greeted teacher and introduced oneself and the period of class enrollment. See Appendix A for the list of the seven lessons of the SACR and the corresponding target behaviors for each lesson. Each lesson plan followed a standard format. The researcher described the skill, identified the goal of the skill, provided skill examples, modeled the skill, practiced the skill with the student, and finally had the student role-play the new skill and any previously learned skills. Role-plays occurred the day after a lesson was introduced. Additionally, after each role-play, students wrote reflections about their performances in the role-plays and discussed the reflection with the researcher. Self-analyzing the role-plays provided the students with opportunities to review and critique their performances and make adjustments in future role-plays.

\section{SACR Template}

A SACR template is an outline of a specific lesson that includes the main components of each lesson. During the intervention phase, a template of each SACR lesson was provided to the student to use as a reference or study tool. There are seven SACR templates (see Appendix B for the templates).

\section{Disability Awareness Graphic Organizer}

Prior to the introduction of the SACR, students participated in a disability awareness lesson to identify their specific disabilities, explain how their disabilities impact their ability to learn, and identify accommodations from their IEPs that will enable them to be more successful in the general education classroom. As a result of this 
lesson, students completed a researcher-developed graphic organizer. The graphic organizer was used to document the participants' disabilities, strengths and needs, and accommodations that are outlined in their IEPs (see Appendix C for a copy of the graphic organizer).

\section{IEP at a Glance}

An individualized IEP report page, IEP at a Glance, generated from the electronic IEP program, Easy IEP ${ }^{\mathrm{TM}}$ was used to provide students with the accommodations specified in their IEPs. This report also included the students' disability areas in addition to their IEP goals.

\section{Student Binder}

Participants were given a 3-ring binder divided into three sections. Section 1 included a copy of the graphic organizer that the students completed before Lesson 1 of the SACR intervention. The IEP at a Glance report was also included in this section. Section 2 stored copies of each of the SACR lesson templates that students received, and Section 3 included student reflection notes that were written after they viewed their roleplays.

\section{SACR Poster}

A researcher-generated SACR poster was hung on an easel in the conference room during intervention. This poster included all 14 target behaviors for requesting accommodations, but only the behaviors that had been taught or reviewed were visible during a session (see Appendix D for a picture of the SACR poster). This poster provided students with a visual reference of the target behaviors for requesting accommodations. Participants were able to reference this poster while practicing the 
skills during the intervention; however, this poster was not available during baseline, intervention, or maintenance role-plays.

\section{Student Reflection Poster}

A researcher-developed poster was displayed in the conference room during intervention to help students analyze elements of their role-plays and write their personal reflections. This poster included questions and open-ended statements to assist students in generating ideas (see Appendix E for a picture of the reflection poster). Students could reference this poster if they elected to do so.

\section{Technology Tools}

An Apple iPad 216 GB Wi-Fi was used to video record the intervention role-plays for each participant. Participants then viewed their role-plays on the iPad in order to analyze them and write reflections. A Sony HandyCam Video Camera was used to record all baseline, intervention, and maintenance sessions to collect interobserver reliability and procedural reliability data.

\section{Data Collection Procedures}

\section{Interventionist}

The interventionist for this study was the researcher. The researcher is a doctoral candidate in Special Education at Illinois State University who has more than 30 years of experience teaching students with high incidence disabilities in a suburban school district in a Midwestern state. She holds a Master's degree in Special Education.

\section{Data Collector}

A retired special education teacher assisted the researcher with interobserver reliability and procedural fidelity data collection. This teacher had more than 25 years of 
experience teaching students with high incidence disabilities in a suburban school district in a Midwestern state. She holds a Master's degree in Special Education.

\section{Dependent Variable}

The dependent variable in this study was the number of correctly demonstrated target behaviors exhibited by a participant during role-play assessments and in the general education setting when a participant was requesting academic accommodations, the same as the one used by Walker and Test (2011). See Appendix F for the list of target behaviors for requesting accommodations. Role-plays were assessed during baseline, intervention, and maintenance. During intervention, role-play assessments occurred the day after a lesson was introduced and practiced. For example, the role-play for Lesson 1 occurred at the beginning of the next session before Lesson 2 was introduced. This procedure was followed until all seven lessons had been presented. Role-play assessments were then continued until the established criterion was attained. The recording procedure was direct observational recording, which utilized an event recording data collection system, consisting of a checklist of the 14 target behaviors (i.e., stated a greeting, introduced self, identified disability, explained disability, identified accommodation(s), explained benefit of accommodation, requested accommodation, identified resources, explained student responsibility, asked for agreement, affirmed agreement, restated accommodation, clarified roles, and provided closure). On the data collection sheet, yes was checked for all demonstrated behaviors and no for those that were not displayed. For example, when a student displayed target behaviors two and three (i.e., introduced self and disclosed disability) during a role-play, but did not display target behavior one (i.e., greeted teacher), the no column was checked for target behavior 
one. However, yes was checked for the behaviors that were demonstrated. The total number of correctly displayed behaviors was then recorded for each role-play. A partial display of a behavior was checked as a no. For example, target behavior number two (i.e., introduced self) required the student to state his or her name and identify the class period that he or she was enrolled in the teacher's class. If a student only stated the class period of enrollment, no will be checked for target behavior two. The same checklist was used during baseline, intervention, generalization, and maintenance. For the pregeneralization and postgeneralization assessments, the general education teacher completed the checklist. I met with each general education teacher to review and explain the target behavior checklist to enable them to complete the checklists after the student met with them.

\section{Interobserver Reliability}

To train the observer to collect reliability data, I developed five different role-play scenarios that included a combination of the 14-targeted behaviors of the SACR. I then video recorded myself role-playing these scenarios. The number of target skills demonstrated in each scenario varied to provide examples that were more representative of student role-plays over the course of the study. In addition, the observer was exposed to examples of all of the targeted skills. Observer training occurred prior to the baseline condition. I began the training by explaining the Interobserver Agreement (IOA) data collection form to the observer. A copy of the IOA data collection form is located in Appendix G. Next, the observer and I viewed a video recording of a role-play scenario, and I modeled the scoring procedures. Then, the observer and I independently viewed 
and scored four additional role-plays scenarios until a $90 \%$ or better agreement occurred on two consecutive role-play probes.

All role-play probes in baseline, intervention, and maintenance were video recorded for data collection. To collect the data, the trained observer viewed randomly selected role-play videos and scored them using the IOA data form. IOA data were collected at least once per condition for each participant or between 30 to $38 \%$ of all sessions. For each probe that was evaluated by the observer, I calculated the percentage of agreement by dividing the number of agreements by the total number of agreements and disagreements and then multiplying by 100 . High-reliability percentages support the findings in a study (Gast, 2010); therefore, the IOA was repeatedly monitored throughout the study. The Definitions of Target Behaviors sheet was developed to further operationalize and redefine the target behaviors to provide additional clarification during baseline (see Appendix $\mathrm{H}$ for this sheet).

\section{Procedural Reliability}

The same data collector evaluated the accuracy of instruction by the researcher and utilized the video recordings to collect this observational data. To collect the data, the trained observer viewed randomly selected role-play videos and scored them using procedural reliability checklists. Procedural reliability checklists were developed to collect this data during baseline, intervention, and maintenance. Procedural reliability data were collected at least once per condition per student or between 30 to $38 \%$ of all sessions. During the baseline and maintenance conditions, the researcher only demonstrated two behaviors. A copy of the procedural checklist identifying the two researcher behaviors for the baseline and maintenance phases is located in Appendix I. 
During the intervention phase, the researcher demonstrated up to 10 behaviors, depending on the session. For example, the first four behaviors were not demonstrated in Session 2 because the researcher did not require the student to role-play in this session; therefore, only six behaviors were observable. A copy of the procedural checklist identifying these 10 behaviors and the sessions in which these behaviors would be demonstrated during the intervention phase is located in Appendix J. Percentage agreement was reported for each target behavior. The formula for collecting procedural reliability was the number of observed behaviors divided by the number of planned behaviors multiplied by 100 . For each role-play that was evaluated by the observer, I calculated the percentage of agreement.

\section{Social Validity}

Social validity data on the procedures and outcomes of the study were collected after the postgeneralization session. Social validity questionnaires were completed by each student and the general education teachers from whom these students requested their accommodations. The student questionnaire included a Likert-like scale $(1=$ strongly disagree, $2=$ disagree, 3 = agree, 4 = strongly agree) to rate students' perceptions regarding their ability to advocate for academic accommodations as a result of instruction with the SACR. Additionally, students evaluated the usefulness of the intervention and determined if they would follow the learned procedures in future classes. Students also rated the usefulness of the disability awareness protocol that they completed. Finally, students answered an open-ended question to identify the most challenging aspects of the intervention. Data were reported by identifying the mean response for each question. See Appendix K for a copy of the student social validity questionnaire. The general 
education teacher questionnaire also included a Likert-like scale ( 1 = strongly disagree, $2=$ disagree, $3=$ agree, $4=$ strongly agree) to determine teachers' views regarding the value and benefits of teaching students to advocate for accommodations and the effectiveness of the intervention. Data were reported by identifying the mean response for each question. See Appendix L for a copy of the general education teacher social validity questionnaire.

\section{Experimental Design}

This study employed a multiple probe design across participants (Gast, 2010) to evaluate the effects of the modified SACR on the ability of five high school students to request their academic accommodations during role-play assessments. The research questions guided the selection of the design. A multiple probe design was deemed more practical since continuous measures in baseline are not always necessary (Gast, 2010). When it is unlikely for a participant to correctly demonstrate the identified behaviors without the introduction of the intervention, collecting probe data intermittently would be an acceptable method of documenting behavior stability (Gast, 2010). The study began with the pregeneralization probe and the baseline condition, followed by the intervention condition once stability was established in baseline, and concluded with the postgeneralization probe and maintenance sessions.

Visual-analysis guidelines recommended by Gast (2010) were followed to determine if a functional relationship existed between the SACR and the self-advocating skills of the students. Gast identified level and trend as the two primary qualities of data that should be analyzed when conducting visual analyses. To evaluate the level of data, level stability within conditions and changes in level (i.e., absolute and relative) between 
conditions were analyzed and interpreted. When calculating absolute level between conditions, I compared the last data point in the baseline condition to the first data point in the intervention condition and then determined the difference. Relative level change between conditions was calculated by subtracting the median value of the second half of the data in the baseline condition from the median value of the first half of data in the intervention condition. The level of the data was considered stable if a specified number of data points fell on or within an identified range (e.g., $80 \%$ of the data points falling on or within $25 \%$ of the median value). To evaluate the trend of the data series, I analyzed trend direction (i.e., accelerating, decelerating, or zero celerating) and changes in trend (i.e., improving or deteriorating) within and between conditions. Lastly, the percentage of non-overlapping data (PND) between adjacent conditions (i.e., baseline and intervention) was calculated. PND was calculated by (a) finding the range of values in the baseline condition, (b) counting the number of data points in the intervention condition, (c) determining the number of data points in the intervention condition that fall outside of the range of values in the baseline condition, and (d) dividing the number of data points in the intervention condition that fall outside the range of the baseline condition by the total number of data points in the intervention condition and multiplying by 100 (Gast, 2010). A higher PND between adjacent conditions usually indicates the intervention had a greater impact on the dependent variable (Gast, 2010). Therefore, the greater the percentage of non-overlapping data points between adjacent conditions, the greater the impact of the SACR on the accommodations-requesting skills of the students. Although a multiple probe design across participants does not produce intrasubject direct replication of effect, this design allows for inter-subject replication. In this 
study, the inter-subject replication along with generalization probes promoted external validity by increasing the generality of findings. In a multiple probe design across participants, experimental control is demonstrated when replication occurs across at least three tiers, and the introduction of the intervention is staggered across participants. Therefore, five students participated in this study and the introduction of the intervention was staggered across the participants. Furthermore, experimental control is demonstrated by taking into account the level, trend, stability, and overlap of data, in addition to the immediacy of effect when the intervention is introduced.

In a multiple probe design across participants, controlling for threats to internal validity promotes confidence that the independent variable, as opposed to alternative explanations, caused the change in behavior (Gast, 2010). To control for threats of history and maturation, the intervention was staggered across five tiers. Inter-subject replication further helped detect and control history threats. To control for the threat of testing, no reinforcement was provided in baseline. In addition, implementing a multiple probe design instead of a multiple baseline design controlled for the threat of testing. The threat of attrition was addressed by including five participants in the study. Furthermore, collecting IOA data once per condition or at least 30 to $38 \%$ of all sessions controlled for threats to instrumentation. Procedural fidelity data were also collected once per condition or at least 30 to $38 \%$ of all sessions to address the threat of procedural infidelity. Lastly, by familiarizing the students with the researcher, the iPads, and the process of selfanalysis prior to baseline, the threat of adaptation was addressed. 


\section{Procedures}

Participants were excused from their Learning Skills classroom to individually meet with the researcher between the hours of 7:30 a.m. and 1:00 p.m. each day. Overall, there were three to five sessions each week. The number of sessions varied due to the school calendar and the availability of the students. The length of the sessions ranged from 15 minutes to 70 minutes. Since a class period was only 50 minutes, some sessions continued on the next day. The session length was dependent on the condition of the study (i.e., baseline, intervention, or maintenance), the goals of the lesson, and the complexity of the target behaviors for individual students. For example, during Session 2 students reviewed and practiced skills from Lesson 1 of the SACR. The target behaviors from Lesson 1 in the intervention condition were skills the students were more familiar with (i.e., appropriately greet a teacher, introduce themselves, and identify the period that they are enrolled in that teacher's class), and this lesson did not include a video role-play probe or a student reflection. As a result, this session was shorter than the other intervention sessions. However, Sessions 3 and 4 included more challenging target behaviors (e.g., explaining the disability in functional terms and identifying the benefit of the accommodation), which extended the session length for three students (i.e., Monique, La'Shay, and Sasha). When a session continued to a second day in order to finish a lesson, the role-play probe was not administered until the day after the the lesson was completed. The approximate duration of the study was 20 weeks. Before the study began, I met with the general education teachers to discuss the data collection sheet and review the targeted behaviors. When necessary, I modeled the targeted behaviors to clear up any confusion the teachers may have had. 
During the first week of the study, I met with each of the students to explain that they would be scheduling two meetings (i.e., pregeneralization and postgeneralization probes) with their teachers to independently request their accommodations from them. I informed the students that the meetings would occur in the teachers' classrooms at the beginning and end of the study. At these initial meetings, I realized most of the students were not familiar with the term accommodations. To prepare students for their pregeneralization meetings with their general education teachers, I defined and discussed the word accommodation and presented them with an accommodation from their IEPs. I then familiarized each student with the procedures for video self-analyses. Thus, the study began with the pregeneralization probe, which was followed by the baseline and intervention conditions, and then concluded with postgeneralization and maintenance probes.

\section{Pregeneralization Probe}

Prior to the baseline condition, students scheduled the first meeting (i.e., pregeneralization) with their teachers to request their accommodations. Specifically, students were prompted to contact their teachers, request an afterschool meeting within one week, and request their accommodations from their teachers at this meeting. Prior to the pregeneralization meetings, teachers were informed that the students would be requesting their accommodations from them. The goal was to have all pregeneralization meetings completed within one week from the time the study began. Teachers were available for after-school study support from 2:30-3:00 on Mondays through Thursdays, so students were to schedule their meetings in the teachers' classrooms during this time. One student did not schedule this initial pregeneralization meeting within the week time 
frame, so I arranged a meeting between the student and his teacher in the conference room in the library. I intervened because this student became anxious about scheduling the meeting with his teacher and agreed it would be better if I would schedule it. After each pregeneralization meeting, the general education teacher completed a target behavior checklist that was used to collect generalization data. On these checklists, the teachers identified the target skills the students demonstrated. Teachers were not instructed to follow any specific procedures during the meetings to maintain a more natural setting. When the pregeneralization meetings were completed, all of the students entered the baseline condition.

\section{Baseline Procedures}

The purpose of the baseline condition was to determine the level at which a student was able to advocate for academic accommodations while displaying targeted behaviors prior to the introduction of the intervention. The goal was to establish stability in baseline before the intervention was introduced. The minimum number of probes in baseline was three, as recommended by Gast (2010). During baseline, students were asked to role-play individually with the researcher how they would request classroom accommodations from a general education teacher. The researcher assumed the role of the general education teacher during each of the baseline role-play probes. No instruction, feedback, or reinforcement were provided during baseline. All role-play probes in baseline were video recorded for data collection. Baseline role-plays were conducted for all students for the first three sessions of the study until a stable baseline was achieved for one of the students. Because more than one student achieved three stable baseline points, the student with the lowest baseline data was the first to enter 
intervention. Probe sessions for the remaining students continued at least once a week. After the first student in intervention completed Lesson 5, the next student with stable baseline data entered intervention. The same procedure was followed until all students entered intervention. Baseline stability was established for subsequent students before they entered intervention.

\section{Intervention Procedures}

The independent variable in this study was a modified version of the SACR. This is the same independent variable used in Walker and Test (2011), except additional modifications were implemented to adapt the training for high school students. The conflict resolution component of the SACR was not utilized since accommodations for high school students must be adhered to if deemed necessary by the IEP team and included in their IEPs. As a result, students did not have to negotiate their accommodations with their teachers.

The modified version of the SACR consisted of seven lessons, which were introduced in Sessions 2 through 8 of the intervention condition (see Appendix M for the seven SACR lesson plans). Each lesson included six procedural components (i.e., a skill description of the lesson, the goal of the skill, skill examples, instructor modeling, repeated student practice with the researcher, and a summary of the lesson). General reinforcement was provided (e.g., that's right, you got it, or nice job) when a participant correctly demonstrated each target behavior during the repeated practice component of the lesson. Corrective feedback was also provided as needed during practice. No reinforcement or feedback was provided during the intervention role-play probes. Roleplay assessments occurred during Sessions 3, 4, 5, 6, 7, 8, 9, and 10. If a student did not 
reach the mastery criterion during Session 10, additional role-play probes were provided in subsequent sessions. Booster sessions were provided as needed. The procedures for intervention booster sessions are discussed after Session 10 is presented.

In the intervention condition, between eight and 10 data points were collected for all students. After each role-play probe, students viewed their video recorded role-plays and wrote a self-evaluation reflection. The students then discussed their role-play performances with the researcher, at which time they were allowed to ask the researcher for clarification or support. When students did not recognize their mistakes, the researcher provided additional feedback. Students were given a SACR lesson template during Sessions 2 through 8 . These templates were stored in the students' binders, and students were allowed to reference them anytime during a session as long as the student was not performing a role-play assessment. The specific procedures for each session are described in the next section.

Session 1. Prior to the introduction of the SACR, a disability awareness component was presented (see Appendix N for a copy of the Disability Awareness Lesson Plan). Though IEPs include students' strengths, needs, accommodations, and disability areas, high school students with disabilities are not always aware of their needs as learners, the accommodations to address those needs, and the value of requesting and receiving those accommodations. Therefore, the disability awareness component incorporated a discussion of the students' disabilities, their strengths and needs, as well as accommodations specifically outlined in their IEPs. All students received a copy of their IEP at a Glance report that was generated from Easy IEP (тм). This report enabled 
students to review their disability areas and accommodations. I met with each student individually for the disability awareness lesson.

The disability awareness lesson began when I stated the objective and reviewed the vocabulary terms that were used in the lesson (i.e., disabilities, strengths, needs, and accommodations). Besides defining the terms, I clarified the terms and cited examples of each term. For example, an accommodation was defined as a support that changes "the input and/or output method used by the teacher and/or student related to the intended instructional outcome" (King-Sears, 2001, p. 73). I clarified the term by stating that an accommodation is a support that will help the student access, learn, or demonstrate knowledge of the course material. Examples of accommodations were then provided (e.g., using digital texts or electronic books for students who have reading difficulties, having a graphic organizer available for students who have difficulties organizing their thoughts for writing assignments, or going to the resource room to receive testing supports). After reviewing the terms and having the student define the terms in his or her own words, I then had the student complete the Disability Awareness Graphic Organizer using data from his or her IEP as a resource. The student was also allowed to include additional strengths, needs, or accommodations not listed in the IEP. At the end of the disability awareness lesson, each student had a completed the graphic organizer that summarized his or her disability, learning strengths, functional needs, and accommodations as they relate to a general education content course in which he or she was enrolled. Ultimately, the students were able to identify their disabilities, explain how their disabilities impacted their ability to learn, and identify an accommodation that they eventually requested from their general education content area teacher. Acquisition of 
this foundational knowledge was necessary for students to accurately demonstrate selfawareness target behaviors (i.e., disclosing the disability, identifying the impact of the disability on learning, identifying the accommodation, and explaining the benefit of the accommodation) of the SACR.

Session 2. Lesson 1 of the SACR was introduced and practiced. Students practiced how to greet a teacher as well as introduce themselves to the teacher by including their names and the class they were enrolled in with that teacher. For example, a student may have said, "Hello, I'm Don Smith, and I'm in your $4^{\text {th }}$ period Career Tech class." Session 2 only included the six procedural components of a lesson and ended when I summarized the skills from Lesson 1 of the SACR.

Session 3. This session began with me referencing the SACR poster to review the target skills from Lesson 1. Using the iPad, I then video recorded the student roleplaying the steps for requesting accommodations from his or her teacher. Next, the student viewed the role-play and wrote a reflection. Lastly, the student and I discussed the role-play. I provided feedback if the student had questions or as I deemed appropriate. After the student wrote the self-reflection and discussed this role-play with me, Lesson 2 of the SACR was introduced and practiced. In this lesson, students learned how to state their disability to a teacher and explain to that teacher how their disability impacts their learning and/or functioning in the class. For example, a student may have said, "I have a learning disability in reading and it takes me a very long time to read a short story or a chapter in a textbook." At the end of this session, I summarized and reviewed the target skills from Lessons 1 and 2. 
Session 4. This session began with me referencing the SACR poster to review the target skills from Lessons 1 and 2. I then video recorded the student role-playing the steps for requesting accommodations from his or her teacher. Next, the student viewed the role-play and wrote a reflection. Lastly, the student and I discussed the role-play. I provided feedback if the student had questions or as I deemed appropriate. After the roleplay was reviewed and the self-reflection was written, Lesson 3 of the SACR was introduced and practiced. During Lesson 3, students practiced how to state an accommodation that was in their IEPs, explained how this accommodation would benefit them in the class, and requested to use that accommodation in the class. A student may have said, "In the past I have listened to electronic books to keep up with the daily readings. This accommodation allows me to participate in class discussions. In this class I would like to use electronic books as well." At the end of this session, I summarized and reviewed the target skills from Lessons 1 through 3.

Session 5. This session began with me referencing the SACR poster to review the target skills from Lessons 1 through 3. I then video recorded the student role-playing the steps for requesting accommodations from his or her teacher. Next, the student viewed the role-play and wrote a reflection. Lastly, the student and I discussed the role-play. I provided feedback if the student had questions or as I deemed appropriate. After the roleplay was reviewed and the self-reflection was written, Lesson 4 of the SACR was introduced and practiced. In Lesson 4, students learned to identify available resources they could use to implement the accommodation and explain their responsibility for the accommodation. At this point a student may have said, "I will work with my IEP teacher to access the electronic copies of the readings." Lesson 4 included an accountability 
component in which the student took responsibility for accessing the accommodation. The session ended when I summarized the skills from Lessons 1 through 4.

Session 6. This session began with me referencing the SACR poster to review the target skills from Lessons 1 through 4 . I then video recorded the student role-playing the steps for requesting accommodations from his or her teacher. Next, the student viewed the role-play and wrote a reflection. Lastly, the student and I discussed the role-play. I provided feedback if the student had questions or as I deemed appropriate. After the roleplay was reviewed and a self-reflection was written, Lesson 5 of the SACR was introduced and practiced. During Lesson 5, students learned to ask the teachers for agreement with the accommodation plan and how to reply with an affirmative statement. A student may have responded by saying, "Will our plan work for you? Sounds good." The session concluded with me summarizing the skills from Lessons 1 through 5 .

Session 7. This session began with me referencing the SACR poster to review the target skills from Lessons 1 through 5. I then video recorded the student role-playing the steps for requesting accommodations from his or her teacher. Next, the student viewed the role-play and wrote a reflection. Lastly, the student and I discussed the role-play. I provided feedback if the student had questions or as I deemed appropriate. After the roleplay was reviewed and a self-reflection was written, skills from Lesson 6 of the SACR were introduced and practiced. In Lesson 6, students acquired the skills to restate the accommodation and identify both the student's and the teacher's responsibilities.

A student may have learned to say, "On testing days I'll plan to have my tests read by the resource room teacher. If you let me know a few days ahead of time, I can make the 
arrangements with the resource room teacher." The session ended when I summarized the skills from Lessons 1 through 6.

Session 8. This session began with me referencing the SACR poster to review the target skills from Lessons 1 through 6. I then video recorded the student role-playing the steps for requesting accommodations from his or her teacher. Next, the student viewed the role-play and wrote a reflection. Lastly, the student and I discussed the role-play. I provided feedback if the student had questions or as I deemed appropriate. After the roleplay was reviewed and a self-reflection was written, Lesson 7 of the SACR was introduced and practiced. During Lesson 7, the student learned how to provide closure by making a positive statement about the teacher, the class, the accommodation plan, or by expressing appreciation for the teacher's help. A student may have said, 'I'm so glad you understand how important this accommodation is to me. Thanks so much." The session concluded when I summarized the skills from Lessons 1 through 7.

Session 9. This session began when I referenced the SACR poster to review the target skills from Lessons 1 through 7. I then video recorded the student role-playing the steps for requesting accommodations from his or her teacher. Next, the student viewed the role-play and wrote a reflection. Lastly, the student and I discussed the role-play. I provided feedback if the student had questions or as I deemed appropriate. This session ended after the role-play discussion.

Session 10. This session began with me referencing the SACR poster to review the target skills from Lessons 1 through 7. I then video recorded the student role-playing the steps for requesting accommodations from his or her teacher. Next, the student viewed the role-play and wrote a reflection. Lastly, the student and I discussed the role- 
play. I provided feedback if the student had questions or as I deemed appropriate. At the end of this session, the student may have possibly achieved the mastery criterion and moved from intervention to generalization. The mastery criterion was $100 \%$ of correctly demonstrated target behaviors for two consecutive days. If a student did not attain the mastery criterion, a booster session and additional role-play sessions were provided.

Intervention booster sessions. I was prepared to provide a booster session during the intervention sessions for any student who was not acquiring the target behaviors as the lessons progressed, or any student who did not reach the mastery criterion by the end of Session 10. During the practice sessions and role-play assessments, students continued to make progress and demonstrate the new target behaviors, so no booster sessions were needed. However, one student (i.e., Sasha) did not attain the mastery criterion during Session 10, so booster sessions were provided. These booster sessions occurred after the role-play assessments in Sessions 10 and 11. During the booster sessions, I reviewed the skills that needed to be retaught or required more practice. To identify these skills, the student and I conducted error analyses while viewing the role-play videos from Sessions 10 and 11. These role-plays were viewed on the iPad. The SACR poster was also referenced before and after viewing the role-play to identify the target skills. At the end of Sessions 10 and 11, the student practiced requesting accommodations with the researcher by demonstrating all 14 target behaviors. Additional sessions (i.e., Sessions 12 and 13) were then provided until the student displayed all target behaviors for two consecutive role-plays. These subsequent sessions included a review of the skills using the SACR poster, a role-play, and a student reflection. 


\section{Postgeneralization Probe}

Prior to the postgeneralization meetings, I again met with the students' general education teachers to review the data collection sheet and targeted behaviors. This second meeting with the researcher provided teachers an opportunity to address any questions they may have had regarding the targeted behaviors. Once again, teachers were not instructed to follow any specific procedures during the generalization meetings in order to maintain a more natural setting. The postgeneralization meetings were to initially occur within one week from the time each student reached the mastery criterion during intervention. Once a student met the mastery criterion, the student was to schedule this second meeting (i.e., postgeneralization) with his or her general education teacher to request accommodations. The students were prompted to contact their teachers, request an afterschool meeting within a week, and request their accommodations from their teachers at this meeting. Due to unforeseen circumstances (e.g., scheduling conflicts, student nervousness, the school calendar, and spring vacation), none of the postgeneralization meetings happened within the week time frame. Consequently, these meetings occurred between 2 to 3 weeks after reaching mastery. Teachers were available for after-school study support from 2:30-3:00 on Mondays through Thursdays. As a result, three of the meetings were scheduled during this time. The other two meetings occurred during the school day because of teacher and/or student scheduling conflicts. After each postgeneralization meeting, the general education teacher completed a target behavior checklist that was used to collect generalization data. On these checklists, the teachers identified the target skills the students demonstrated. 
Teachers also completed a social validity questionnaire after this postgeneralization meeting.

A postgeneralization booster session was provided for one student who struggled with scheduling her final meeting with her teacher. This session consisted of a collaborative problem solving meeting to identify the conflict and arrive at a solution with the student. More specifically, Monique stated that she did not schedule her postgeneralization meeting because her teacher was so busy with other meetings, and she did not want to take more of her time. Consequently, Monique and I decided that I would arrange for her to meet with her teacher during the first period when Monique usually met with me. Monique's teacher did not have a first period class, so she agreed that this time would be better for the meeting. Since it had been 3 weeks since Monique met the mastery criterion, she asked to look at the SACR poster before she went to her meeting. One other postgeneralization booster session was provided. At this session, Sasha asked to view the SACR poster because she had just returned from spring vacation, and she stated there were a lot of things she had to remember.

\section{Maintenance Procedures}

During maintenance, a total of three data points were collected. Two, four, and six weeks after the students met the mastery criterion, role-play probes were administered. These probes occurred in the conference room in the same manner as the baseline and intervention probes. No review, instruction and feedback were provided during a maintenance session. The purpose of the maintenance probes was to determine if a student maintained the target skills to effectively advocate for accommodations. The 
students completed the social validity questionnaires after the first maintenance probe (i.e., 2 weeks after mastery). 


\section{CHAPTER IV}

\section{RESULTS}

This study measured the effectiveness of a self-advocacy strategy, the SACR, on the ability of high school students with high incidence disabilities to advocate for academic accommodations. A multiple probe design across participants was used to evaluate the effects of the SACR on 14-targeted behaviors. The chapter begins by presenting interobserver reliability and procedural fidelity results. Next, the research questions guide the presentation of the findings of the impact of the SACR on the dependent variable. Lastly, results from the social validity questionnaires are presented.

\section{Interobserver Reliability}

Interobserver agreement (IOA) of data was calculated using an item-by-item analysis. The percentage of agreement was determined by dividing the number of agreements by the number of agreements plus disagreements and multiplying by 100 . The total number of agreements and disagreements equaled 14 since there were 14targeted behaviors. IOA data were collected $35 \%$ of all sessions across baseline, intervention, and maintenance for all students. Mean IOA data across all sessions was $97 \%$ (range $86 \%-100 \%$ ). During the baseline condition, IOA data were collected an average of $33 \%$ of the sessions. Mean IOA during baseline was $95 \%$ (range $=86 \%$ $100 \%$ ) for all students. During the intervention condition, IOA data were collected an average of $37 \%$ of the sessions. Mean IOA during intervention was $97 \%$ (range $=86 \%$ - 
$100 \%$ ). During maintenance, IOA data were collected an average of $33 \%$ of the sessions. Mean IOA on maintenance probes was 99\% (range $=93 \%-100 \%)$. The IOA data for each participant in each condition are presented in Table 3.

Table 3

IOA Data Collection Results by Condition and Participant

\begin{tabular}{|c|c|c|c|c|c|}
\hline Condition & Monique & La'Shay & Sasha & John & Todd \\
\hline \multicolumn{6}{|l|}{ Baseline } \\
\hline $\begin{array}{l}\% \text { of } \\
\text { sessions }\end{array}$ & $33 \%$ & $33 \%$ & $38 \%$ & $30 \%$ & $33 \%$ \\
\hline Range & $100 \%$ & $93 \%-100 \%$ & $86 \%-93 \%$ & $93 \%-100 \%$ & $93 \%-$ \\
\hline & & & & & $100 \%$ \\
\hline Average & $100 \%$ & $97 \%$ & $91 \%$ & $98 \%$ & $95 \%$ \\
\hline \multicolumn{6}{|l|}{ Intervention } \\
\hline $\begin{array}{l}\% \text { of } \\
\text { sessions }\end{array}$ & $38 \%$ & $38 \%$ & $36 \%$ & $38 \%$ & $38 \%$ \\
\hline Range & $86 \%-100 \%$ & $93 \%-100 \%$ & $86 \%-100 \%$ & $100 \%$ & $93 \%-$ \\
\hline & & & & & $100 \%$ \\
\hline Average & $95 \%$ & $98 \%$ & $95 \%$ & $100 \%$ & $98 \%$ \\
\hline \multicolumn{6}{|l|}{ Maintenance } \\
\hline $\begin{array}{l}\% \text { of } \\
\text { sessions }\end{array}$ & $33 \%$ & $33 \%$ & $33 \%$ & $33 \%$ & $33 \%$ \\
\hline IOA $\%$ & $100 \%$ & $100 \%$ & $100 \%$ & $100 \%$ & $93 \%$ \\
\hline
\end{tabular}

Procedural fidelity data were collected on the researcher's performance (i.e., fidelity of implementation of the SACR) for a total of 34 observations or $33 \%$ (range 
$30 \%-38 \%$ ) of all sessions across baseline, intervention, and maintenance conditions for all students. Mean procedural fidelity across all sessions and conditions was $100 \%$. Percentage agreement was reported for each target behavior. The formula for collecting procedural fidelity was the number of observed behaviors divided by the number of planned behaviors multiplied by 100 . Mean procedural fidelity during baseline, intervention, and maintenance sessions was $100 \%$ for all participants.

\section{Effect of the SACR on the Dependent Variable}

\section{Requesting Accommodations in Role-Play Simulations}

Research Question 1: Does instruction using the SACR increase the ability of high school students with high incidence disabilities to independently request academic accommodations in role-play simulations?

To determine the effect of the SACR on the ability of students to request accommodations, the number of correctly demonstrated target behaviors during roleplays was evaluated during baseline, intervention, and maintenance. Data within and between conditions (i.e., baseline and intervention) were examined using visual-analysis guidelines. Specifically, the levels, trends, and variability of the data are reported for students within conditions or between the baseline and intervention conditions. The percentage of non-overlapping data (PND) between adjacent conditions (i.e., baseline and intervention) was also evaluated and identified. Lastly, descriptive statistics (mean, median, and range) were used to summarize results of the data. Figure 1 includes a graphical display of the number of target behaviors students demonstrated during roleplay assessments across all conditions, including maintenance and generalization 
sessions. Graphical data from Figure 1 indicate an improvement in accommodationrequesting skills for all students during the intervention condition.

Monique. During the baseline condition, Monique did not demonstrate any of the 14 target behaviors. She scored a zero on the three baseline probes; therefore, no change in level occurred, and a zero-celerating trend was observed. As a result, stability in baseline was demonstrated prior to the introduction of the intervention. Between the baseline and intervention conditions, there was an absolute level change of 3 and a relative change of 5.5, indicating an abrupt change in level in a therapeutic direction after the introduction of the intervention. A change in trend direction from zero celerating in the baseline condition to accelerating in the intervention condition was observed between the adjacent conditions. The PND between adjacent conditions was $100 \%$. Within the intervention condition, Monique's scores ranged from 3 to $14(21 \%-100 \%)$ indicating an accelerating trend in a therapeutic direction. Monique met the mastery criterion in 10 sessions. After 2 weeks Monique maintained 10 of the 14 skills (71\%). She did not demonstrate target skills 10, 11, 12, and 13 (i.e., ask for agreement, affirm agreement, restate accommodations, and clarify student and/or teacher roles). After 4 weeks, she maintained 11 of the skills (79\%). At this time, she did not display target skills 10,11 , and 13 (i.e. ask for agreement, affirm agreement, and clarify student and/or teacher roles), but she did restate her accommodations. After 6 weeks, she maintained 11 of the skills (79\%). Once again, she did not demonstrate skills 10,11, and 13. During maintenance, Monique displayed 10 or 11 of the target skills during role-plays, for an average of 10.7 of the skills $(76 \%)$ over a 6 -week period. 


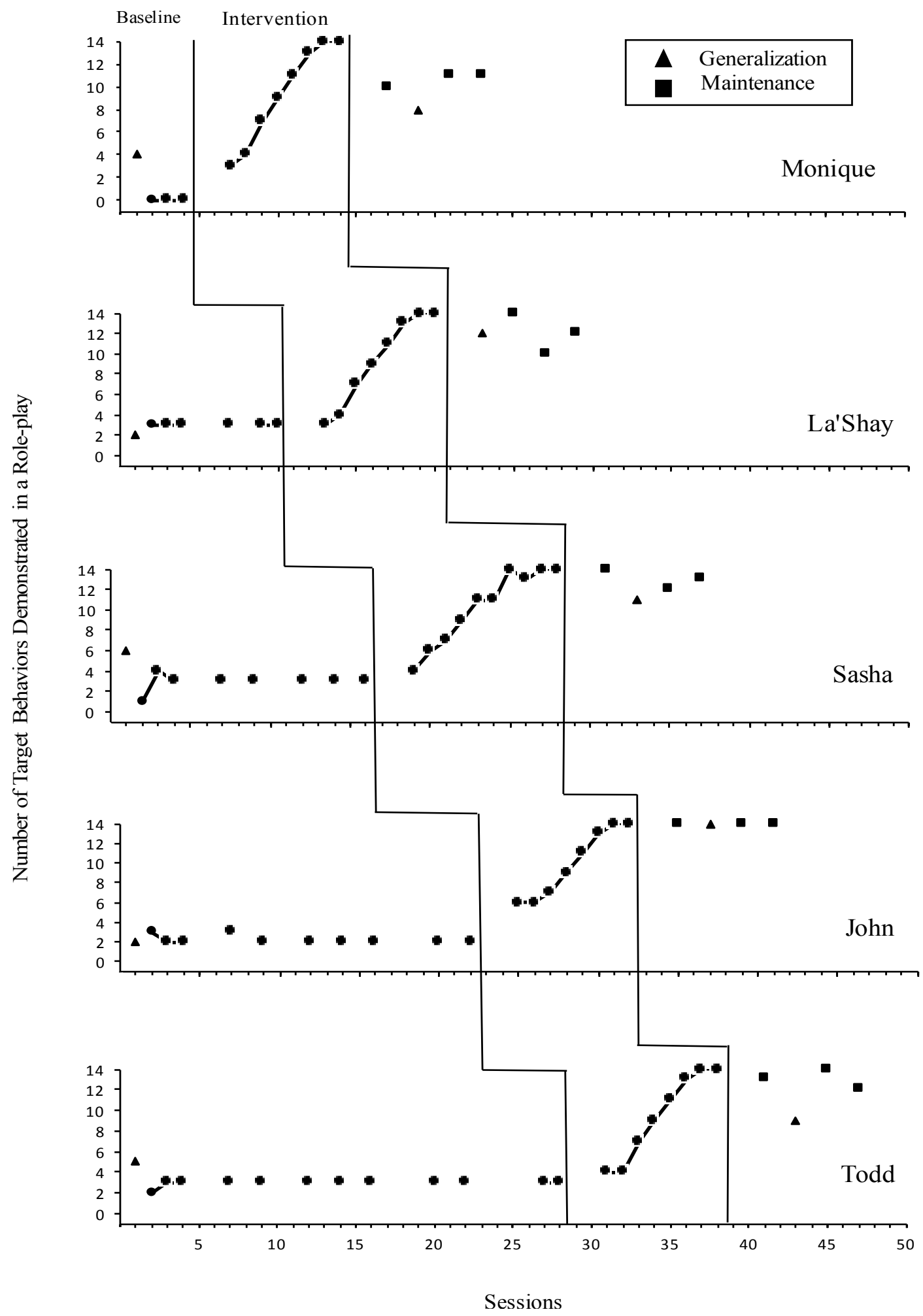

Figure 1. Number of target behaviors demonstrated during role-plays. 
La'Shay. La'Shay demonstrated 3 target behaviors (i.e., greet teacher, identify accommodation, and request accommodation) in all baseline probes. Consequently, stability in baseline was established because there was no change or variability in level, and the trend was zero celerating. Upon introduction of the intervention, the absolute change in level was zero. La'Shay demonstrated the same number of target behaviors during the first role-play in the intervention condition that she did in her last baseline probe; however, between adjacent conditions, there was a change in trend from zero celerating to accelerating in a therapeutic direction. The relative change between conditions was 2.5 , indicating a gradual change in level. The PND between adjacent conditions was $87.5 \%$. One data point in the intervention condition overlapped with the range of data points in the baseline condition. Specifically, La'Shay did not display one component of target behavior number two (i.e., identify her class or class period), so the number of behaviors she demonstrated in the first role-play during the intervention condition (i.e., 3) was the same as the number of behaviors she displayed on each probe during baseline. Also important to note, during Session 4 in the intervention condition, La'Shay did not display the target behaviors (i.e., identify the accommodations and request the accommodations) she had previously demonstrated in role-plays during the baseline condition and in Session 3 of the intervention condition. Although these target behaviors had not yet been introduced in the intervention, she had previously demonstrated them. Within the intervention condition, La'Shay's scores ranged from 3 to $14(21 \%-100 \%$ of the target behaviors) indicating a continually accelerating trend in a therapeutic direction. La'Shay met the mastery criterion in 10 sessions. After 2 weeks La'Shay maintained 14 of the 14 skills (100\%). After 4 weeks she maintained 10 of the 
14 skills (71\%). At this time, she did not display target skills 10, 11, 12, and 13 (i.e., ask for agreement, affirm agreement, restate accommodations, and clarify role of teacher and student). After 6 weeks she maintained 12 of the skills (86\%), but did not demonstrate skills 10 and 12 (i.e., ask for agreement and restate accommodations). During maintenance, La'Shay displayed between 10 and 14 target skills during role-plays, for an average of 12 skills ( $86 \%$ ) over the 6-week period.

Sasha. During the baseline condition, Sasha's scores ranged from 1 to 4 with a mean of 2.88 and a median of 3. To determine level stability, Gast (2010) suggested analyzing the last 3-5 data points in a long data series (i.e., seven or more data points). Based on Gast's recommendation, level stability was demonstrated because Sasha scored a 3 on each of the last five data points (i.e., no variability) in baseline. Upon introduction of the SACR, there was a gradual change in level in a therapeutic direction (i.e., absolute change of 1 and a relative change of 4). The PND between adjacent conditions was $87.5 \%$. One data point during the intervention condition overlapped with the range of data points in the baseline condition. Particularly, during one baseline probe, Sasha demonstrated four of the target behaviors, which was the same number of behaviors she demonstrated in one of the intervention role-plays. Within the intervention condition, Sasha's scores ranged from 4 to 14 (29\% - 100\% of the target behaviors) indicating an accelerating trend in a therapeutic direction. Sasha met the mastery criterion in 13 sessions. During Sessions 10 and 11, Sasha was having a difficult time remembering all 14 of the steps, even though she had demonstrated all of the target behaviors in Session 9. As a result, Sasha did not demonstrate all of the target skills in the role-plays during Sessions 10 and 11. Therefore, intervention booster sessions were provided at the end of 
Sessions 10 and 11. During these booster sessions, Sasha and the researcher analyzed the role-play videos together to determine which skills she had not demonstrated and to discuss why those skills were challenging to her. After these analyses, Sasha again practiced requesting her accommodations with the researcher until she demonstrated all 14 target skills and stated that she was prepared for the next session's role-play. Sasha then reached mastery after two more sessions (i.e., Sessions 12 and 13). Sessions 12 and 13 included a review using the SACR poster, a role-play, and a student reflection. It is important to note that Sasha commented several times during the booster sessions about how challenging it was to remember all of the steps. After 2 weeks, Sasha maintained 14 of the 14 skills (100\%). After 4 weeks, she maintained 12 of the 14 skills (86\%). At this time, she did not display target skills 8 and 9 (i.e., identify available resources and explain your responsibility). After 6 weeks she maintained 13 of the skills (93\%), but did not demonstrate skill 11 (i.e., affirm agreement). During maintenance, Sasha displayed between 12 and 14 target skills during role-plays, for an average of 13 skills (93\%) over the 6-week period.

John. During the baseline condition, John's scores ranged from 2 to 3 with a mean of 2.2 and a median of 2. Stability in baseline was demonstrated because of low variability in the scores and $80 \%$ of the data points fell within $20 \%$ of the median level. Furthermore, John had a long data series within the baseline condition (i.e., 10 data points) in which he demonstrated the same number of target behaviors (i.e., 3 ) on the last six probes in baseline. Upon introduction of the SACR, there was an immediate and abrupt change in level as indicated by an absolute level change of 4 and a relative change of 4.5 in a therapeutic direction. The PND between adjacent conditions was $100 \%$. 
Within the intervention condition, John's scores ranged from 6 to 14 (43\% - 100\% of the target behaviors) indicating an accelerating trend in a therapeutic direction. John met the mastery criterion in 10 sessions. From 2 weeks through 6 weeks after reaching mastery, John maintained 14 of the 14 skills (100\%).

Todd. During the baseline condition, Todd's scores ranged from 2 to 3 with a mean of 2.9 and a median of 3 . Stability in baseline was demonstrated because $92 \%$ of the scores in baseline fell within $20 \%$ of the median level. Furthermore, Todd had a long data series within the baseline condition (i.e., 12 data points) in which he demonstrated the same number of target behaviors (i.e., 3) on the last 11 probes in baseline. Upon introduction of the SACR, there was a gradual change in level as indicated by an absolute change of 1 and a relative change of 2.5 in a therapeutic direction. The PND between adjacent conditions was $100 \%$. While in the intervention condition, Todd's scores ranged from 4 to 14 (29\% - 100\% of the target behaviors) indicating an accelerating trend in a therapeutic direction. Todd met the mastery criterion in 10 sessions. After 2 weeks Todd maintained 13 of the 14 skills (93\%). He did not demonstrate target skill 11 (i.e., affirm agreement). After 4 weeks, he maintained 14 of the skills (100\%). After 6 weeks he maintained 12 of the skills (86\%), but did not demonstrate skills 11 and 14 (i.e., affirm agreement and provide closure). However, after Todd requested his accommodations for the final maintenance check, he recognized that he had forgotten to provide closure. Todd stated, "I always forget to say thanks and make a comment at the end." During maintenance, Todd displayed between 12 and 14 of the target skills during role-plays, for an average of 13 skills (93\%) over the 6-week time period. 


\section{Requesting Accommodations in the General Education Classroom}

Research Question 2: Does instruction using the SACR increase the ability of high school students with disabilities to independently request academic accommodations in the natural academic classroom?

To determine the effect of the SACR on the ability of students to independently request accommodations in the classroom setting, generalization probes (i.e., pregeneralization and postgeneralization) were administered before and after intervention. Students first requested their accommodations from their general education teachers prior to the baseline condition and then again after attaining the mastery criterion in which they demonstrated $100 \%$ of the target behaviors (i.e., 14 out of 14 ) on two consecutive role-play probes in the intervention condition. As a result of the pregeneralization probe, the average number of targeted behaviors observed for all students was 3.8 (range $=2-6)$. In other words, the students as a group demonstrated $27 \%$ of the behaviors. During the postgeneralization probe, students demonstrated an average of $10.8($ range $=8-14)$ targeted behaviors $(77 \%)$. From pregeneralization to postgeneralization, the students as a group demonstrated a mean increase of 7 target behaviors $(50 \%)$. Generalization data for individual students are presented next.

Monique. During the pre-generalization session, Monique demonstrated 4 of the 14 target behaviors (29\%). Within a week of attaining mastery in the intervention condition, Monique did not schedule her postgeneralization meeting with her teacher. Even after several reminders, she still had not scheduled her meeting. Consequently, the researcher arranged a postgeneralization meeting in the teacher's classroom during the same time period in which Monique was meeting with the researcher. This meeting 
eventually occurred 3 weeks after mastery was achieved. Prior to the meeting, the researcher provided a booster session for Monique that included collaborative problem solving to identify the conflict (i.e., reason the meeting had not occurred), determine a solution (i.e., make arrangements for the meeting), and review the 14 target behaviors from the SACR poster. Monique exhibited 8 of the target behaviors (57\%) during her postgeneralization meeting. She did not demonstrate target behaviors 2, 3, 4, 9, 10, and 11 (i.e., introduce self, disclose disability, identify impact of disability, explain student responsibility, ask for agreement, and affirm agreement). In the postgeneralization meeting, Monique remembered to specifically request her accommodations from her teacher and identify resources, two skills she had not previously demonstrated for her teacher. From pregeneralization to postgeneralization, Monique displayed an additional four target skills or an increase of $28 \%$ of the target skills.

La'Shay. During the pregeneralization session, La'Shay demonstrated 2 of the 14 target behaviors (14\%). La'Shay did not meet with her teacher for her postgeneralization meeting within the initial week time frame. The meeting occurred 2 weeks after reaching the mastery criterion. During the postgeneralization probe, she displayed 12 of the target behaviors (86\%). La'Shay did not demonstrate target behaviors 12 and 13 (i.e., restate accommodations and clarify roles of student and teacher). La'Shay did disclose her disability, identify the impact of the disability, explain the benefit of the accommodations, and request the accommodations. These were skills she had not previously demonstrated. From pregeneralization to postgeneralization, she exhibited an additional 10 target skills, or an increase of $72 \%$ of the target skills. 
Sasha. During the pregeneralization session, Sasha demonstrated 6 of the 14 target behaviors (43\%). Sasha's postgeneralization meeting did not occur within one week of attaining mastery. Her teacher was not available before spring vacation, so Sasha had to wait another week until school resumed. During the postgeneralization probe, she displayed 11 of the target behaviors (79\%). Sasha did not demonstrate target behaviors 6, 9, and 13 (i.e., explain benefit of accommodation, explain student responsibility, and clarify role of teacher and student). However, Sasha disclosed her disability and explained the benefit of her disability in the postgeneralization session. These were two important skills she did not include during the pregeneralization teacher meeting. From pregeneralization to postgeneralization, Sasha demonstrated an additional 5 target skills, or an increase of $36 \%$ of the target skills. After Sasha's postgeneralization session, she wanted to discuss her teacher meeting with me. Sasha explained that when she was requesting her accommodations from her teacher, the teacher began to compliment her about the changes she has noticed in Sasha. The teacher stated that Sasha was now taking more responsibility for her work and doing much better in the class. Although Sasha was pleased with the compliments from the teacher, she also said the teacher's comments distracted her. Consequently, Sasha acknowledged she could not remember if she had included everything she had intended to say.

John. During the pregeneralization session, John demonstrated 2 of the 14 target behaviors (14\%). John's postgeneralization meeting did not occur within one week of attaining mastery. His teacher was not available before spring vacation, so John had to wait another week until school resumed. During the postgeneralization probe, he displayed all 14 of the target behaviors (100\%). From pregeneralization to 
postgeneralization, he exhibited an additional 12 target skills, or an increase of $86 \%$ of the target skills.

Todd. During the pregeneralization session, Todd demonstrated 5 of the 14 target behaviors (36\%). Todd's postgeneralization meeting occurred 2 weeks after he met the mastery criterion. Todd was reluctant to schedule his postgeneralization meeting, so I coordinated the date with his teacher. His final meeting had to be rescheduled two times before he and his teacher were finally able to meet. Todd's teacher was detained on the first meeting date, and Todd was not able to wait. On the second scheduled date, Todd forgot about the meeting. When they finally did meet for the postgeneralization meeting, Todd displayed 9 of the target behaviors (64\%). Todd did not demonstrate target behaviors $2,8,9,12$, and 13 (i.e., introduce self, identify resources, explain student responsibility, restate accommodations, clarify role of teacher and student). During his postgeneralization session, Todd did disclose his disability and explain the benefit of the accommodations, which were two critical skills he did not include in the first meeting with his teacher. From pregeneralization to postgeneralization, he exhibited an additional 4 target skills, or an increase of $28 \%$ of the target skills.

\section{Social Validity}

To evaluate the practicality of the goals, procedures, and effects of the study, social validity data were collected from the five students and the five teachers from whom the students requested their accommodations. Students and teachers completed questionnaires to assess how much they agreed or disagreed with statements about the importance of self-advocating for accommodations and the effects of the intervention. Ratings were based on a 4-point Likert scale (i.e., $1=$ strongly disagree to $4=$ strongly 
agree). Descriptive statistics (i.e., mean and range) were used to evaluate the responses and assign numerical values. The student questionnaire included seven statements, and the teacher questionnaire included six statements. Both questionnaires also included an open-ended question that required a written response. The written responses are summarized, and the results are presented.

\section{Student Perceptions}

Research Question 3: Do high school students with high incidence disabilities believe the SACR had a positive effect on their ability to identify their learning needs and the accommodations to address those needs?

Research Question 4: Do high school students with high incidence disabilities believe the SACR had a positive effect on their ability to independently request academic accommodations?

Students responded to five statements that addressed the effects of the intervention. Results indicated that students believed the SACR helped them identify their needs and the accommodations to support their needs (mean 3.6 and range 3 - 4). Students stated they will continue to use the steps of the SACR to request accommodations in future classes (mean 3.6 and range $3-4$ ). They perceived they are now equipped with the skills to continue to request their accommodations (mean 3.6 and range 3 - 4) and acknowledged they would prefer to self-advocate for their accommodations rather than have a teacher advocate for them (mean 3.2 and range 3 - 4). Additionally, students rated two statements about the procedures of the SACR. Results indicated that students enjoyed learning the procedures of the intervention (mean 3.4 and range 3 - 4) and believed all of the steps of the SACR were important (mean 3.2 and 
range $2-4)$. The percentage of responses for each rating category is presented in Table 4. When students were asked what aspects of the program were the most challenging for them, responses included remembering so many steps, seeing myself in a video, and learning how to put all of the steps together. Specifically, four out of five students expressed that remembering 14 behaviors was very challenging.

Table 4

Students' Perceptions of the SACR

\begin{tabular}{lcccc}
\hline & $\begin{array}{c}\text { Strongly } \\
\text { Disagree }\end{array}$ & Disagree & Agree & $\begin{array}{c}\text { Strongly } \\
\text { Agree }\end{array}$ \\
\hline $\begin{array}{l}\text { 1. The self-advocacy intervention helped } \\
\text { me identify my learning needs and the } \\
\text { accommodations to address those needs. }\end{array}$ & $0 \%$ & $0 \%$ & $40 \%$ & $60 \%$ \\
$\begin{array}{l}\text { 2. I will continue to use this intervention } \\
\text { in future classes where accommodations } \\
\text { will be needed. }\end{array}$ & $0 \%$ & $0 \%$ & $40 \%$ & $60 \%$ \\
$\begin{array}{l}\text { 3. As a result of this intervention, I } \\
\text { believe I have the skills to independently } \\
\text { request accommodations from my } \\
\text { teachers. }\end{array}$ & $0 \%$ & $0 \%$ & $40 \%$ & $60 \%$ \\
$\begin{array}{l}\text { 4. I now prefer to request } \\
\text { accommodations from my teachers rather } \\
\text { than have another teacher request them } \\
\text { for me. }\end{array}$ & $0 \%$ & $0 \%$ & $80 \%$ & $20 \%$ \\
$\begin{array}{l}\text { 5. As a result of this training, I now } \\
\text { understand the importance of how } \\
\text { requesting accommodations in high } \\
\text { school will better prepare me for the } \\
\text { challenges I may face in college. }\end{array}$ & & & & \\
$\begin{array}{l}\text { 6. I enjoyed learning the procedures to } \\
\text { effectively advocate for } \\
\text { accommodations. }\end{array}$ & $0 \%$ & $0 \%$ & $20 \%$ & $80 \%$ \\
$\begin{array}{l}\text { 7. I believe all of the steps were } \\
\text { necessary to learn how to effectively } \\
\text { advocate for accommodations. }\end{array}$ & & & & \\
\hline
\end{tabular}




\section{Teacher Perceptions}

Research Question 5: Do general education teachers believe the SACR had a positive effect on the ability of high school students to request academic accommodations?

Teachers' perceptions of the effects of the intervention and the importance of teaching students to self-advocate for their accommodations were assessed. Findings indicated that teachers believed students acquired the skills to request accommodations from them (mean 3.4 and range 3-4) and from other teachers (mean 3.4 and range 3 - 4). Furthermore, teachers strongly agreed that other students (i.e., students with and without disabilities) would benefit from this type of intervention (mean 4), and students should learn these skills while in high school to prepare them for college (mean 4). Their responses also indicated that students, rather than teachers, should request the accommodations (mean 3.8 and range $3-4$ ), and instructional time should be used to teach students these skills (mean 3.8 and range 3 - 4). The percentage of responses for each rating category is presented in Table 5. When teachers were asked why they believed other students (i.e., general education and special education students) would benefit from this type of intervention, one teacher stated that she sees this inability in many of her students, and students should be taught to advocate for themselves. Several other teachers expressed that this type of intervention may enhance students' selfconfidence as well as provide them with a voice and an opportunity to use that voice. Another teacher expressed that teaching students these skills may help them take more responsibility for their work. Further, one teacher explained that students may begin to think more critically about their academic success as a result of this type of self-advocacy 
intervention. Lastly, three teachers reinforced the importance of students practicing these skills to prepare them for postschool success.

Table 6

General Education Teachers' Perceptions of the SACR

\begin{tabular}{|c|c|c|c|c|}
\hline & $\begin{array}{l}\text { Strongly } \\
\text { Disagree }\end{array}$ & Disagree & Agree & $\begin{array}{c}\text { Strongly } \\
\text { Agree }\end{array}$ \\
\hline $\begin{array}{l}\text { 1. As a result of this intervention, I } \\
\text { believe my student acquired the skills } \\
\text { to effectively request } \\
\text { accommodations from me. }\end{array}$ & $0 \%$ & $0 \%$ & $60 \%$ & $40 \%$ \\
\hline $\begin{array}{l}\text { 2. As a result of the intervention, I } \\
\text { believe my student acquired the skills } \\
\text { to request accommodations in other } \\
\text { classes. }\end{array}$ & $0 \%$ & $0 \%$ & $60 \%$ & $40 \%$ \\
\hline $\begin{array}{l}\text { 3. I believe other students would } \\
\text { benefit from this self-advocacy } \\
\text { intervention. }\end{array}$ & $0 \%$ & $0 \%$ & $0 \%$ & $100 \%$ \\
\hline $\begin{array}{l}\text { 4. I believe it is important for high } \\
\text { school students to learn the skills to } \\
\text { advocate for their accommodations } \\
\text { while in high school to prepare them } \\
\text { for the challenges they may face in } \\
\text { college. }\end{array}$ & $0 \%$ & $0 \%$ & $0 \%$ & $100 \%$ \\
\hline $\begin{array}{l}\text { 5. I believe it is more practical to } \\
\text { have students request their } \\
\text { accommodations than have their } \\
\text { teachers request them. }\end{array}$ & $0 \%$ & $0 \%$ & $20 \%$ & $80 \%$ \\
\hline $\begin{array}{l}\text { 6. I believe instructional time should } \\
\text { be used to teach students the skills to } \\
\text { self-advocate. }\end{array}$ & $0 \%$ & $0 \%$ & $20 \%$ & $80 \%$ \\
\hline
\end{tabular}




\section{Chapter Summary}

IOA data and procedural fidelity data were collected between $30 \%$ and $38 \%$ of all sessions for all students across baseline, intervention, and maintenance. Mean IOA data across all sessions for all students was 97\% (range 86\% - 100\%). Mean procedural fidelity across all conditions for all students was 100\%. High reliability results (i.e., above $90 \%$ ) addressed threats to internal validity (i.e., instrumentation and procedural infidelity). As a result of the SACR, five demonstrations of effect were noted. The PND between baseline and intervention conditions was between $87.5 \%$ and $100 \%$ for all students, further supporting that the intervention (i.e., SACR) was responsible for the experimental effect. All students attained the mastery criterion during the intervention condition, with four students reaching the criterion in the fewest number of sessions (i.e., 10 sessions). Students maintained between 10 and 14 of the target behaviors up to 6 weeks after exiting the intervention condition. From pregeneralization to postgeneralization, the students demonstrated an increase of $28 \%$ to $86 \%$ of the target behaviors. Overall, social validity results indicated that teachers believed students acquired the skills to request their accommodations and that all students would benefit from self-advocacy training. Students agreed that the SACR had a positive effect on their ability to identify their learning needs and to request accommodations. Lastly, students indicated that remembering 14 target behaviors was the most challenging aspect of the program. 


\section{CHAPTER V \\ DISCUSSION}

The purpose of this study was to determine if instruction using the SACR resulted in five high school students with high incidence disabilities acquiring and then generalizing the skills to request academic accommodations in a high school general education course. Specifically, this study was a systematic replication of Walker and Test (2011) that focused on the impact of an instructional intervention, the SACR, on the ability of students to request academic accommodations. A multiple probe design across participants was utilized to evaluate the effects of the modified SACR on 14-targeted behaviors. As a result, findings indicated a functional relation between the SACR and the self-advocacy behaviors of the five students. More precisely, instruction using the SACR improved the ability of students to request accommodations in role-plays simulations and in the natural academic classroom. Lastly, students and teachers acknowledged the importance of learning to self-advocate and the benefits of the intervention. Results from this study are consistent with previous research on the efficacy of the SACR (Palmer \& Roessler, 2000; Roessler et al., 1998; Walker \& Test, 2011). This study extends current literature by (a) including high school students with high incidence disabilities as participants, (b) incorporating student self-analyses of the role-plays during intervention, and (c) providing a disability awareness component that incorporated data from the students' most recent IEPs. Only two previous studies have implemented an intervention 
to teach high school students with disabilities to request accommodations (Durlak et al., 1994; Wood et al., 2010); therefore, this study's findings specifically add to the dearth of literature for this group of students.

This chapter begins with a presentation of the major findings of the study and the relevance of those findings to extant research. Limitations and future research are then discussed. Finally, implications for practice are presented.

\section{Major Findings and Relevance to Extant Literature}

\section{Effect of the SACR on Student Outcomes}

Research Question 1: Does instruction using the SACR increase the ability of high school students with high incidence disabilities to independently request academic accommodations in role-play simulations?

Findings indicated a functional relation between the SACR and the ability of students with disabilities to effectively request their accommodations, as evidenced by five demonstrations of effect. All of the students acquired the target skills and attained the mastery criterion (i.e., demonstration of $100 \%$ of target skills in two consecutive sessions) in the intervention condition, and four of the students reached the criterion in the minimum number of sessions possible (i.e., 10). The fifth student, Sasha, met the mastery criterion in 13 sessions. A booster session as well as additional role-plays were provided for Sasha. The booster session consisted of an error analysis to determine the target behaviors that were challenging for Sasha, and then additional time to practice those skills. During the baseline condition, students demonstrated between $0 \%$ and 29\% of the target skills. From the introduction of the SACR through the mastery lessons, a 
continual ascent of target behaviors was observed. Overall, students demonstrated between $21 \%$ to $100 \%$ of the skills in the intervention condition.

Although this was the first study to implement the SACR with high school students with disabilities, these results are consistent with previous research in which the SACR was used to teach college students with disabilities to request their accommodations (Palmer \& Roessler, 2000; Roessler et al., 1998; Walker \& Test, 2011). Using single subject design methodology, Roessler et al. (1998) and Walker and Test (2011) identified a functional relationship between the SACR and the ability of students to request their accommodations. These studies, along with the current study, implemented the seven lessons of the self-advocacy component of the SACR and the accompanying skills. However, the number of specific target skills that were calculated for evaluation purposes varied from study to study. For example, Roessler et al. assessed 17 skills; Walker and Test included 11 skills, and the current study evaluated students on 14 target behaviors. Palmer and Roessler (2000) utilized a group experimental design with control and treatment groups to evaluate the effectiveness of the SACR.

Researchers in this study (i.e., Palmer \& Roessler, 2000) also taught students the conflict resolution module of the SACR that was not included in Roessler et al., Walker and Test, and the current study. Yet, when comparing only the results from the self-advocacy component, findings from Palmer and Roessler indicated that the treatment group demonstrated significantly more of the self-advocacy target behaviors (i.e., mean 8.83) than the control group (i.e., mean 3.87) as a result of instruction with the SACR. Thus, the treatment group was recognized as being better prepared to effectively request their accommodation needs. 
In addition to acquiring skills to effectively request accommodations, students in the current study maintained between $71 \%-100 \%$ of the skills from 2 weeks to 6 weeks after exiting the intervention condition. In comparison, students in Walker and Test (2011) maintained between $73 \%$ and $91 \%$ of the skills up to 2 weeks. The results from the present study support and extend findings from Walker and Test in that students maintained most of the target skills after exiting the intervention condition. More precisely, all students in the current study as well as in Walker and Test, continued to disclose their disabilities, explain the impact of their disabilities on learning, identify accommodations, explain the benefit of the accommodations, and request the accommodations. This is not to say that the other behaviors were not as important, but knowledge of self is considered a foundational component of self-advocacy (Test, Fowler, Wood, et al., 2005). Additionally, these results indicate that students were able to independently express their needs and identify the supports to address those needs. During maintenance sessions, students primarily forgot to ask for agreement, affirm agreement, restate the accommodations, and clarify the student and teacher roles. Neither the current study nor Walker and Test collected long term maintenance data (e.g., 3 months, 6 months, or 12 months); therefore, one can conclude that students are able to maintain target skills for a relatively short period of time (e.g. up to 6 weeks), but additional research is warranted to determine long term maintenance effects.

Research Question 2: Does instruction using the SACR increase the ability of high school students with disabilities to independently request academic accommodations in the natural academic classroom? 
This was the second study using the SACR wherein students generalized the target skills to the natural academic setting with their actual teachers. Walker and Test (2011) initially had students request their accommodations from their college instructors; the current study used a pregeneralization probe in addition to a postgeneralization probe. Nonetheless, results from both studies are consistent in that students were able to generalize the target behaviors to the natural academic setting. Students in the current study displayed between $8(57 \%)$ and $14(100 \%)$ of the target behaviors, and students in Walker and Test demonstrated between 7 (64\%) and $11(100 \%)$ of the target skills. Students in Walker and Test had also disclosed their disabilities with Disability Services at their college; therefore, one can conclude that these students had an awareness of the importance of self-disclosing and previous experience discussing their disabilities. On the contrary, self-disclosing and advocating for supports were new skills for students in the current study. Although students in the present study did not generalize all of the target skills, four of the students disclosed their disabilities, identified the impact of the disabilities on learning, requested their accommodations, and developed a plan to get those accommodations. The fifth student identified her accommodations, requested her accommodations, and explained the plan to get the accommodations, but the teacher did not observe her disclosing her disability and identifying the impact of the disability on her learning.

The generalization results of the current study are favorable and consistent with previous research; however, some inconsistencies between the pregeneralization scores and the baseline scores in the present study should be discussed. While both pregeneralization and baseline data were gathered before the introduction of the 
intervention, one would expect these scores for individual students to be similar (i.e. within a point or two). Yet, for several of the students they were not. For example, Monique's teacher indicated that Monique demonstrated 4 behaviors (i.e., greet teacher, identify accommodation, explain the benefit of the accommodation, and provide closure) during the pregeneralization probe, but on the three baseline probes, I did not observe Monique demonstrating these skills. There could be several explanations for the inconsistencies in scores for two of the students (i.e., Monique and Sasha). First of all, the teachers recorded the observed behaviors during the pregeneralization probes, and they may have interpreted the behaviors differently. On the other hand, students may have responded differently because they were in another setting, and teachers may have asked some probing questions. For example, Monique may have instinctively greeted and thanked her teacher while in the teacher's classroom; however, when she role-played for me, she was already in the room and may not have recognized this as a skill that should be part of the advocacy process. Monique may have also remembered from her initial meeting with me that she needed to identify an accommodation when she met with her general education teacher, and the teacher may have possibly asked her why she needed the accommodation. None of the generalization probes were video recorded; therefore, there is no way to determine why the inconsistencies occurred. To reduce inconsistencies in future studies, the researcher may need to spend additional time clarifying and reviewing the target behaviors with the teachers. Nevertheless, students were generalizing these important target skills to authentic settings as a result of the intervention. Furthermore, if students continue to request accommodations from teachers, teachers may become more familiar with the targeted behaviors that will enable 
them to better understand students' needs and the supports to address their needs.

Consequently, both teachers and students may benefit from the student self-advocacy process. Acquiring additional teacher input may also help refine the behaviors that teachers believe are an integral part of the accommodation request process.

\section{Factors Enhancing the Accommodation Request Process}

Providing explicit instruction. Findings from the current study, as well as previous studies that utilized an intervention to teach students to advocate for accommodations (i.e., Durlak et al., 1994; Palmer \& Roessler, 2000; Roessler et al., 1998; Walker \& Test, 2011; White et al., 2014; White \& Vo, 2006; Wood et al., 2010), support the implementation of direct or explicit instructional practices to enhance the ability of students to request accommodations. Explicit practices incorporated into the current study, as well as all previous studies with the SACR, included modeling, repeated skills practice, feedback, and role-plays. As a result of a combination of these practices, participants in all of the studies acquired the skills or knowledge to request accommodations. Explicit instructional practices have also been identified as effective strategies for teaching students to acquire other self-advocacy behaviors (e.g., leading IEP and transition meetings and advocating through writing) (Merchant and Gajar, 1997; Roberts et al., 2014; Test, Fowler, Brewer, et al., 2005). Although research substantiates the effectiveness of explicit instructional practices, when implementing self-advocacy interventions (e.g., the SACR) that consist of multiple strategies (e.g., repeated practice, role-playing, modeling, videos), it is difficult to discern which strategies have the greatest impact on the outcomes; therefore, the need remains for research with component analyses of intervention components (Test, Fowler, Brewer, et al., 2005). 
Promoting effective communication skills. The acquisition of effective communication skills is essential to the self-advocacy process (Test, Fowler, Wood, et al., 2005). To assist students in acquiring the communication skills to advocate for accommodations, each lesson of the intervention provided students with an opportunity to observe the researcher demonstrating the skills before they practiced the skills. Students then participated in repeated practices until they indicated to the researcher that they felt confident in their skill demonstrations. As students practiced the skills, the researcher also provided feedback (i.e., corrective and/or positive) that may have enhanced the acquisition of the targeted skills. Having repeated opportunities to practice the target skills may have also afforded students an opportunity to make the conversations more natural or make them their own. In particular, several of the students reflected on new skills that were being presented and determined how they would incorporate those skills into their role-plays using their words and their voice, rather than simply memorizing the steps. For example, after a lesson was presented, Todd changed his wording several times until he determined exactly how he wanted to convey the information. Further, after some of the students read their self-evaluations of their role-plays, they not only made comments about their advocacy skills, they identified changes in their overall communication skills. For example, John noticed that he was beginning to slow the rate of his speech so that it is easier for others to understand him. Unapparent to me, this was a goal that John had been working on for personal growth. John was quite proud of this accomplishment, as he voiced it several times. These repeated practice opportunities along with other explicit instructional practices may have enhanced the students' 
communication skills and enabled them to effectively articulate their needs and request their accommodations.

\section{Intervention Modifications}

Disability awareness lesson. In addition to implementing the SACR with a different population (i.e., high school students with disabilities), the present study also extended the literature by including a disability awareness lesson. When utilizing the SACR with high school students, Walker and Test (2011) suggested referencing and discussing components of students' IEPs to help them better understand their needs and the identified accommodations to address those needs. This recommendation led to the development of a disability awareness lesson, which in turn provided students with the background knowledge to identify their disabilities, needs, and accommodations, and explain their needs in functional terms. When the researcher met with the students before the study began to inform them about the pregeneralization meetings, only one student acknowledged he was aware of the term accommodation and the purpose of an accommodation. Moreover, this was the only student who was able to initially explain his disability in functional terms. Explaining a disability in functional terms meant the student was able to discuss how his disability impacted his ability to learn and succeed in the class. Contrary to what educators, parents, and other practitioners sometimes assume, high school students are often unaware of their needs and the supports to address their needs, even though they have an IEP and have attended the meetings to develop their IEPs. Therefore, the disability awareness lesson, which resulted in the completion of a student-generated disability awareness graphic organizer, assisted students in acquiring the foundational skills needed to demonstrate specific target behaviors while requesting 
accommodations. More precisely, students were able to identify their specific disability area, their academic and functional needs, and the accommodations to address those needs, while gaining an understanding of the significance of those skills in high school and postsecondary settings. Research supports the importance of self-advocating in postsecondary settings and the acquisition of those skills prior to entering college (Finn, Getzel, \& McManus, 2008; Garrison-Wade, 2012; Getzel \& Thoma, 2008; Gil, 2007; Hadley, 2006; Morningstar et al., 2010; Shaw, Madaus, \& Banerjee, 2009; Skinner, 2004). Equipping students with these skills while in high school may facilitate the college self-advocacy process. During one of the intervention sessions Sasha asked, "How will students know what to do in college if they do not learn it in high school?" This question alone reinforces the importance of learning to self-advocate in high school.

Student role-play self-analyses. Walker and Test (2011) also recommended incorporating self-evaluations of student role-plays into the intervention lessons. No prior studies with the SACR had incorporated this component in a study. In Durlak et al. (1994), student training sessions were videotaped to promote group discussion and feedback; however, participants did not view the videos for individual self-analyses and personal growth. Therefore, this was the first study where students self-evaluated their role-play assessments. Including opportunities for self-evaluation promoted student-led discussions instead of researcher-led discussions after the role-plays. After viewing the role-play, students wrote their self-reflection. The students then read their reflections to the researcher. The researcher only intervened (e.g., used probing questions) if students did not identify errors in their role-plays or if the researcher needed the students to clarify their responses. Even though some of the reflections were very brief (e.g., a few 
sentences), it became apparent that students understood the purpose of the reflection process. For most students, self-analyzing a role-play and writing a reflection on this analysis was a new skill; therefore, students were able to reference the reflection poster if they needed talking points or ideas for their reflections. This poster was developed with the intent of encouraging participation by providing a support. Had this poster not been available to them, some of the students with writing or processing deficits may have been somewhat reluctant to participate in this activity. The value of this support became apparent when students consistently addressed questions and open-ended statements from the reflection poster in their reflections. Scaffolding supports, such as this poster, may be necessary to increase student risk-taking behaviors by encouraging them to perform skills they are not accustomed to completing.

\section{Serendipitous Findings}

Lastly, serendipitous findings (i.e., positive outcomes from the study that were not expected) are worth discussing. To begin with, when I was modeling target behaviors and requesting accommodations for Janet, a fictitious student, Sasha listened to me explain how having a copy of notes in class would benefit Janet. Soon after, Sasha stated that she believed she would benefit from having a note-taking accommodation in her Spanish class. This was not an accommodation in Sasha's IEP, nor was it one that Sasha had previously identified. Sasha explained how understanding new concepts in Spanish is challenging for her, and by having a copy of the notes, she would be able to focus on the information being presented instead of trying to write and process at the same time. Sasha then proceeded to incorporate this accommodation into future role-play requests. Sasha also stated that her social studies teacher approached her about the struggles she 
was having in his class, so she explained her learning challenges and her accommodations to him. As a result, the teacher suggested a testing strategy he would be willing to try with her. Chances are this conversation may not have had the same outcome had Sasha not participated in this study. Similarly, a conversation with Todd's general education teacher resulted in another unanticipated, yet positive finding. This teacher recognized that other students besides Todd were experiencing spelling difficulties that sometimes limited their responses on quizzes. To address Todd's needs, as well as the needs of other students in her class, this teacher chose to modify the format of her math quizzes by including a matching section for vocabulary instead of having students write the vocabulary words or the definitions of the words. The teacher also proudly stated that as a result of this modification, Todd scored a $97 \%$ on his last quiz. Consequently, other students with and without disabilities may benefit from teachers becoming more aware of the needs of their students and the supports to address those needs.

\section{Student Perceptions of the Intervention}

Research Question 3: Do high school students with high incidence disabilities believe the SACR had a positive effect on their ability to identify their learning needs and the accommodations to address those needs?

Research Question 4: Do high school students with high incidence disabilities believe the SACR had a positive effect on their ability to independently request academic accommodations?

To evaluate the practicality of the procedures and effects of the study, social validity data were garnered from students. Findings indicated students overwhelmingly 
agreed that they learned to identify their needs and accommodations and the benefits of self-advocating for those accommodations. These findings are consistent with social validity results from Walker and Test (2011) about the efficacy of the intervention. When students were asked if they would rather advocate for themselves or have a teacher advocate for them, responses indicated they were not as confident about accepting this role. Though all of the students either agreed or strongly agreed with the statement when they completed the questionnaire, there seemed to be some uncertainty and reluctance on the part of a few of the students. As John proclaimed, "It is just so easy to have teachers do it!" Further evidence supporting this reluctance was the lack of initiative Monique and Todd took in scheduling their final meetings with their teachers. For these two students, the researcher intervened and helped them schedule the meetings. Also, four out of five of the students in the study were underclassman (i.e., freshmen or sophomores), so it is only natural that they may have had some reservations about this process. Nevertheless, all of the students did independently advocate for their accommodations with their teachers, and they overwhelmingly acknowledged the importance of acquiring these skills in high school to prepare them for college. Another strong indicator that learning to self-advocate was important to these students was their willingness to voluntarily participate in this study. Students had an option to withdraw from the study at any time for any reason; yet, they all remained and actively participated in each session. In this case, their actions spoke for them. Students also agreed they enjoyed learning the advocacy process and will continue to use these skills when future accommodations are warranted in their classes. La'Shay even put a star next to the statement that asked her if she enjoyed learning the self-advocacy process. Since 
La'Shay was a very reserved young lady who provided limited communication exchanges during the study, this star may have indicated true customer satisfaction. Finally, most students stated the most challenging aspect of the program was the number of steps they had to remember. Although several of the students may have believed that all of the steps were not necessary to effectively advocate, Todd was the only student who indicated his disagreement on the student questionnaire.

\section{Teacher Perceptions of the Intervention}

Research Question 5: Do general education teachers believe the SACR had a positive effect on the ability of high school students to request academic accommodations?

Teachers' perceptions of the effects of the intervention and the importance of teaching students to self-advocate for their accommodations were assessed. To begin with, teachers agreed or strongly agreed that their students acquired the skills to effectively request accommodations from them or potentially from other teachers. These results support the effectiveness of the intervention. The teachers' willingness to participate in the study indicated the importance teachers assigned to students acquiring the skills to request their accommodations. This is notable because expectations for teachers continue to increase; yet, these teachers were willing to give up some of the limited time they have to help students practice these skills. The teachers also strongly agreed that instructional time should be used to teach all students, not just students with disabilities, the skills to self-advocate. Since teachers in this study represented various content areas (e.g., English, math, reading, and Spanish), one can conclude that teachers across the curriculum not only see the benefit of teaching all students to self-advocate, but recognize this as an area of need in many of their students. As the English teacher 
stated, "Students need these skills. I see this inability in the majority of my students." When teachers were asked why they believed other students would benefit from this type of intervention, they provided numerous reasons. First of all, one teacher said that learning to self-advocate gives students a voice and opportunities to stand up for themselves. More specifically, this teacher stated, "Learning how to advocate for yourself is key!" Another teacher explained how she definitely prefers to have students advocate for themselves. Finally, a different teacher explained how this type of intervention teaches students to think more critically about achieving academic success. This unanimous support validates the social significance that teachers assigned to students acquiring this life skill before they matriculate to college.

\section{Limitations and Future Research}

All research has limitations, and it is important to acknowledge these limitations when discussing the findings of a study. By objectively identifying the limitations of research, future studies may take shape (Gast, 2010). One limitation in this study was the research design (i.e., single-subject design). Single-subject research designs, and in the case of this study, a multiple probe across participants design, limit the generality of the findings. This study included only five high students with high incidence disabilities, all of which were African American students who either had a learning disability or ADHD. As a result, the findings do not generalize beyond similar individuals. To promote external validity (i.e., generality of findings) and extend research on the SACR, researchers could replicate the current study with more diverse groups of students with high incidence disabilities to determine the effects of the intervention when presented in a small group setting. Future researchers could also systematically replicate this study by 
changing investigators, participants, settings, or other variables to determine if outcomes are consistent with previous findings. For example, the current study was a systematic replication of Walker and Test (2011) that utilized different participants, a different investigator, a different setting, and additional modifications of the SACR. Results from this study are consistent with Walker and Test, thereby promoting the generality of the findings. The more variables that are changed from one study to the next, while still achieving consistent findings, the greater the generality of the findings (Gast, 2010). Replication and consistency of results promote confidence in the findings.

Having students request their accommodations in only one general education class with one general education teacher was another limitation. Results of the postgeneralization assessments were promising in that students displayed the majority of the target behaviors with their teachers, and the teachers agreed that students effectively requested their accommodations. However, having students continue to request their accommodations from multiple teachers throughout the school year would further support the experimental effect of the SACR on the ability of students to request accommodations. Future research should include additional modifications of the SACR (e.g., problem solving sessions or booster sessions) to support students as they request accommodations from several teachers in several different classes. The needs of students may change from class to class; therefore, the accommodation plan may need to be adjusted. Maintenance data should also be collected for extended time periods (e.g., 3 months, 6 months, or 9 months) to confirm that students are able to independently maintain the skills. The longest period in which maintenance data had been collected in a study implementing the SACR was during the current study and that was only for a 
period of up to 6 weeks. By initiating a study in the beginning of a school year, researchers would be able to collect continuous maintenance and generalization data. Moreover, future research could evaluate the long-term outcomes (e.g., improved grades, improved self-advocacy or self-determination skills, better testing results, graduation, resource room utilization, or enrollment in college) of students' self-advocacy.

In future studies, additional training should be provided for teachers who will be evaluating their students' self-advocacy skills in the natural setting. In this study I met with all of the teachers to explain the target behavior checklist and answer any questions they may have had before they evaluated their students; however, I believe they would have benefitted from additional training. Scoring the target behaviors may have been easier for the teachers had I shown them some of the sample role-plays that I used to train the data collector. It had to be very challenging for some of the teachers to meet with the student and then go back and evaluate them while trying to remember the skills they demonstrated. When I would assess the role-plays for data collection purposes, I often would have to view the video several times to determine which target behaviors were displayed. The teachers did not have this option; their meetings were not video recorded in order to maintain a more authentic classroom setting. To accommodate the teachers and the students in future studies, researchers may reevaluate the target skills for the SACR to determine if any of the target skills can be eliminated. Reiterating what was previously stated, students in this study overwhelmingly agreed that remembering 14 target behaviors was definitely the most challenging aspect of the study.

Another limitation of this study was the researcher as the interventionist. Students were taken from their study skills class to work with the researcher, so students were not 
learning the skills in a natural school setting. Future research should include classroom teachers as interventionists. By incorporating typical intervention agents (i.e., general and special education teachers, social workers, or speech pathologists), social validity would be enhanced. Future research could include special educators implementing the intervention in a study skills or resource classroom, or social workers or speech pathologists incorporating the SACR when they work in groups. A study in which general education teachers incorporate a self-advocacy unit into a Health class or a Speech class could also extend the self-advocacy research base. Teachers in the current study strongly agreed that all students need to learn to advocate for themselves and would benefit from this type of intervention. Including teachers as interventionists in future studies may potentially narrow the research to practice gap.

Lastly, it is not known whether students learned to self-advocate by rehearsing and memorizing a number of steps, or if they were able to internalize the skills. As the researcher, I did not ask students any questions during the role-plays that would have required them to respond, thereby interrupting the advocacy process. For example, if I had asked students to provide more details about how the accommodation would benefit them, this interruption may have affected the advocacy process. Hence, it is not known if students would have been able to continue to display the target behaviors as effectively had the researcher interrupted their thought process by asking questions or interjecting. Future research should include challenges whereas the interventionist interrupts the student with probing questions, so the student has to provide clarifying information about his needs, the accommodations, or the plan to receive the accommodations. These interruptions or questions would require the student to respond and then determine what 
information still needs to be presented to effectively request their accommodations. Although this may challenge students, this type of questioning may better prepare them for more naturally occurring situations.

\section{Implications for Practice}

Results of this study indicate that instruction using a modified version of the SACR is an effective strategy to teach high school students to request their accommodations. By modifying the intervention and including a disability awareness lesson, students gained a basic understanding of the impact their disabilities had on learning and the importance of accessing supports to address their needs. However, opportunities for students to acquire self-advocacy skills may be limited (Roberts et al., 2014; Test, Fowler, Wood et al., 2005), and self-advocacy instructional strategies may not be an instructional priority for teachers, (Carter et al., 2008). As a result, we may not be equipping students with the tools to prepare them to advocate in postsecondary settings. The focus of the current study was to prepare students with the skills to request accommodations in high school and college; however, students with disabilities may also need to seek supports in other postsecondary settings (e.g., postsecondary employment and independent living). Therefore, self-advocacy interventions such as the SACR could be modified to prepare students to advocate for supports in any postschool setting.

When working with students who have more significant processing, cognitive, memory, or language deficits, the number of target behaviors required in the selfadvocacy process could be reduced or simplified to address the challenge of remembering 14 target skills. Practitioners could incorporate a target behavior checklist into the design of the intervention for students to use when advocating for their accommodations in role- 
plays or the natural academic setting. This checklist would include specific skills or steps of the accommodation process. Depending on the age or ability level of the students, the checklist may include words, pictures, or both words and pictures. Practitioners would also have the option of having a paper checklist or an electronic version. The needs or abilities of the students would dictate the level of support provided. In a pilot study that evaluated the effects of a self-advocacy training program, even college students with disabilities had the option of referencing a Seven- Step Checklist to assist them when requesting ADA accommodations during role-plays (White et al., 2014). This SevenStep Checklist included the behaviors of the accommodations negotiations process. A target skills checklist is an example of a scaffolding support that would enable more students to successfully advocate for accommodations.

Furthermore, self-advocacy is a life-long process, and students would benefit from ongoing practice and opportunities to develop their self-advocacy skills beginning as early as elementary school. As more and more students with disabilities are included in general education settings, equipping them with the skills to self-advocate for their accommodations may facilitate the learning process (Hart \& Brehm, 2013). Practitioners can determine which skills of the accommodation process (i.e., steps of the SACR) would be most appropriate for different ages or grade levels of students and then continue to enhance these skills while incorporating additional target behaviors over time. For example, introducing students to the concepts of strengths and needs (i.e., selfknowledge) early in their educational careers may prepare them to later communicate this information. Once students can effectively convey their strengths and needs to others, practitioners could then introduce the concept of accommodations and teach students to 
identify the supports that will benefit them. The earlier students understand the benefits of being their own advocate and the importance of attaining the skills to effectively advocate, the better prepared they will be for the future.

Lastly, social validity results from teachers strongly support the integration of self-advocacy instruction into the education of students with and without disabilities. Teachers agreed that instructional time should be used to prepare students to selfadvocate; however, it may be unrealistic to believe that all teachers would have time to incorporate a structured, behavioral intervention (e.g., SACR) into their lesson plans. An intervention such as the SACR could be modified to address the needs of all students who would benefit from self-advocacy instruction; yet, it may be more feasible to teach practitioners how to incorporate self-advocacy strategies into the general education curriculum. For example, in the beginning of a school year any teacher could incorporate a self-awareness component into their lesson plans. In this lesson, students would complete a learner profile to identify their strengths, needs, and preferences, in addition to supports that had previously benefitted them. The teacher could then discuss these profiles with the class and explain how the information they provide may benefit her as well as other students in the class. If teachers are aware of students' needs earlier in the school year, they may incorporate supports in their classes before students begin to struggle. Further, when students have opportunities to listen to challenges that other students have faced and accommodations that are benefitting these students, they may be more comfortable seeking supports for themselves. 


\section{Conclusion}

It is critical for high school students with disabilities to learn to advocate for accommodations before they enter postsecondary settings. If these students will be required to disclose their disabilities to receive accommodations, they must be equipped with skills to do so. When requesting accommodations, students must have an awareness of their strengths and needs in order to recognize and seek effective supports.

Findings from this study indicated the SACR is an effective intervention to teach students with disabilities how to effectively request accommodations. As a result of the intervention, high school students were able to acquire, maintain, and generalize target behaviors. These results not only support findings from previous research using the SACR (Palmer \& Roessler, 2000; Roessler et al., 1998; Walker \& Test, 2011), but extend the literature by demonstrating the effectiveness of the SACR with high school students.

As high school students continue to advocate for accommodations, the need for parents and teachers to advocate for them will decline. In turn, teachers will become more knowledgeable of supports that will not only benefit these students but other students as well. Consequently, teachers may be more inclined to provide supports that may benefit students with and without disabilities. 


\section{REFERENCES}

Americans With Disabilities Act of 1990, Pub. L. No. 101-336, § 1, 104 Stat. 328 (1990). Retrieved from http://www.ada.gov/pubs/adastatute08.pdf

Abernathy, T. V., \& Taylor, S. S. (2009). Teacher perceptions of students' understanding of their own disability. Teacher Education \& Special Education, 32, 121-136. doi: $10.1177 / 0888406409334084$

Agran, M., Snow, K., \& Swaner, J. (1999). Teacher perceptions of self-determination: Benefits, characteristics, strategies. Education and Training in Mental Retardation and Developmental Disabilities, 34, 293-301.

Angell, M. E., Stoner, J. B., \& Fulk, B. M. (2010). Advice from adults with physical disabilities on fostering self-determination during the school years. TEACHING Exceptional Children, 42(3), 64-75.

Ankeny, E., \& Lehmann, J. P. (2011). Journey toward self-determination: Voices of students with disabilities who participated in a secondary transition program on a community college campus. Remedial and Special Education, 32, 279-289. doi: $10.1177 / 0741932510362215$

Arndt, S. A., Konrad, M., \& Test, D. W. (2006). Effects of the self-directed IEP on student participation in planning meetings. Remedial and Special Education, 27, 194-207. doi: 10.1177/0741932510362215 
Aune, E. (1991). A transition model for post-secondary-bound students with learning disabilities. Learning Disabilities and Research, 6, 177-187.

Bangser, M., \& National High School, C. (2008). Preparing high school students for successful transitions to postsecondary education and employment. Issue brief. National High School Center. Retrieved from ERIC database. (ED502596)

Barretti, M. R. (1993). Increasing the success of learning disabled high school students in their transition to the community college through the use of support services. Retrieved from ERIC database. (ED365075)

Bersani, H. (1996). Leadership in developmental disabilities: Where we've been, where we are, and where we are going. In G. Dybwad \& H. Bersani (Eds.), New voices: Self-Advocacy by people with disabilities (pp. 258-269). Cambridge, MA: Brookline Books.

Brinkerhoff, L. C. (1993). Self-advocacy: A critical skill for college students with learning disabilities. Family Community Health, 16(3), 23-33.

Campbell-Whatley, G. D. (2008). Teaching students about their disabilities: Increasing self-determination skills and self-concept. International Journal of Special Education, 23, 137-144.

Carter, E. W., Lane, K. L., Pierson, M. R., \& Stang, K. K. (2008). Promoting selfdetermination for transition-age youth: Views of high school general and special educators. Exceptional Children, 75, 55-70.

Carter, E. W., Swedeen, B., Walter, M. J., Moss, C. K., \& Hsin, C. (2011). Perspectives of young adults with disabilities on leadership. Career Development For Exceptional Individuals, 34, 57-67. doi: 10.1177/0885728810387411 
Cease-Cook, J., Test, D. W., \& Scroggins, L. S. (2013). Effects of the CD-rom version of the self-advocacy strategy on quality of contributions in IEP meetings of high school students with intellectual disability. Education \& Training in Autism \& Developmental Disabilities, 48, 258-268.

Chambers, C. R., Wehmeyer, M. L., Saito, Y., Lida, K. M., Lee, Y., \& Singh, V. (2007). Self-determination: What do we know? Where to we go? Exceptionality, 15, 3-15. doi: 10.1207/s1532703ex1501_2

Cho, H., Wehmeyer, M., \& Kingston, N. (2011). Elementary teachers' knowledge and use of interventions and barriers to promoting student self-determination. Journal Of Special Education, 45, 149-156. doi: 10/1177/0022466910362588

Cuenca-Carlino, Y., \& Mustian, A. L. (2013). Self-regulated strategy development: Connecting persuasive writing to self-advocacy for students with emotional and behavioral disorders. Behavioral Disorders, 39, 3-15.

Dalke, C. (1993). Making a successful transition from high school to college: A model program. In S. Vogel \& P. B. Adelman (Eds.), Success for college students with learning disabilities (pp. 56-79). New York, NY: Springer-Verlag. doi: 10.1007/978-1-4684-6416-0_4

Davison, H. K., O'Leary, B. J., Schlosberg, J. A., \& Bing, M. N. (2009). Don't ask and you shall not receive: Why future American workers with disabilities are reluctant to demand legally required accommodations. Journal Of Workplace Rights, 14, 4973. doi: 10.2190/WR.14.1.d

Denny, S. C., \& Daviso, A. W. (2012). Self-determination: A critical component of education. American Secondary Education, 40, 43-51. 
Durlak, C. M., Rose, E., \& Bursuck, W. D. (1994). Preparing high school students with learning disabilities for the transition to postsecondary education: Teaching the skills of self-determination. Journal of Learning Disabilities, 27, 51-59.

doi: $10.1177 / 002221949402700108$

Dybwad, G. (1996). Setting the stage historically. In G. Dybwad \& H. Bersani (Eds.), New voices: Self-Advocacy by people with disabilities (pp. 1-17). Cambridge, MA: Brookline Books.

Edyburn, D. L. (2006). Assistive technology and mild disabilities. Special Education Technology Practice, 8(4), 18-28.

Fiedler, C. R., \& Danneker, J. E. (2007). Self-advocacy instruction: Bridging the research-to-practice gap. Focus on Exceptional Children, 39(8), 1-20.

Field, S. (1996). Self-determination instructional strategies for youth with learning disabilities. Journal of Learning Disabilities, 27, 40-52.

doi: $10.1177 / 002221949602900107$

Field, S., Martin, J., Miller, R., Ward, M., \& Wehmeyer, M. (1998). Self-determination for persons with disabilities: A position statement of me division on career development and transition. Career Development for Exceptional Individuals, 21, 113-128. doi: 10.1177/088572889802100202

Finn, D., Getzel, E. E., \& McManus, S. (2008). Adapting the self-determined learning model of instruction for college students with disabilities. Career Development for Exceptional Individuals, 31(2), 85-93. doi: 10.1177/0885728808318327 
Garrison-Wade, D. (2012). Listening to their voices: Factors that inhibit or enhance postsecondary outcomes for students' with disabilities. International Journal of Special Education, 27(2), 113-125.

Gast, D, L. (2010). Single subject research methodology in behavioral science. New York: Routledge Publishers.

Getzel, E. E., \& Thoma, C. A. (2008). Experiences of college students with disabilities and the importance of self-determination in higher education settings. Career Development for Exceptional Individuals, 31, 77-84.

doi: $10.1177 / 0885728808317658$

Gil, L. A. (2007). Bridging the transition gap from high school to college: Preparing students with disabilities for a successful postsecondary experience. TEACHING Exceptional Children, 40(2), 12-15.

Grenwelge, C., \& Zhang, D. (2013). The effects of the Texas youth leadership forum summer training on the self-advocacy abilities of high school students with disabilities. Journal of Disability Policy Studies, 24, 158-169. doi: $10.1177 / 1044207312457415$

Grenwelge, C., Zhang, D., \& Landmark, L. (2010). Comprehensive leadership training for youth with disabilities. TEACHING Exceptional Children, 42(4), 62-68.

Hadley, W. M. (2006). L.D. students' access to higher education: Self-advocacy and support. Journal of Developmental Education, 30(2), 10-16.

Halpern, A. S., Herr, C. M., Wolf, N. K., Doren, B., Johnson, M. D., \& Lawson, J. D. (1997). Next S.T.E.P.: Student transition and educational planning. Austin, TX: PRO-ED. 
Hart, J. E., \& Brehm, J. (2013). Promoting self-determination. TEACHING Exceptional Children, 45(5), 40-48.

Hatch, T., Shelton, T. T., \& Monk, G. (2009). Making the invisible visible: School counselors empowering students with disabilities through self-advocacy training. Journal of School Counseling, 7(14), 2-19.

Hoffman, A., \& Field, S. (1995). Promoting self-determination through effective curriculum development. Intervention in School and Clinic, 30, 134-141. doi:10.1177/105345129503000302

Individuals with Disabilities Education Act of 1990, PL 101-476, 20 U.S.C. 1400 § et seq.

Individuals with Disabilities Education Act Amendments of 1997, PL 105-17, 20 U.S.C. $\S 1400$ et seq.

Individuals with Disabilities Education Improvement Act of 2004. PL108-446, 20 U.S.C. $\S 1400$ et seq.

Karvonen, M., Test, D. W., Wood, W. M., Browder, D., \& Algozzine, B. (2004). Putting self-determination into practice. Exceptional Children, 71, 23-41. doi: $10.1177 / 001440290407100102$

Kline, K. M., \& Kurz, C. A. (2014). Collaboration between rehabilitation counselors and secondary educational institutions to optimize successful outcomes for high school students with disabilities. Journal of Applied Rehabilitation, 45, 18-24.

Konrad, M., Fowler, C. H., Walker, A. R., Test, D. W., \& Wood, W. M. (2007). Effects of self-determination interventions on the academic skills of students with learning disabilities. Learning Disability Quarterly, 30, 89-113. doi: 10.2307/30035545 
Kotzer, E., \& Margalit, M. (2007). Perception of competence: Risk and protective predictors following an e-self-advocacy intervention for adolescents with learning disabilities. European Journal of Special Needs Education, 22, 443-457. doi: $10.1080 / 08856250701650060$

Lachapelle, Y., Wehmeyer, M., Haelewyck, M., Courbois, Y., Keith, K., Schalock, R., et al. (2005). The relationship between quality of life and self-determination: An international study. Journal of Intellectual Disability Research, 49, 740-744. doi: 10.1111/j.1365-2788.2005.00743.x

Lancaster, P., Schumaker, J., \& Deshler, D. (2002). The development and validation of an interactive hypermedia program for teaching a self-advocacy strategy to students with disabilities. Learning Disability Quarterly, 25, 277-302. doi: $10.2307 / 1511358$

Landmark, L. J., Ju, S., \& Zhang, D. (2010). Substantiated best practices in transition: Fifteen plus years later. Career Development for Exceptional Individuals, 33, 165176. doi: $10.1177 / 0885728810376410$

Madaus, J. W., Gerber, P. J., \& Price, L. A. (2008). Adults with learning disabilities in the workforce: Lessons for secondary transition programs. Learning Disabilities Research \& Practice (Wiley-Blackwell), 23, 148-153. doi: $10.1111 / \mathrm{j} .1540-5826.2008 .00272 . x$

Martin, J. E., Marshall, L. H., Maxson, L., \& Jerman, P. (1996). Self-directed IEP. Longmont, CO: Sopris West. 
Martin, J. E., Van Dycke, J. L., Christensen, W., Greene, B. A., Gardner, J., \& Lovett, D. L. (2006). Increasing student participation in IEP meetings: Establishing the selfdirected IEP as an evidence-based practice. Exceptional Children, 72, 299-316. doi: $10.1177 / 001440290607200303$

Mason, C. Y., McGahee-Kovac, M., Johnson, L., \& Stillerman, S. (2002). Implementing student-led IEPs: Student participant and student teacher reactions. Career Development for Exceptional Individuals, 25, 171-192. doi: $10.1177 / 088572880202500206$

Mazzotti, V., Rowe, D. A., Cameto, R., Test, D. W., \& Morningstar, M. E. (2013). Identifying and promoting transition evidence-based practices and predictors of success: A position paper of the division on career development and transition. Career Development and Transition for Exceptional Individuals, 36(3), 140-151. doi: $10.1177 / 2165143413503365$

McDougal, J., Evans, J., \& Baldwin, P. (2010). The importance of self-determination to perceived quality of life for youth and young adults with chronic conditions and disabilities. Remedial and Special Education, 31, 252-260.

doi: $10.1177 / 0741932509355989$

Merchant, D., \& Gajar, A. (1997). A review of the literature on self-advocacy components in transition programs for students with learning disabilities. Journal of Vocational Rehabilitation, 8, 223-231.

Mishna, F., Muskat, B., Farnia, F., \& Wiener, J. (2011). The effects of a school-based program on the reported self-advocacy knowledge of students with learning disabilities. Alberta Journal of Educational Research, 57, 185-203. 
Morningstar, M. E., Frey, B. B., Noonan, P. M., Ng, J., Clavenna-Deane, B., Graves, P., ... Williams-Diehm, K. (2010). A preliminary investigation of the relationship of transition preparation and self-determination for students with disabilities in postsecondary educational settings. Career Development for Exceptional Individuals, 33, 80-94. doi: 10.1177/0885728809356568

Newman, L., Wagner, M., Knokey, A.-M., Marder, C., Nagle, K., Shaver, D., ... Schwarting, M. (2011). The post-high school outcomes of young adults with disabilities up to 8 years after high school (A report from the National Longitudinal Transition Study-2, NCSER 2011-3005). Menlo Park, CA: SRI International. Retrieved from www.nlts2.org/reports/

Neale, M. H., \& Test, D. W. (2010). Effects of the "I can use effort" strategy on quality of student verbal contributions and individualized education program participation with third- and fourth-grade students with disabilities. Remedial \& Special Education, 31, 184-194. doi: 10.1177/0741932508327462

Nirje, B. (1972). The right to self-determination. In W. Wolfensberger, The principle of normalization in human services (pp. 177-193). Downsview, Toronto: National Institute on Mental Retardation.

Overton, T. (2012). Assessing learners with special needs: An applied approach. Upper Saddle River, NJ: Pearson

Palmer, C., \& Roessler, R. T. (2000). Requesting classroom accommodations: Selfadvocacy and conflict resolution training for college students with disabilities. Journal of Rehabilitation, 66(3), 38-43. 
Perske, R. (1996). Self-advocates on the move: A journalist's view. In G. Dybwad \& H. Bersani (Eds.), New voices: Self-Advocacy by people with disabilities (pp. 18-34). Cambridge, MA: Brookline Books.

Prater, M.A., Redman, A. S., Anderson, D., \& Gibb, G. S. (2014). Teaching adolescent students with learning disabilities to self-advocate for accommodations. Intervention in School and Clinic, 49, 298-305. doi: 10.1177/1053451213513958

Pocock, A., Lambros, S., Karvonen, M., Test, D. W., Algozzine, B., Wood, W., \& Martin, J. E. (2002). Successful strategies for promoting self-advocacy among students with LD: The LEAD group. Intervention in School \& Clinic, 37, 209-216. doi: $10.1177 / 105345120203700403$

Powers, L., Turner, A., Westwood, D., Matuszewski, J., Wilson, R., \& Phillips, A. (2001). TAKE CHARGE for the future: A controlled field-test of model to promote students' involvement in transition planning. Career Development for Exceptional Individuals, 24, 89-104. doi: 10.1177/105345120203700403

Riesen, T., Schultz, J., Morgan, R., \& Kupferman, S. (2014). School-to-work barriers as identified by special educators, vocational rehabilitation counselors, and community rehabilitation professionals. Journal of Rehabilitation, 80(1), 33-44.

Roberts, E. L., Ju, S., \& Zhang, D. (2014). Review of practices that promote selfadvocacy for students with disabilities. Journal of Disability Policy Studies, 1-12. doi: $10.1177 / 1044207314540213$ Retrieved from http://dps.sagepub.com/content/early/2014/07/24/1044207314540213 
Roessler, R. T., Brown, P. L., \& Rumrill, P. D. (1998). Self-advocacy training: Preparing students with disabilities to request classroom accommodations. Journal of PostSecondary Education and Disability, 13, 20-31.

Rosetti, C. W., \& Henderson, S. J. (2013). Lived experiences of adolescents with learning disabilities. The Qualitative Report, 18(24), 1-17. Retrieved from http://www.nova.edu/ssss/QR/QR18/rosetti47.pdf

Rothman, T., Maldonado, J. M., \& Rothman, H. (2008). Building self-confidence and future career success through a pre-college transition program for individuals with disabilities. Journal of Vocational Rehabilitation, 28, 73-83.

Rumrill, P., Palmer, C. Roessler, R., \& Brown, P. (1999). Self-advocacy and conflict resolution training: Strategies for the classroom accommodation request. Project Accommodations Planning Training (APT), University of Arkansas.

Rumrill, P., Roessler, R., \& Brown, O. (1994). Self-advocacy: A training manual. Fayetteville, AR: Department of Rehabilitation.

Schaaf, V., \& Bersani, H. (1996). People first of Oregon: An organizational history and personal perspective. In G. Dybwad \& H. Bersani (Eds.), New voices: SelfAdvocacy by people with disabilities (pp. 171-179). Cambridge, MA: Brookline Books.

Schreiner, M. B. (2007). Effective self-advocacy: What students and special educators need to know. Intervention in School \& Clinic, 42, 300-304.

doi: $10.1177 / 10534512070420050701$

Sebag, R. (2010). Behavior management through self-advocacy. TEACHING Exceptional Children, 42(6), 22-29. 
Section 504 of the Rehabilitation Act of 1973, 29 U.S.C. § 794.

Shaw, S. F., Madaus, J. W., \& Banerjee, M. (2009). Enhance access to postsecondary education for students with disabilities. Intervention in School and Clinic, 44, 185190. doi: $10.1177 / 1053451208326047$

Skinner, M. E. (2004). College students with learning disabilities speak out: What it takes to be successful in postsecondary education. Journal of Postsecondary Education and Disability, 17, 91-104.

Test, D. W., \& Cease-Cook, J. (2012). Evidence-based secondary transition practices for rehabilitation counselors. Journal Of Rehabilitation, 78, 30-38.

Test, D. W., Fowler, C. H., Brewer, D. M., \& Wood, W. M. (2005). A content and methodological review of self-advocacy intervention studies. Exceptional Children, 72, 101-125. doi: 10.1177/001440290507200106

Test, D. W., Fowler, C. H., Richter, S., White, J. A., Mazzotti, V. L., Walker, A. R.,...Kortering, L. (2009). Evidence-based practices in secondary transition. Career Development for Exceptional Individuals, 32, 115-128. doi: $10.1177 / 0885728809336859$

Test, D. W., Fowler, C. H., Wood, W. M., Brewer, D. M., \& Eddy, S. (2005). A conceptual framework of self-advocacy for students with disabilities. Remedial \& Special Education, 26, 43-54. doi: 10.1177/07419325050260010601

Test, D. W., Mason, C., Hughes, C., Konrad, M., Neale, M., \& Wood, W. M. (2004). Student involvement in individualized education program meetings. Exceptional Children, 70, 391-412. 
Test, D. W., Mazzotti, V. L., Mustian, A. L., Fowler, C. H., Kortering, L., \& Kohler, P. (2009). Evidence-based secondary transition predictors for improving postschool outcomes for students with disabilities. Career Development for Exceptional Individuals, 32, 160-181. doi: 10.1177/08885728809346960

Test, D. W., \& Neale, M. (2004). Using the "self-advocacy strategy" to increase middle graders' IEP participation. Journal of Behavioral Education, 13, 135-145. doi: 10.1023/b:jobe.0000023660.21195.c2

Thoma, C. A., \& Getzel, E. E. (2005). "Self-determination is what it's all about": What post-secondary students with disabilities tell us are important considerations for success. Education and Training in Developmental Disabilities, 40, 234-242.

U.S. Department of Education, National Center for Education Statistics. (2010). Digest of Education Statistics, 2009 (NCES 2010-013). Retrieved from http://nces.ed.gov/programs/digest/d09/tables/dt09_239.asp

Van Reusen, A. K., \& Bos, C. S. (1994). Facilitating student participation in individualized education programs through motivation. Exceptional Children, 60, 466-475.

Van Reusen, A. K., Bos, C. S., Schumaker, J. B., \& Deshler, D. D. (1994). The selfadvocacy strategy for education and transition planning. Lawrence, KS: Edge Enterprises.

Walker, A. R., \& Test, D. W. (2011). Using a self-advocacy intervention on African American college students' ability to request academic accommodations. Learning Disabilities Research \& Practice (Wiley-Blackwell), 26, 134-144.

doi: $10.1111 / \mathrm{j} .1540-5826.2011 .00333 . x$ 
Ward, M. J. (2005). An historical perspective of self-determination in special education: Accomplishments and challenges. Research and Practice for Persons with Severe Disabilities, 30, 108-112. doi: 10.2511/rpsd.30.3.108

Webb, K., Patterson, K., Syverud, S., \& Seabrooks-Blackmore, J. (2008). Evidenced based practices that promote transition to postsecondary education: Listening to a decade of expert voices. Exceptionality, 16, 192-206.

doi: $10.1080 / 09362830802412182$

Wehmeyer, M. L. (1999). A functional model of self-determination: Describing development and implementing instruction. Focus on Autism and Developmental Disabilities, 14, 53-61. doi:10.1177/108835769901400107

Wehmeyer, M. L. (2014). Framing for the future: Self-determination. Remedial and Special Education, 36, 20-23. doi: 10.1177/0741932514551281

Wehmeyer, M. L., Agran, M., \& Hughes, C. (1998). Teaching self-determination to students with disabilities: Basic skills for successful transition. Baltimore: Brookes.

Wehmeyer, M. L., Agran, M., \& Hughes, C. (2000). A national survey of teachers' promotion of self-determination and student-directed learning. Journal of Special Education, 34, 58-68. doi: 10.1177/002246690003400201

Wehmeyer, M. L., Bersani, H., \& Gagne, R. (2000). Riding the third wave: Selfdetermination and self-advocacy in the $21^{\text {st }}$ century. Focus on Autism and Other Developmental Disabilities, 15, 106-115. doi: 10.1177/108835760001500206

Wehmeyer, M.L., \& Kelchner, K. (1995). The Arc's Self-Determination Scale: Adolescent version. Arlington, TX: Arc of the United States. 
Wehmeyer, M. L. \& Lawrence, M. (1995). Whose future is it anyway? Promoting student involvement in transition planning. Career Development for Exceptional Individuals, 18, 69-83. doi: 10.1177/088572889501800202

Wehmeyer, M. L. \& Palmer, S. B. (2003). Adult outcomes for students with cognitive disabilities three years after high school: The impact of self-determination. Education and Training in Developmental Disabilities, 38, 131-144.

Wehmeyer, M. L., Palmer, S. B., Soukup, J. H., Garner, N. W., \& Lawrence, M. (2007). Self-determination and student transition planning knowledge and skills: Predicting involvement. Exceptionality, 15, 31- 44. doi: 10.1080/09362830709336924

Wehmeyer, M. L., Sands, D. J., Doll, B., \& Palmer, S. (1997). The development of selfdetermination and implications for educational interventions with students with disabilities. International Journal of Disability, Development and Education, 44, 305-328. doi: 10.1080/0156655970440403

Wehmeyer, M. L., \& Schwartz, M. (1997). Self-determination and positive adult outcomes: A follow-up study of youth with mental retardation or learning disabilities. Exceptional Children, 63, 245-255.

White, G. W., Summers, J. A., Zhang, E., \& Renault, V. (2014). Evaluating the effects of a self-advocacy training program for undergraduates with disabilities. Journal of Postsecondary Education and Disability, 27, 229-244.

White, G. W., \& Vo, Y. H. (2006). Requesting accommodations to increase full participation in higher education: An analysis of self-advocacy training for postsecondary students with learning and other disabilities. Learning Disabilities: A Multidisciplinary Journal, 14, 41-56. 
Williams, P., \& Shoultz, B. (1982). We can speak for ourselves. Bloomington, Indiana: University Press.

Wolman, J., Campeau, P., Dubois, P., Mithaug, D., \& Stolarski, V. (1994). AIR SelfDetermination Scale and user guide. Palo Alto, CA: American Institute for Research.

Wood, W. M., Karvonen, M., Test, D. W., Browder, D., \& Algozzine, B. (2004). Promoting student self-determination skills in IEP planning. TEACHING Exceptional Children, 36(3), 8-16.

Wood, C. L., Kelley, K. R., Test, D. W., \& Fowler, C. H. (2010). Comparing audiosupported text and explicit instruction on students' knowledge of accommodations, rights, and responsibilities. Career Development for Exceptional Individuals, 33, 115-124. doi: 10.1177/0885728810361618

Woods, L. L., Martin, J. E., \& Humphrey, M. J. (2013). The difference a year makes: An exploratory self-directed IEP case study. Exceptionality, 21, 176-189.

doi: $10.1080 / 09362835.2013 .802233$ 
APPENDIX A

SEVEN LESSONS OF MODULE I OF THE SACR

\begin{tabular}{|c|c|c|}
\hline Lesson & $\begin{array}{c}\text { Skill } \\
\text { Description }\end{array}$ & Goal of the Lesson \\
\hline 1 & Introduction & $\begin{array}{l}\text { Student greets teacher, introduces self, and } \\
\text { identifies the class or class period he/she is } \\
\text { enrolled in }\end{array}$ \\
\hline 2 & Disclosure & $\begin{array}{l}\text { Student identifies disability and explains it in } \\
\text { functional terms }\end{array}$ \\
\hline 3 & Solution & $\begin{array}{l}\text { Student identifies an effective accommodation, } \\
\text { states the benefit to him/her, and makes a request } \\
\text { to use the accommodation }\end{array}$ \\
\hline 4 & Resources & $\begin{array}{l}\text { Student identifies who will assist him/her in } \\
\text { accessing the accommodation and his/her } \\
\text { personal responsibility }\end{array}$ \\
\hline 5 & Agreement & $\begin{array}{l}\text { Student asks the teacher if the accommodation } \\
\text { would be acceptable and makes an affirmative } \\
\text { response when the teacher agrees }\end{array}$ \\
\hline 6 & Summary & $\begin{array}{l}\text { Student restates the accommodation and clarifies } \\
\text { his/her role and the role of the teacher }\end{array}$ \\
\hline 7 & Closure & $\begin{array}{l}\text { Student makes a positive remark about the } \\
\text { teacher, the class, or the accommodation } \\
\text { arrangement and/or includes an expression of } \\
\text { appreciation }\end{array}$ \\
\hline
\end{tabular}




\section{APPENDIX B \\ SACR STUDENT LESSON TEMPLATES}

\section{Lesson 1 - Introduction}

Skill Description - The introduction is a friendly greeting that tells the teacher who you are and opens the conversation.

$\checkmark$ Approach the conversation in a relaxed manner

$\checkmark$ Avoid fidgeting or verbal signs of nervousness

$\checkmark$ Establish eye contact

$\checkmark$ Smile and stand up or sit up tall

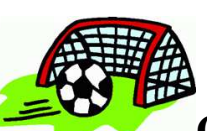

Goal of the Skill - The goal of the introduction is to:

$\checkmark$ Establish a friendly conversation

$\checkmark$ Let the teacher know who you are

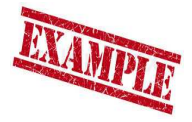

\section{Skill Examples}

$\checkmark$ First, say a greeting like "hello" or "good morning"

$\checkmark$ Then, state you name and your class or class period - "I'm Johnny Smith from your $5^{\text {th }}$ period class"

Summary - You have learned the first step of advocating for yourself, which is introducing yourself to your teacher. 
$\checkmark$ Say hello

$\checkmark$ Introduce yourself

$\checkmark$ Identify the class or class period you are enrolled in 


\section{Lesson 2 - Disclosure}

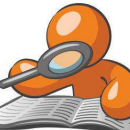

Skill Description - A brief explanation of your disability in specific terms

$\checkmark$ Focus on your needs

$\checkmark$ Explain how your disability affects you in the classroom

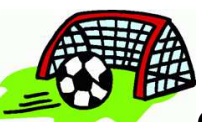

Goal of the Skill - The goal of the disclosure is to:

$\checkmark$ Identify your disability

$\checkmark$ Explain your disability in functional terms

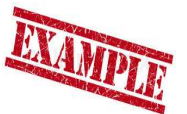

\section{Skill Examples}

$\checkmark$ First, make a general statement like "I have a learning disability."

$\checkmark$ Then, explain how the disability affects you. "It takes me longer to read and understand the material."

Summary - Besides knowing how to introduce yourself, you now know how to disclose your disability.

$\checkmark$ State your disability area

$\checkmark$ Explain how it affects you in the classroom 


\section{Lesson 3 - Solution}

Skill Description - The solution statement explains what accommodation has worked for you in the past and includes a request to use this accommodation in the class.

$\checkmark$ Request the accommodation in a statement not a question

$\checkmark$ Providing the solution rather than having the teacher come up with it is a key to successful advocacy

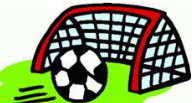

Goal of the Skill - The goal of the solution is to:

$\checkmark$ Cite an effective accommodation

$\checkmark$ State the benefit to you

$\checkmark$ Request the accommodation (in statement form)

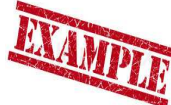

\section{Skill Examples}

$\checkmark$ First, state the accommodation. "I have used a reader when taking tests."

$\checkmark$ Then, explain the benefit of the accommodation in the class. "When I have a test read to me, I don't have to spend all of my time trying to read the words. I can focus on determining the answer."

$\checkmark$ Lastly, request the accommodation. I would like to have my tests read in the Resource Room."

\section{SUMMARY}

Summary - Besides learning how to introduce yourself and disclose your disability, you now know how to:

$\checkmark$ State the accommodation

$\checkmark$ State how the accommodation helps you

$\checkmark$ Request the accommodation 


\section{Lesson 4 - Resources}

Skill Description - At this point you want to identify the resources you will use to arrange the accommodation.

$\checkmark$ Identify who and/or what will assist you in accessing accommodation

$\checkmark$ Identify your role in accessing the accommodation

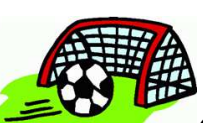

Goal of the Skill - The goal of explaining resources is to:

$\checkmark$ Describe who and/or what will assist you

$\checkmark$ State what your role will be

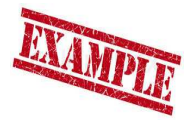

\section{Skill Examples}

$\checkmark$ First, state who will help you. "The resource room teacher will read the test to me."

$\checkmark$ Then, state your responsibility. "I will make all of the arrangements with the resource teacher on testing days."

Summary - Besides learning how to introduce yourself, disclose your disability, and request the accommodation, you now know how to:

$\checkmark$ State the resources you will need

$\checkmark$ State what your role will be 


\section{Lesson 5 - Agreement}

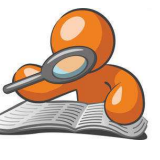

Skill Description - At this point you want to ask the teacher if the accommodation is acceptable.

$\checkmark$ Ask for confirmation of the accommodation

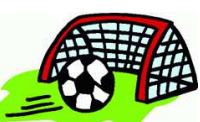

Goal of the Skill - The goal of the agreement is to:

$\checkmark$ Ask for agreement from the teacher

$\checkmark$ Confirm the agreement with an affirming statement

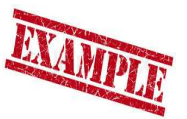

\section{Skill Examples}

$\checkmark$ First, ask the teacher if the plan sounds agreeable. "Does this seem like a workable plan?"

$\checkmark$ Then, respond with an affirmative statement. "Thanks."

SUMMARY

Summary - Besides learning how to introduce yourself, disclose your disability, request the accommodation, and identify your resources, you now know how to:

$\checkmark$ Ask for confirmation to use the accommodation

$\checkmark$ Make an affirming statement to confirm 


\section{Lesson 6 - Summary}

Skill Description - The summary statement restates what has been agreed upon and who will be responsible.

$\checkmark$ Clarify what the accommodation will be

$\checkmark$ Clarify each person's responsibility

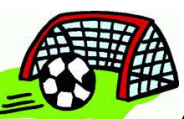

Goal of the Skill - The goal of the summary is to:

$\checkmark$ Restate the accommodation

$\checkmark$ State your responsibility

$\checkmark$ State the teacher's responsibility

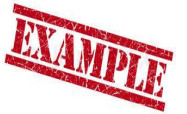

\section{Skill Examples}

$\checkmark$ First, state the accommodation. "O.K. I'll plan to use a reader on test days?"

$\checkmark$ Then, state your role. "I'll make arrangements with the resource room teacher."

$\checkmark$ Finally, state the teacher's role. "I will need you to let me know upcoming dates for tests."

Summary - Besides learning how to introduce yourself, disclose your disability, request the accommodation, identify your resources, and confirm the agreement, you now know how to:

$\checkmark$ Restate the accommodation

$\checkmark$ State what your role will be

$\checkmark$ State what the teacher's role will be 


\section{Lesson 7 - Closure}

Skill Description - Closure is a positive statement indicating a close to the conversation and contains an expression of appreciation.

$\checkmark$ Relax

$\checkmark$ Maintain eye contact

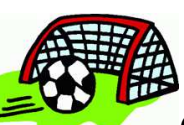

Goal of the Skill - The goal of the closure is to:

$\checkmark$ Make a positive statement about the teacher, the class, or the accommodation

$\checkmark$ Thank the teacher

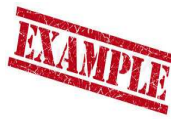

\section{Skill Examples}

$\checkmark$ First, make a general statement. "I'm really looking forward to see how I will do in your class."

$\checkmark$ Then, express your appreciation. "Thanks for your help."

SUMMARY

Summary - Besides learning how to introduce yourself, disclose your disability, request the accommodation, identify your resources, confirm the agreement, and summarize the accommodation and accompanying responsibilities, you now know how to:

$\checkmark$ Make a positive closing statement

$\checkmark$ Thank the teacher 
APPENDIX C

\section{DISABILITY AWARENESS GRAPHIC ORGANIZER}

Name

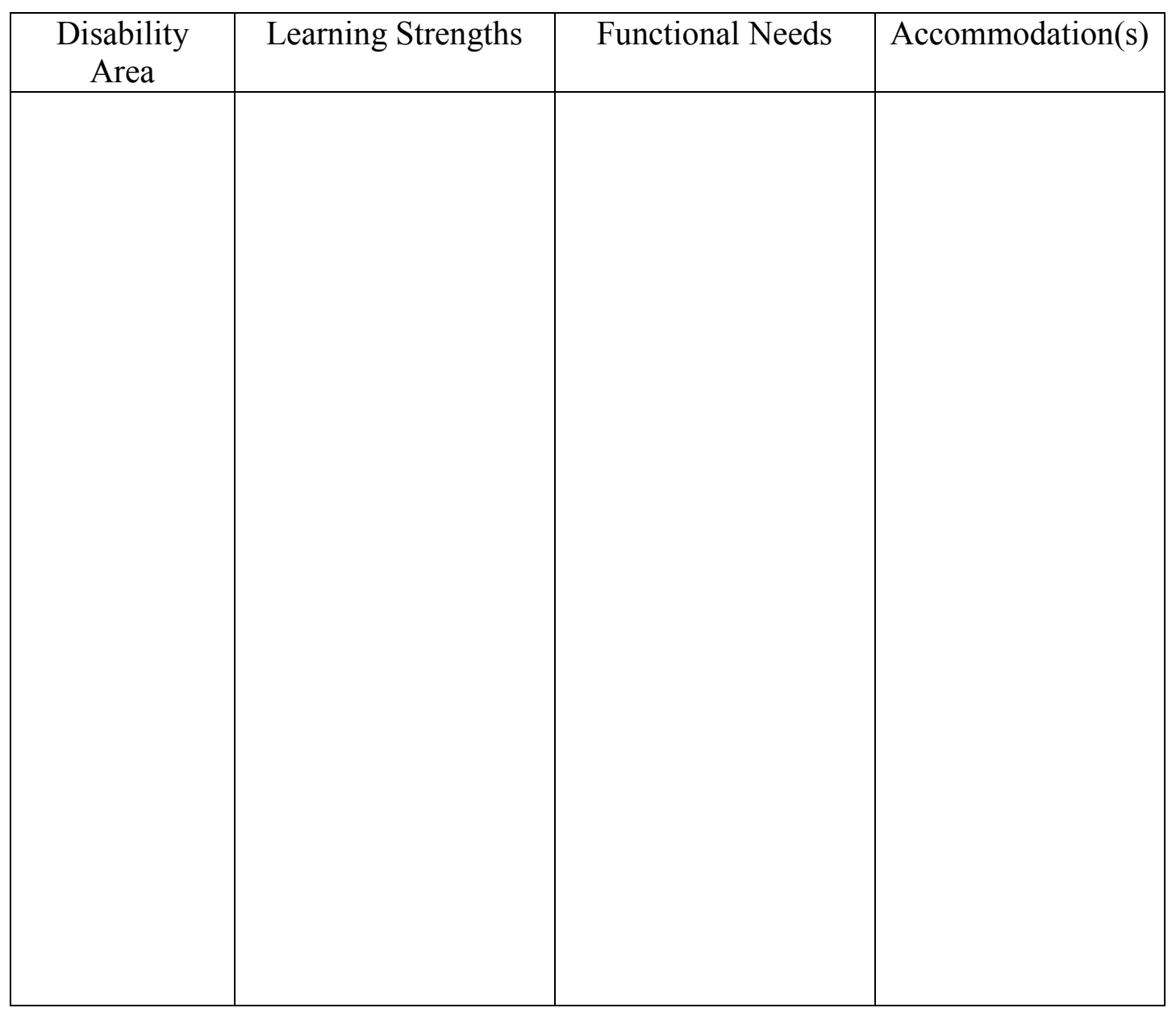




\section{APPENDIX D}

\section{SACR POSTER}

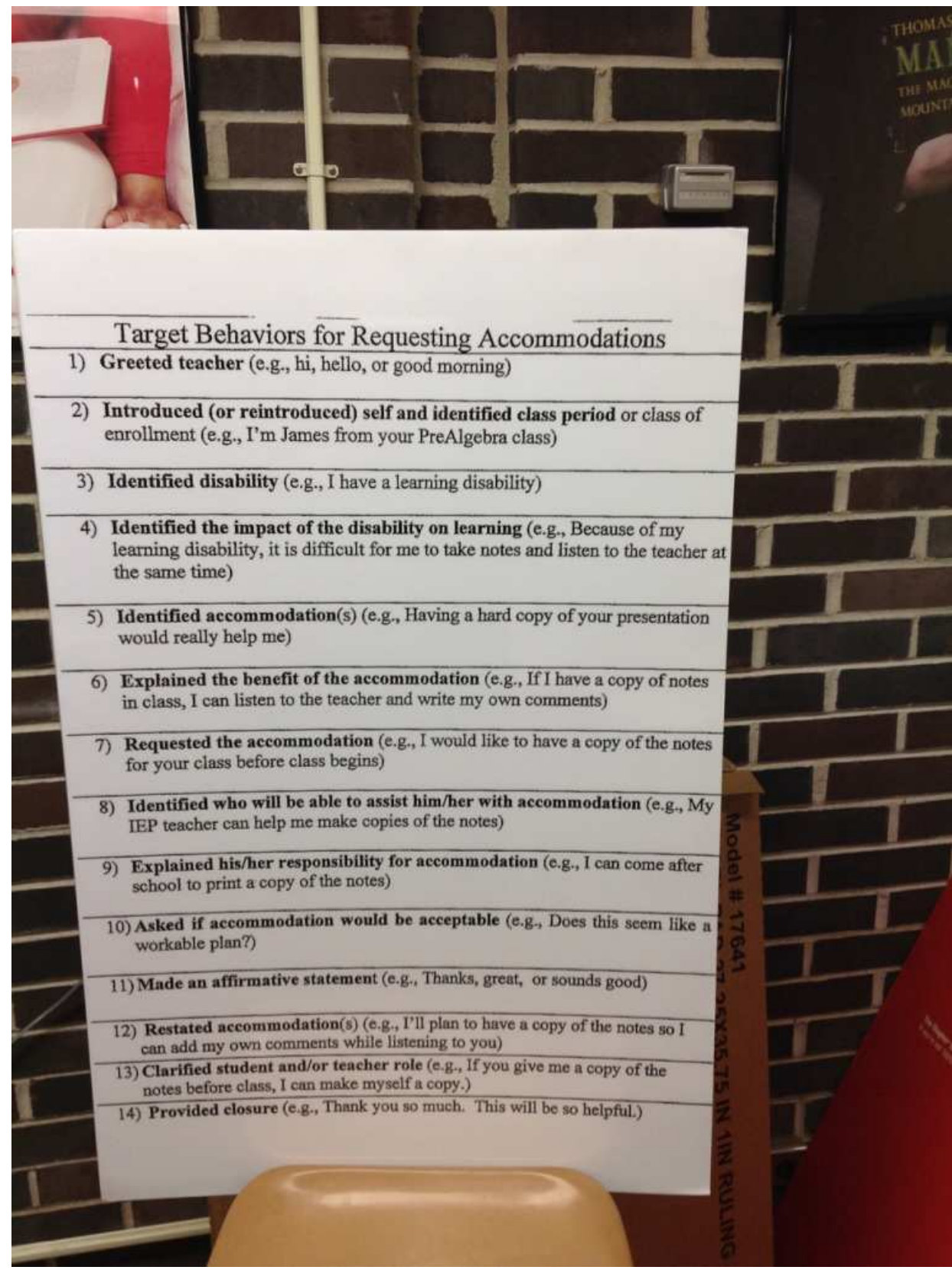




\section{APPENDIX E \\ STUDENT REFLECTION POSTER}

Things to think about when I write my role-play reflection

- Did I make eye contact?

- Was the volume of my voice ok?

- Did I identify the target skills?

- Did I request my accommodations?

- Did I include everything I wanted to say (or did I forget something)?

- Was anything challenging? If so, what was challenging?

- Would I say or do anything differently next time?

- From performing the role-plays, I am learning... 


\section{APPENDIX F \\ TARGET BEHAVIORS FOR REQUESTING ACCOMMODATIONS}

1. Greet teacher

2. Introduce self to teacher

3. Disclose disability

4. Identify impact of disability on learning

5. Identify accommodation(s)

6. Explain accommodation benefit

7. Request accommodation

8. Identify resources

9. Explain student responsibility

10. Ask for agreement

11. Affirm Agreement

12. Restate accommodation

13. Clarify role of student and teacher

14. Provide closure 
APPENDIX G

INTEROBSERVER RELIABILITY FOR REQUESTING ACCOMMODATIONS

Student

Observer __ Date

Session: Baseline

Intervention

Maintenance

\begin{tabular}{|c|c|c|}
\hline Observable Target Behaviors & Yes & No \\
\hline $\begin{array}{l}\text { 1. Greet teacher } \\
>\text { Student verbally states a greeting such as "hi, hello, or } \\
\text { good morning." }\end{array}$ & & \\
\hline $\begin{array}{l}\text { 2. Introduce himself/herself to teacher } \\
\text { Student introduces or reintroduces himself/herself by name } \\
\text { and identifies the class or class period that he/she is } \\
\text { enrolled in. (e.g. I'm James; I'm in your } 6^{\text {th }} \text { period class.) }\end{array}$ & & \\
\hline $\begin{array}{l}\text { 3. Disclose disability } \\
\text { - Student verbally identifies his/her disability (e.g., I have a } \\
\text { learning disability.) }\end{array}$ & & \\
\hline $\begin{array}{l}\text { 4. Identify the impact of disability on learning } \\
\text { - Student verbally explains disability in functional terms. } \\
\text { (e.g., Because of my learning disability, it is very difficult } \\
\text { for me to take accurate notes and listen to the teacher at the } \\
\text { same time.) }\end{array}$ & & \\
\hline $\begin{array}{l}\text { 5. Identify the accommodation(s) } \\
\text { - Student verbally identifies potential accommodations. (e.g., } \\
\text { Having a hard copy of the presentation would be helpful.) }\end{array}$ & & \\
\hline $\begin{array}{l}\text { 6. Explain the accommodation benefit } \\
\text { - Student verbally explains how the accommodation(s) will } \\
\text { benefit him/her. (e.g., If I have a copy of the notes in class, } \\
\text { I can listen to what the teacher is saying and add my own } \\
\text { comments. This will help me understand the material } \\
\text { better.) }\end{array}$ & & \\
\hline
\end{tabular}


7. Request the accommodation(s)

- Student verbally requests the accommodation(s) (e.g., I would like to have a copy of the classroom notes for your class.)

8. Identify available resources

- Student verbally identifies who will be able to assist him/her in accessing the accommodation (e.g., My IEP teacher, Ms. Smith, can help me make copies of the notes.), or what resources are available (e.g., I can take my tests in the resource room with Ms. Lane.)

9. Explain your responsibility

- Student verbally states what his/her responsibility will be in acquiring the accommodation (e.g., If you post the notes for the upcoming unit on your website, I will print them after school in the library.)

10. Ask for agreement

- Student verbally asks the teacher if the accommodation(s) would be acceptable to use in class. (e.g., Does this seem like a workable plan?)

11. Affirm agreement

- Student verbally responds to the teacher's agreement with an affirmative statement. (e.g., Thanks or sounds good.)

12. Restate accommodation(s)

- Student verbally restates the accommodation. (e.g., Great. I'll plan to have a copy of all class notes so I can follow along with the lesson and add my own comments.)

13. Clarify your role and/or the role of the instructor

- Student verbally states what he/she will do to access the accommodation and/or what the instructor will do. (e.g., If you post a copy of the notes, I will make sure I print a copy before I come to class the next day.)

14. Provide closure

- Student makes a positive statement about the teacher, the class or the accommodation arrangements and/or expresses his/her appreciation for the teacher's assistance. (e.g., You've been so helpful. Thanks.) 
APPENDIX H

DEFINITION OF TARGET BEHAVIORS

\begin{tabular}{|c|c|c|}
\hline $\begin{array}{c}\text { Observable Target } \\
\text { Behavior }\end{array}$ & Demonstrated (Yes) & $\begin{array}{c}\text { Did Not Demonstrate } \\
\text { (No) }\end{array}$ \\
\hline 1. Greet Teacher & $\begin{array}{l}\text { - Stated a greeting } \\
\text { such as hi, hello, } \\
\text { good morning }\end{array}$ & $\begin{array}{l}\text { Identified the } \\
\text { teacher by name, } \\
\text { but did not include } \\
\text { a greeting }\end{array}$ \\
\hline $\begin{array}{l}\text { 2. Introduce } \\
\text { himself/herself } \\
\text { to teacher }\end{array}$ & 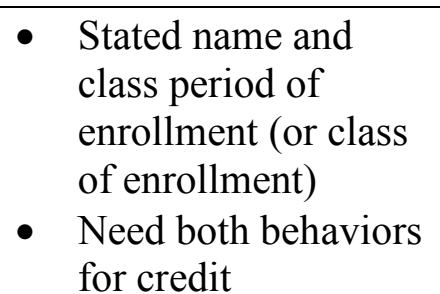 & $\begin{array}{l}\text { - Only stated name or } \\
\text { class period - did } \\
\text { not include both } \\
\text { behaviors }\end{array}$ \\
\hline $\begin{array}{ll}\text { 3. } & \text { Disclose } \\
\text { Disability }\end{array}$ & $\begin{array}{l}\text { Identified a specific } \\
\text { disability such as : } \\
\text { learning disability, } \\
\text { reading disability, } \\
\text { emotional disability, } \\
\text { other health } \\
\text { impairment, ADHD }\end{array}$ & $\begin{array}{l}\text { Did not identify a } \\
\text { specific disability } \\
\text { May have stated an } \\
\text { area of difficulty, } \\
\text { but not a specific } \\
\text { disability }\end{array}$ \\
\hline $\begin{array}{l}\text { 4. Identify the } \\
\text { impact of } \\
\text { disability on } \\
\text { learning }\end{array}$ & $\begin{array}{l}\text { Explained disability } \\
\text { in functional terms } \\
\text { that includes the } \\
\text { challenges } \\
\text { - For example, student } \\
\text { stated that note } \\
\text { taking is challenging } \\
\text { for him because of } \\
\text { the challenges he has } \\
\text { in spelling and } \\
\text { copying information } \\
\text { quickly from the } \\
\text { board } \\
\text { Can identify this } \\
\text { behavior without } \\
\text { disclosing disability }\end{array}$ & $\begin{array}{l}\text { - Only identified that } \\
\text { a skill (e.g., note } \\
\text { taking, reading, or } \\
\text { remembering) is } \\
\text { hard } \\
\text { - Did not explain } \\
\text { "why" a learning } \\
\text { task or behavior is } \\
\text { challenging (e.g., } \\
\text { math is hard for me, } \\
\text { reading is } \\
\text { challenging, or I } \\
\text { have a hard time } \\
\text { taking notes in } \\
\text { class) }\end{array}$ \\
\hline
\end{tabular}




\begin{tabular}{|c|c|c|}
\hline $\begin{array}{l}\text { 5. Identify the } \\
\text { accommodation(s) }\end{array}$ & 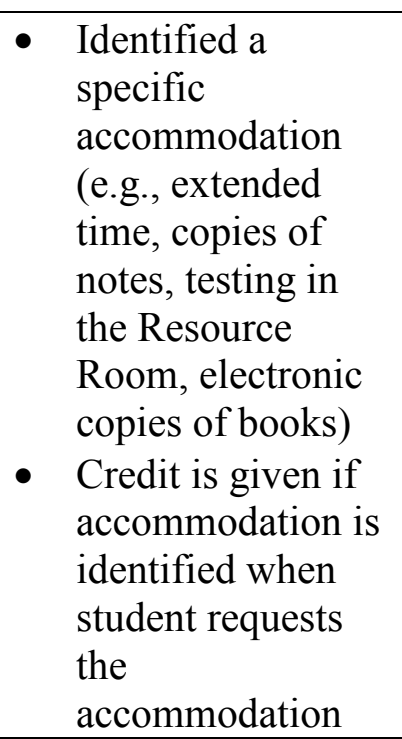 & $\begin{array}{l}\text { - Did not identify an } \\
\text { accommodation }\end{array}$ \\
\hline $\begin{array}{l}\text { 6. Explain the } \\
\text { benefit of the } \\
\text { accommodation }\end{array}$ & $\begin{array}{l}\text { After identifying } \\
\text { the } \\
\text { accommodation, } \\
\text { explained how or } \\
\text { why the } \\
\text { accommodation } \\
\text { will help } \\
\text { (Can not display } \\
\text { this behavior if an } \\
\text { accommodation } \\
\text { was not identified) }\end{array}$ & $\begin{array}{l}\text { - Did not explain } \\
\text { how or why the } \\
\text { accommodation } \\
\text { will help }\end{array}$ \\
\hline $\begin{array}{l}\text { 7. Request the } \\
\text { accommodation }\end{array}$ & $\begin{array}{l}\text { - Informed the } \\
\text { teacher that he/she } \\
\text { would like to use } \\
\text { the } \\
\text { accommodation in } \\
\text { that class } \\
\text { - Student may have } \\
\text { stated, "I would } \\
\text {.." } \\
\text { It's ok if student } \\
\text { stated the } \\
\text { accommodation(s) } \\
\text { and benefits and } \\
\text { then stated that } \\
\text { he/she would like } \\
\text { to use "these } \\
\text { accommodations" } \\
\text { in this class } \\
\text { (Without restating }\end{array}$ & $\begin{array}{l}\text { Did not state that } \\
\text { he/she would like } \\
\text { to use the } \\
\text { accommodation in } \\
\text { that class }\end{array}$ \\
\hline
\end{tabular}




\begin{tabular}{|c|c|c|}
\hline & $\begin{array}{l}\text { exact } \\
\text { accommodation) }\end{array}$ & \\
\hline $\begin{array}{l}\text { 8. Identify available } \\
\text { resources }\end{array}$ & 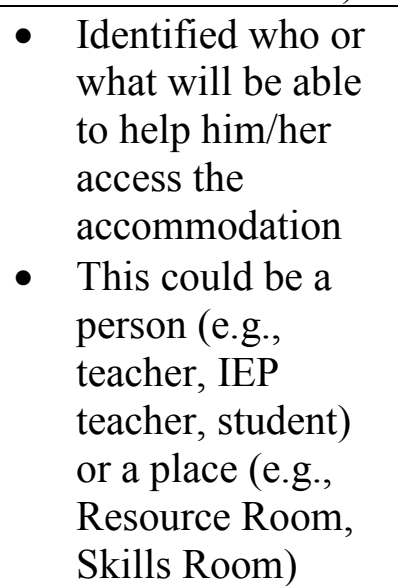 & $\begin{array}{l}\text { Did not identify } \\
\text { the resources to } \\
\text { access the } \\
\text { accommodation } \\
\text { - May have stated } \\
\text { the } \\
\text { accommodation, } \\
\text { but not who or } \\
\text { what is } \\
\text { available to help } \\
\text { access the } \\
\text { accommodation }\end{array}$ \\
\hline $\begin{array}{ll}\text { 9. } & \text { Explain your } \\
\text { responsibility }\end{array}$ & 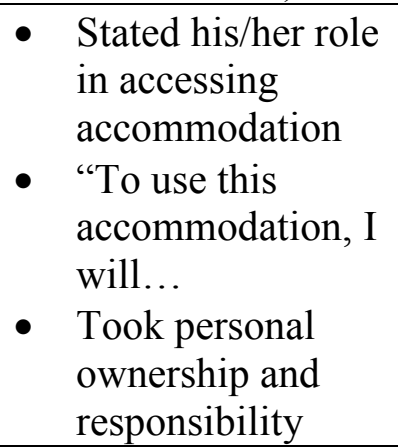 & $\begin{array}{l}\text { Did not take any } \\
\text { responsibility for } \\
\text { obtaining } \\
\text { accommodation } \\
\text { - } \quad \begin{array}{l}\text { Did not identify } \\
\text { his/her role }\end{array}\end{array}$ \\
\hline $\begin{array}{l}\text { 10. Ask for agreement } \\
\text { *Question format }\end{array}$ & $\begin{array}{l}\text { Asked teacher if } \\
\text { accommodations } \\
\text { are ok for class } \\
\text { Asked in question } \\
\text { format to elicit a } \\
\text { response from } \\
\text { teacher } \\
\text { (e.g., Does this } \\
\text { plan work? Is this } \\
\text { plan ok with you?) }\end{array}$ & $\begin{array}{l}\text { Did not ask the } \\
\text { teacher if } \\
\text { accommodation } \\
\text { would be allowed } \\
\text { or acceptable. } \\
\text { Did not ask in } \\
\text { question format }\end{array}$ \\
\hline $\begin{array}{l}\text { 11. Affirm agreement } \\
\text { *Affirmation } \\
\text { directly follows } \\
\text { teacher's statement } \\
\text { of agreement }\end{array}$ & 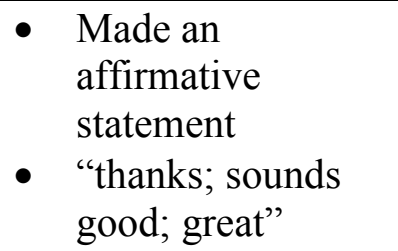 & $\begin{array}{l}\text { After teacher } \\
\text { agrees, student } \\
\text { doesn't respond } \\
\text { with an affirmative } \\
\text { statement }\end{array}$ \\
\hline $\begin{array}{l}\text { 12. Restate } \\
\text { accommodation } \\
\text { *Occurs after } \\
\text { affirmation }\end{array}$ & $\begin{array}{l}\text { Restates the } \\
\text { accommodation(s) } \\
\text { and/or resources }\end{array}$ & $\begin{array}{l}\text { Did not restate the } \\
\text { accommodation(s) } \\
\text { and/or resources } \\
\text { after affirmation }\end{array}$ \\
\hline
\end{tabular}




\begin{tabular}{|c|c|c|}
\hline $\begin{array}{l}\text { 13. Clarify your role } \\
\text { and/or role of the } \\
\text { instructor } \\
\text { *Occurs after } \\
\text { affirmation }\end{array}$ & $\begin{array}{l}\text { Identified his/her } \\
\text { role in accessing } \\
\text { accommodation } \\
\text { - } \begin{array}{l}\text { Identified role of } \\
\text { teacher if there } \\
\text { was one }\end{array} \\
\end{array}$ & $\begin{array}{l}\text { Did not identify } \\
\text { his/her role } \\
\text { - Did not identify } \\
\text { role of teacher if } \\
\text { there was one }\end{array}$ \\
\hline 14. Provide closure & $\begin{array}{l}\text { Made a positive } \\
\text { statement about } \\
\text { teacher, class, or } \\
\text { accommodation or } \\
\text { expressed his/her } \\
\text { appreciation }\end{array}$ & 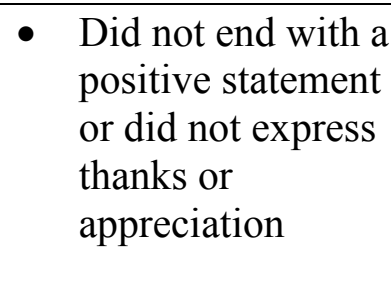 \\
\hline
\end{tabular}




\begin{tabular}{lc}
\multicolumn{2}{c}{ APPENDIX I } \\
BASELINE AND MAINTENANCE PROCEDURAL RELIABILITY CHECKLIST \\
Date__ Session \\
Observer
\end{tabular}

The researcher states that they are going to role-play and have the student ask his/ her teacher for accommodations.

The researcher states that she will play the role of the general education teacher. 


\section{APPENDIX J}

\section{INTERVENTION PROCEDURAL RELIABILITY CHECKLIST}

(For SACR Intervention Sessions 2-10+)

Date Student

Session

Observer

Lesson

The researcher verbally reviewed the targeted skills from all previous sessions using the SACR poster. (Except during Session 2)

The researcher and student role-played (Except during Session 2)

The student viewed the role-play and writes a self-reflection (Except during Session 2)

The researcher and student discussed the role-play and the student's reflection. (Except during Session 2)

The researcher verbally stated the skill description for the targeted behavior. (Except during Sessions 9+)

The researcher verbally stated the goal of the skill.

(Except during Sessions 9+)

The researcher verbally stated the skill examples.

(Except during Sessions 9+)

The researcher modeled the skill.

(Except during Sessions 9+)

The researcher practiced the skill with the student. If the student did not practice the new skill, in addition to the previous skills correctly, the researcher asked the student to repeat the skill.

(Except during Sessions 9+)

The researcher verbally summarized the skill taught in the lesson and any previously taught skills. (Except during Sessions 9+) 


\section{APPENDIX K}

\section{STUDENT SOCIAL VALIDITY SURVEY}

Directions: After reading statements 1-7, circle the number that indicates how much you agree or disagree with each statement. Please write a response for the final question.

\begin{tabular}{|c|c|c|c|c|}
\hline & $\begin{array}{l}\text { Strongly } \\
\text { Disagree }\end{array}$ & Disagree & Agree & $\begin{array}{c}\text { Strongly } \\
\text { Agree }\end{array}$ \\
\hline $\begin{array}{l}\text { 1. The self-advocacy intervention } \\
\text { helped me identify my learning needs } \\
\text { and the accommodations to address } \\
\text { those needs. }\end{array}$ & 1 & 2 & 3 & 4 \\
\hline $\begin{array}{l}\text { 2. I will continue to use this } \\
\text { intervention in future classes where } \\
\text { accommodations will be needed. }\end{array}$ & 1 & 2 & 3 & 4 \\
\hline $\begin{array}{l}\text { 3. As a result of this intervention, I } \\
\text { believe I have the skills to } \\
\text { independently request } \\
\text { accommodations from my teachers. }\end{array}$ & 1 & 2 & 3 & 4 \\
\hline $\begin{array}{l}\text { 4. I now prefer to request } \\
\text { accommodations from my teachers } \\
\text { rather than have another teacher } \\
\text { request them for me. }\end{array}$ & 1 & 2 & 3 & 4 \\
\hline $\begin{array}{l}\text { 5. As a result of this training, I now } \\
\text { understand the importance of how } \\
\text { requesting accommodations in high } \\
\text { school will better prepare me for the } \\
\text { challenges I may face in college. }\end{array}$ & 1 & 2 & 3 & 4 \\
\hline $\begin{array}{l}\text { 6. I enjoyed learning the procedures } \\
\text { to effectively advocate for } \\
\text { accommodations. }\end{array}$ & 1 & 2 & 3 & 4 \\
\hline $\begin{array}{l}\text { 7. I believe all of the steps were } \\
\text { necessary to learn how to effectively } \\
\text { advocate for accommodations. }\end{array}$ & 1 & 2 & 3 & 4 \\
\hline
\end{tabular}


What aspects of this program were most challenging to you? (Be specific) 


\section{APPENDIX L}

\section{TEACHER SOCIAL VALIDITY SURVEY}

Directions: After reading statements 1-6, circle the number that indicates how much you agree or disagree with each statement. Please write a response for the last question.

\begin{tabular}{|c|c|c|c|c|}
\hline & $\begin{array}{l}\text { Strongly } \\
\text { Disagree }\end{array}$ & Disagree & Agree & $\begin{array}{c}\text { Strongly } \\
\text { Agree }\end{array}$ \\
\hline $\begin{array}{l}\text { 1. As a result of this intervention, I } \\
\text { believe my student acquired the skills } \\
\text { to effectively request } \\
\text { accommodations from me. }\end{array}$ & 1 & 0 & 3 & 4 \\
\hline $\begin{array}{l}\text { 2. As a result of the intervention, I } \\
\text { believe my student acquired the skills } \\
\text { to request accommodations in other } \\
\text { classes. }\end{array}$ & 1 & 2 & 3 & 4 \\
\hline $\begin{array}{l}\text { 3. I believe other students would } \\
\text { benefit from this self-advocacy } \\
\text { intervention. }\end{array}$ & 1 & 2 & 3 & 4 \\
\hline $\begin{array}{l}\text { 4. I believe it is important for high } \\
\text { school students to learn the skills to } \\
\text { advocate for their accommodations } \\
\text { while in high school to prepare them } \\
\text { for the challenges they may face in } \\
\text { college. }\end{array}$ & 1 & 2 & 3 & 4 \\
\hline $\begin{array}{l}\text { 5. I believe it is more practical to } \\
\text { have students request their } \\
\text { accommodations than have their } \\
\text { teachers request them. }\end{array}$ & 1 & 2 & 3 & 4 \\
\hline $\begin{array}{l}\text { 6. I believe instructional time should } \\
\text { be used to teach students the skills to } \\
\text { self-advocate. }\end{array}$ & 1 & 2 & 3 & 4 \\
\hline
\end{tabular}

Explain why you believe other students (i.e., general education and special education students) would or would not benefit from this type of intervention? 
APPENDIX M

\section{MODIFIED SACR LESSON PLANS}

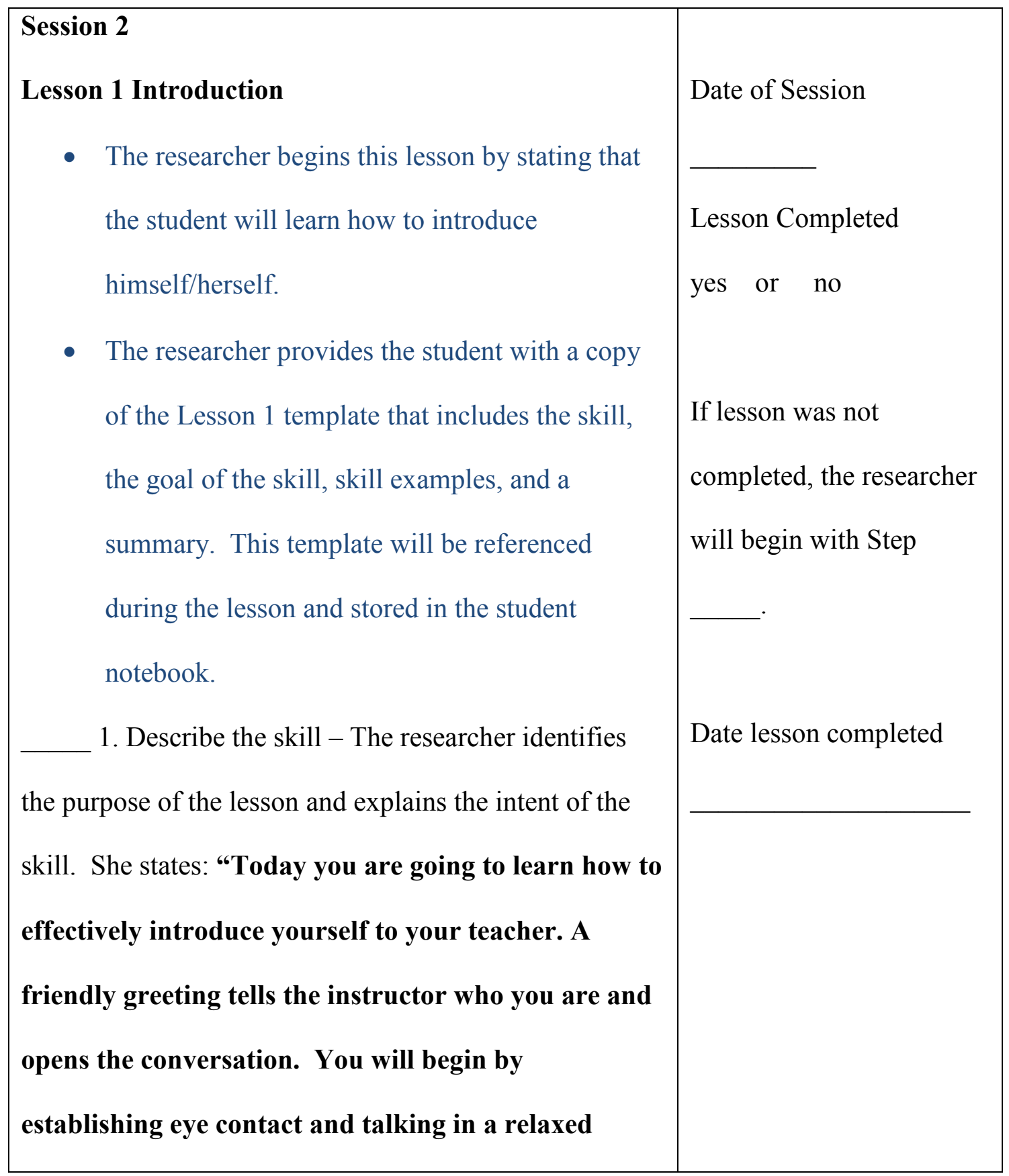




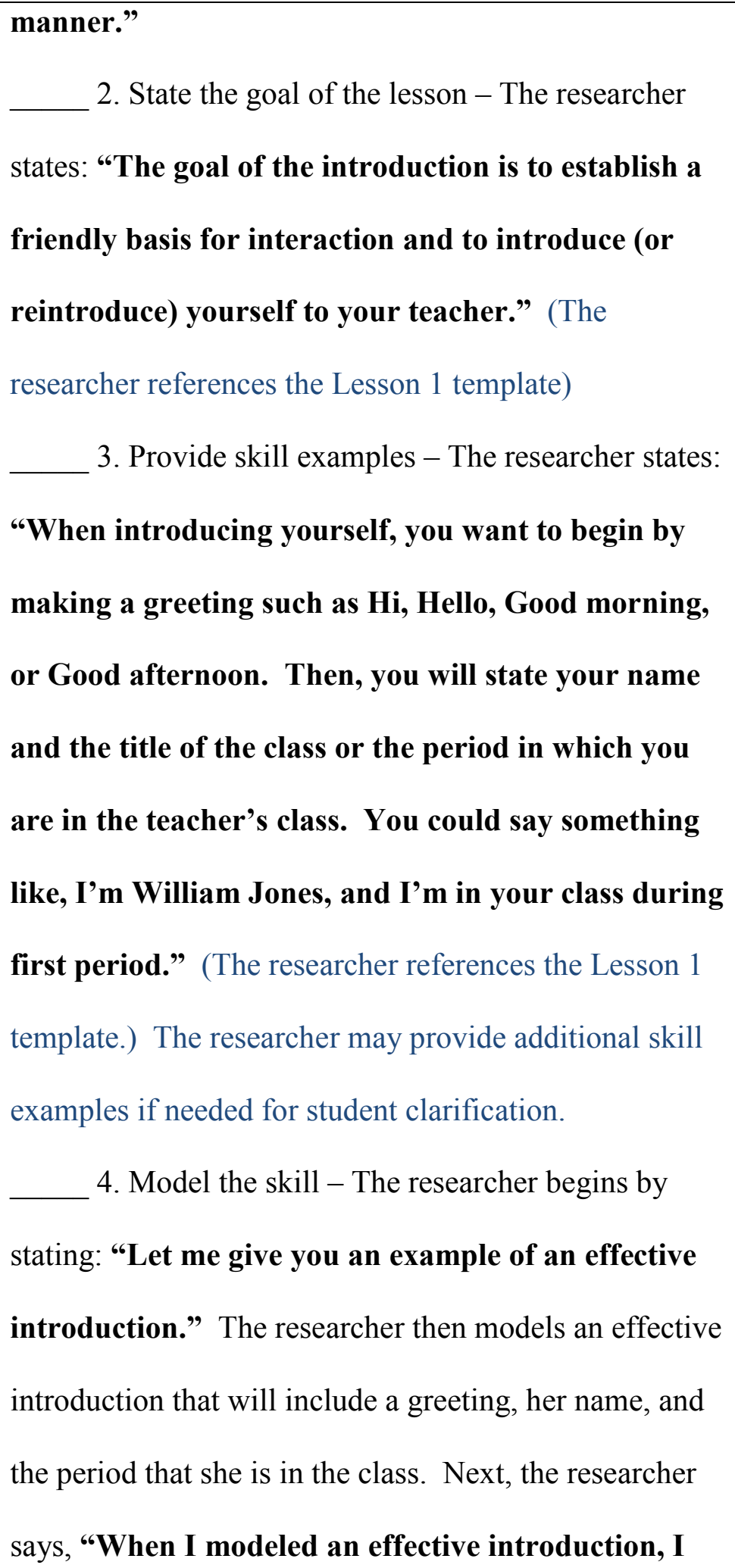

3. Provide skill examples - The researcher states:

"When introducing yourself, you want to begin by making a greeting such as Hi, Hello, Good morning, or Good afternoon. Then, you will state your name and the title of the class or the period in which you are in the teacher's class. You could say something like, I'm William Jones, and I'm in your class during first period." (The researcher references the Lesson 1 template.) The researcher may provide additional skill examples if needed for student clarification.

4. Model the skill - The researcher begins by stating: "Let me give you an example of an effective introduction." The researcher then models an effective introduction that will include a greeting, her name, and the period that she is in the class. Next, the researcher says, "When I modeled an effective introduction, I 


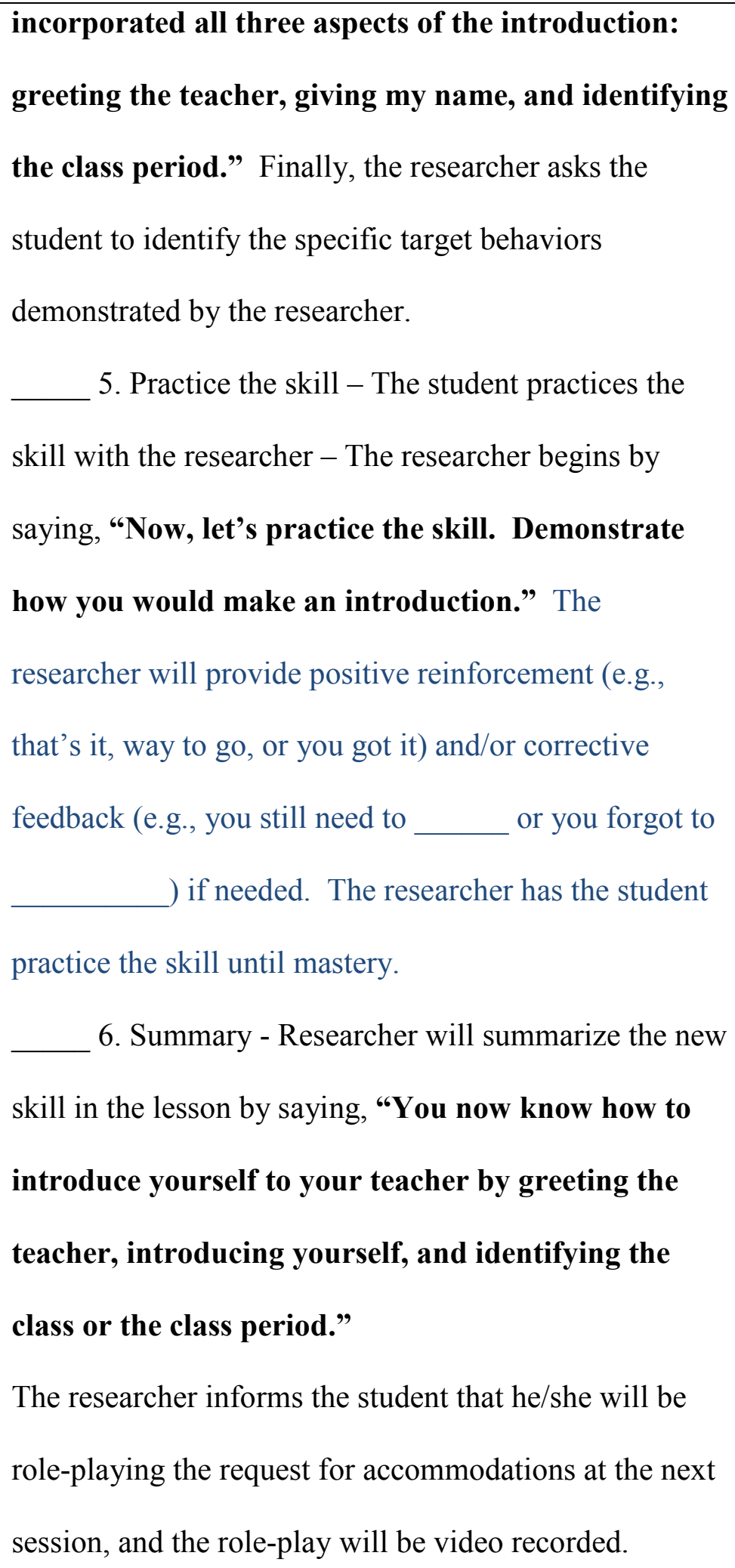


Session 3

Lesson 2 Disclosure

Date of Session

- SACR Review - This session begins with the researcher reviewing the target skills from Lesson 1(i.e., Introduction) on the SACR poster. The student may reference his or her binder during this review.

- Role-Play Probe - After the review, the researcher asks the student to role-play how he/she would request an accommodation from a teacher. The researcher will remind the student to include the targeted skills as well as any other skills he/she deems appropriate. The researcher states that the student will have an opportunity to view the role-play and write a reflection after the role-play has been completed. The student may use the Student Reflection Poster to assist him/her in generating ideas for the role-play reflection. After the student writes the reflection, the researcher and student discuss the role-play. The student may ask the researcher for clarification or support during this review. If a 


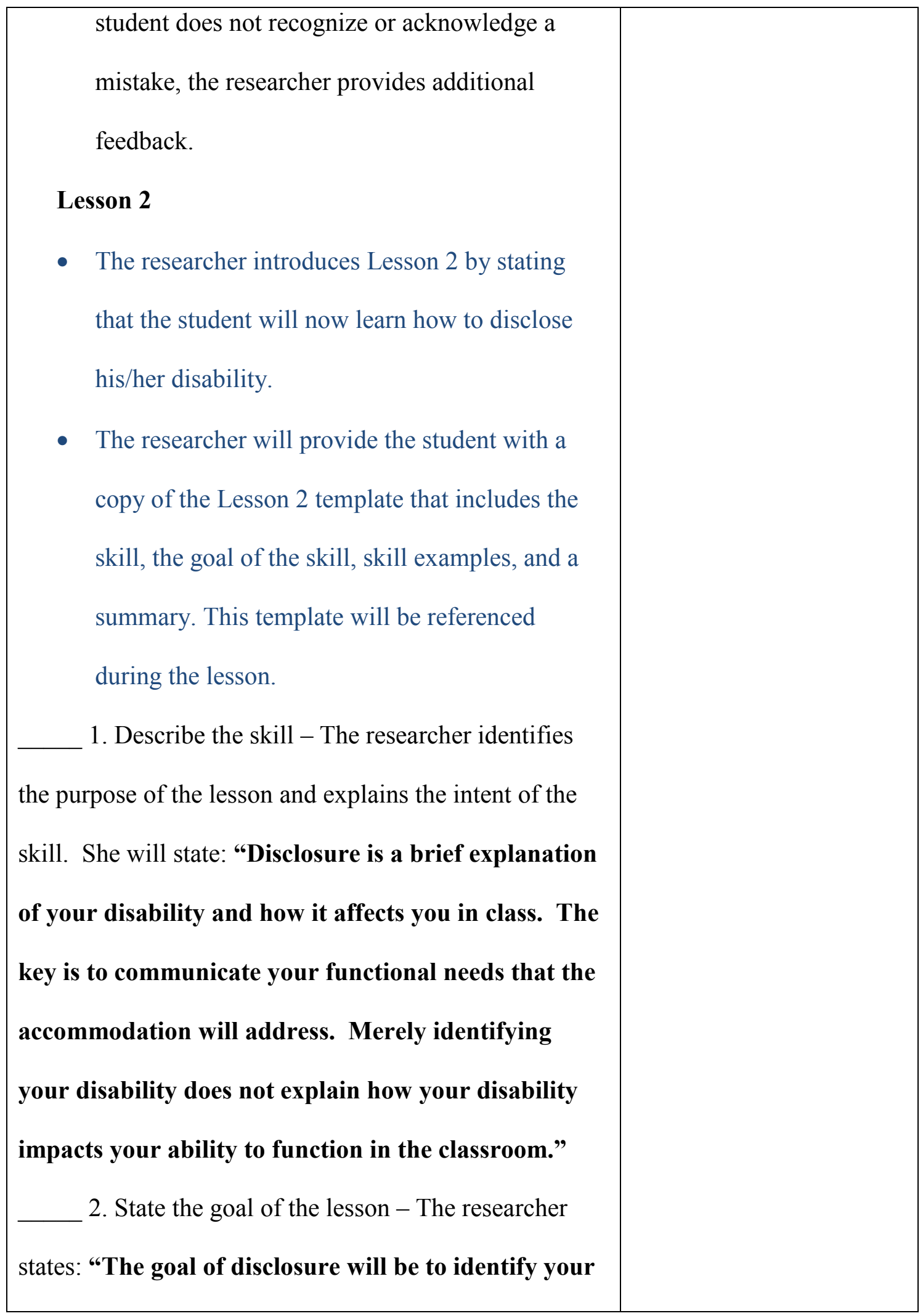




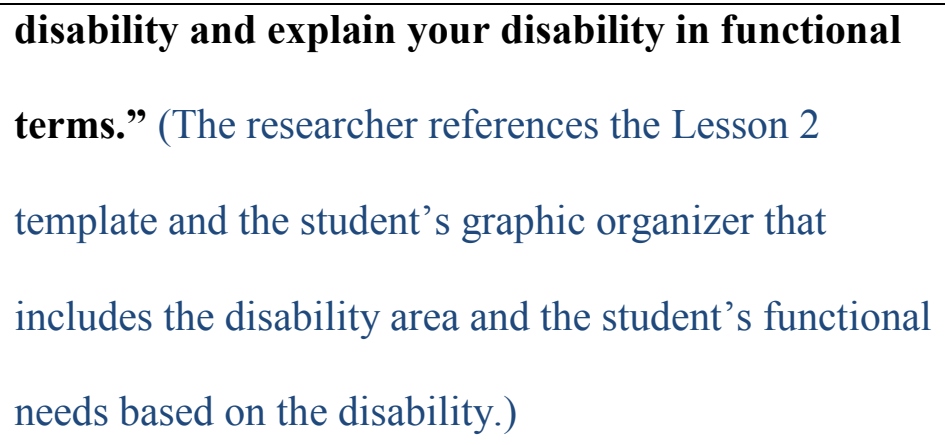

3. Provide skill examples - The researcher states:

"To begin with, you will make a general statement about your disability. For example, you may say: I have a learning disability. Then, you will explain how the disability affects you. You could say something like: As a result of my learning disability, it is difficult for me to take thorough notes. By explaining how the disability impacts you in class, you will be identifying your accommodation needs without focusing on the disability itself." (The researcher references the Lesson 2 template. The researcher may provide additional skill examples if needed for student clarification.)

4. Model the skills - The researcher begins by stating: "Let me give you an example of an introduction and disclosure." The researcher then models an effective introduction and disclosure. Next, 


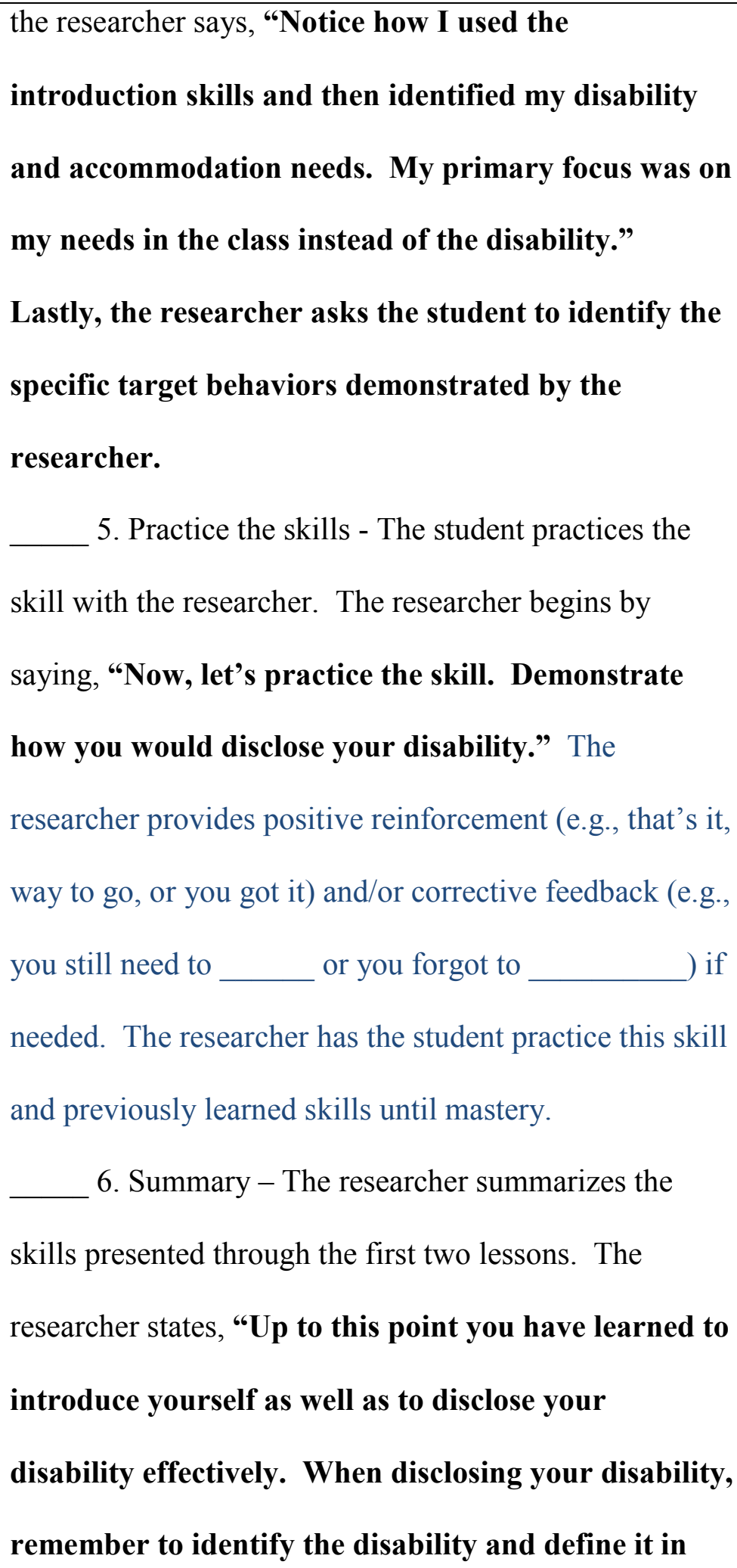
or you forgot to ) if

needed. The researcher has the student practice this skill and previously learned skills until mastery.

6. Summary - The researcher summarizes the

skills presented through the first two lessons. The researcher states, “Up to this point you have learned to introduce yourself as well as to disclose your disability effectively. When disclosing your disability, remember to identify the disability and define it in 


\section{functional terms."}

The researcher informs the student that they will be roleplaying the request for accommodations at the next session, and the role-play will be video recorded. 
Session 4

Lesson 3 Solution

Date of Session

- SACR Review - This session begins with the researcher reviewing the target skills from

Lessons 1-2 (i.e., Introduction and Disclosure) on the SACR poster. The student may reference his or her binder during this review.

- Role-Play Probe - After the review, the researcher asks the student to role-play how he/she would request an accommodation from a teacher. The researcher will remind the student to include the targeted skills as well as any other skills he/she deems appropriate. The researcher states that the student will have an opportunity to view the role-play and write a reflection after the role-play has been completed. The student may use the Student Reflection Poster to assist him/her in generating ideas for the role-play reflection. After the student writes the reflection, the researcher and student discuss the role-play. The student may ask the researcher for clarification or support during this review. If a 


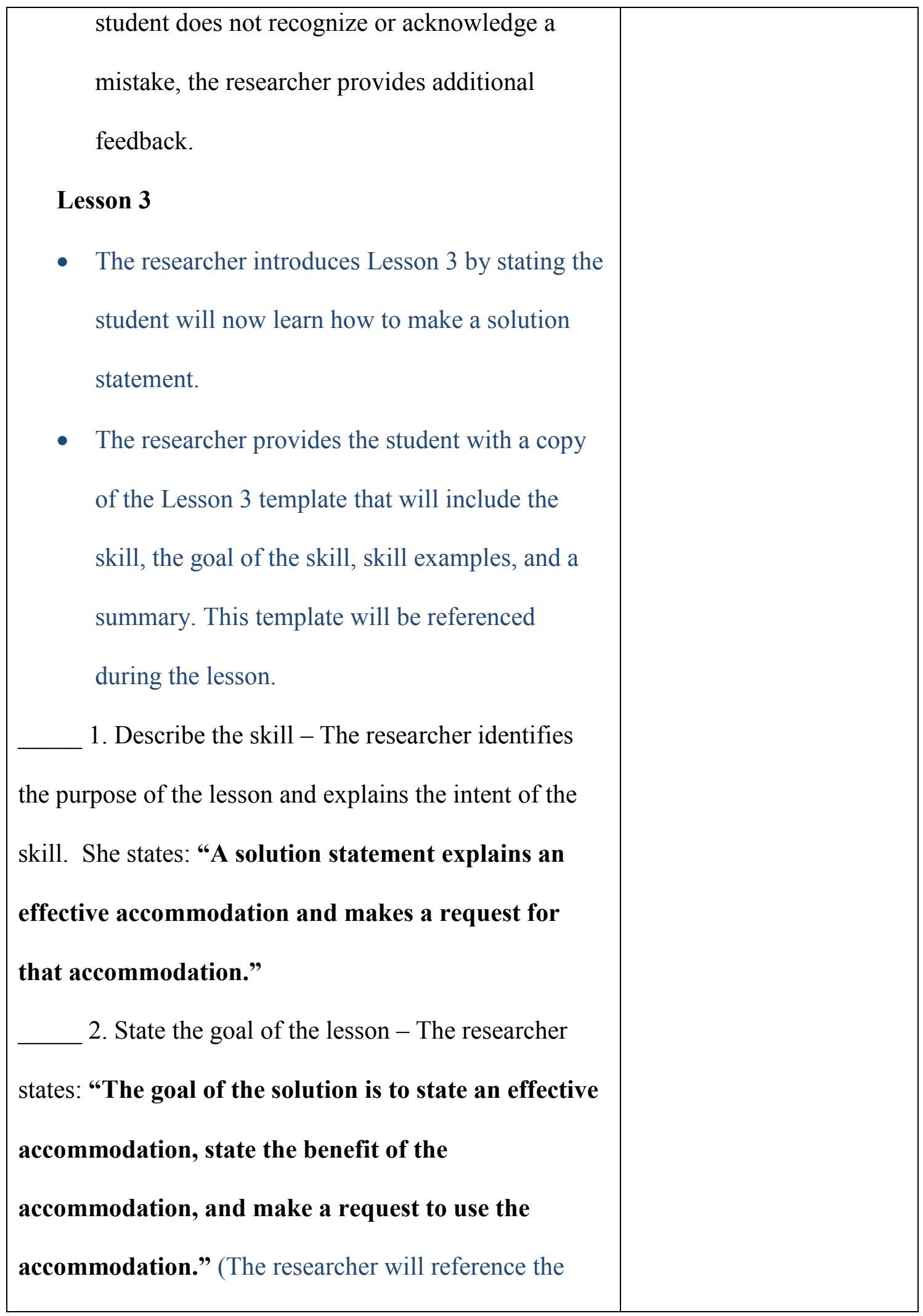


Lesson 3 template and the student's graphic organizer that includes the student's identified accommodations.)

3. Provide skill examples - The researcher begins by stating:

- "First, you will want to state an example of an accommodation such as: I have had teachers give me a copy of their notes."

- "Next, you will want to explain how you benefit from this accommodation. You may say: By having a copy of the notes, I do not have to worry about the spelling of every word I copy."

- "Finally, you will want to complete the request by stating that you think the accommodation will help you in the class. An example would be: I think having a copy of the notes would really be helpful in this class."

(The researcher references the Lesson 3 template for skill examples, and provides additional skill examples if needed for student clarification.)

4. Model the skills - The researcher begins by stating: "Let me show you how the solution follows 


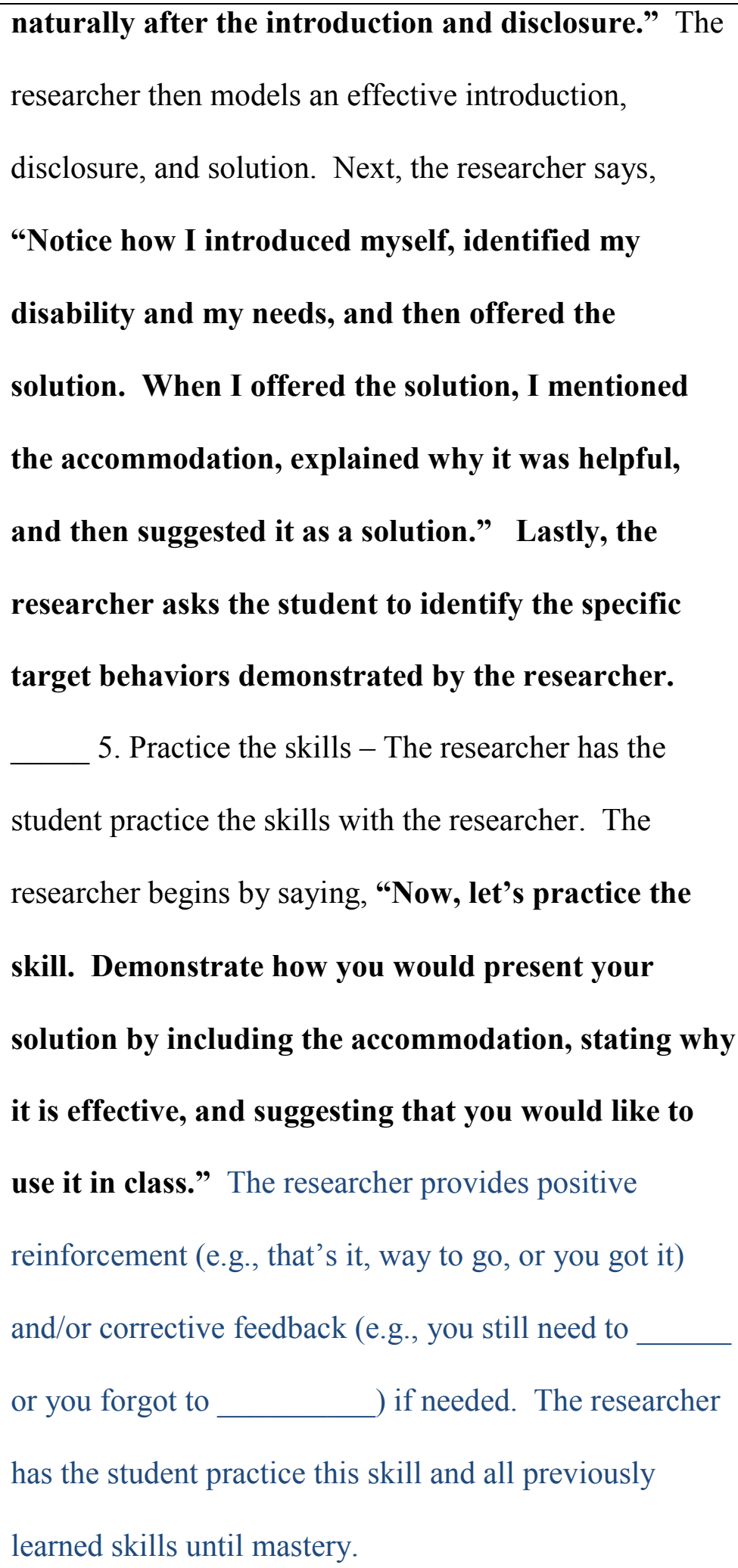




6. Summary - The researcher summarizes the
skills presented through the first three lessons. The
researcher states, "Up to this point you have learned to
introduce yourself, disclose your disability, and
present an effective accommodation to use in the
class. When offering the solution, remember to state
the accommodation, explain how it helps you, and
suggest it as a solution."
The researcher informs the student that they will be role-
playing this request for accommodations at the next
session, and the role-play will be video recorded.




\section{Session 5}

Lesson 4 Resources

Date of Session

- SACR Review - This session begins with the researcher reviewing the target skills from

Lessons 1-3 (i.e., Introduction, Disclosure, and

Solution) on the SACR poster. The student may

reference his or her binder during this review.

- Role-Play Probe - After the review, the researcher asks the student to role-play how he or she would request an accommodation from a teacher. The researcher reminds the student to include the targeted skills as well as any other skills he/she deems appropriate. The researcher states that the student will have an opportunity to view the role-play and write a reflection after the role-play has been completed. The student may use the Student Reflection Poster to assist him/her in generating ideas for the role-play reflection. After the student writes the reflection, the researcher and student will discuss the roleplay. The student may ask the researcher for clarification or support during this review. If a 


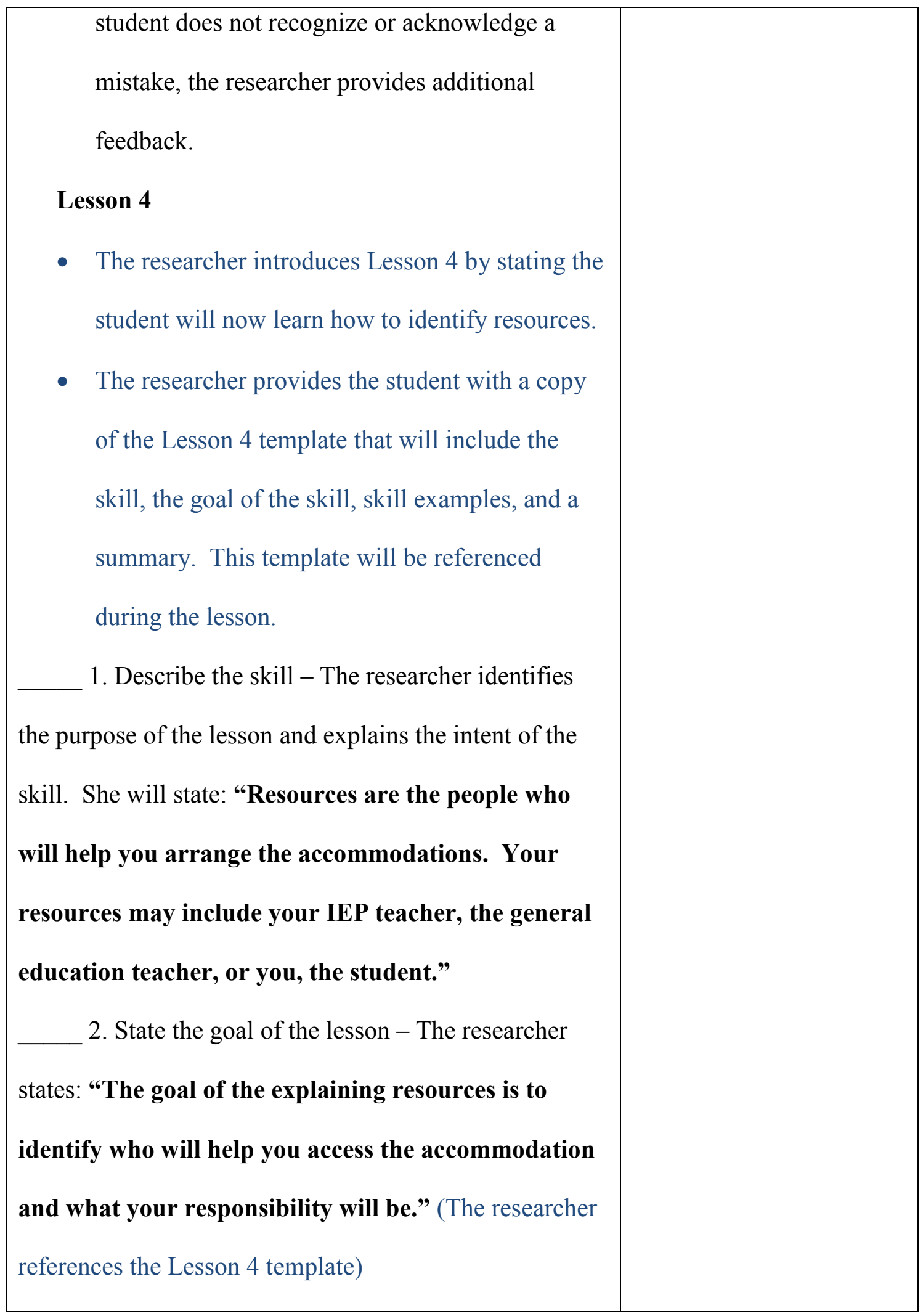




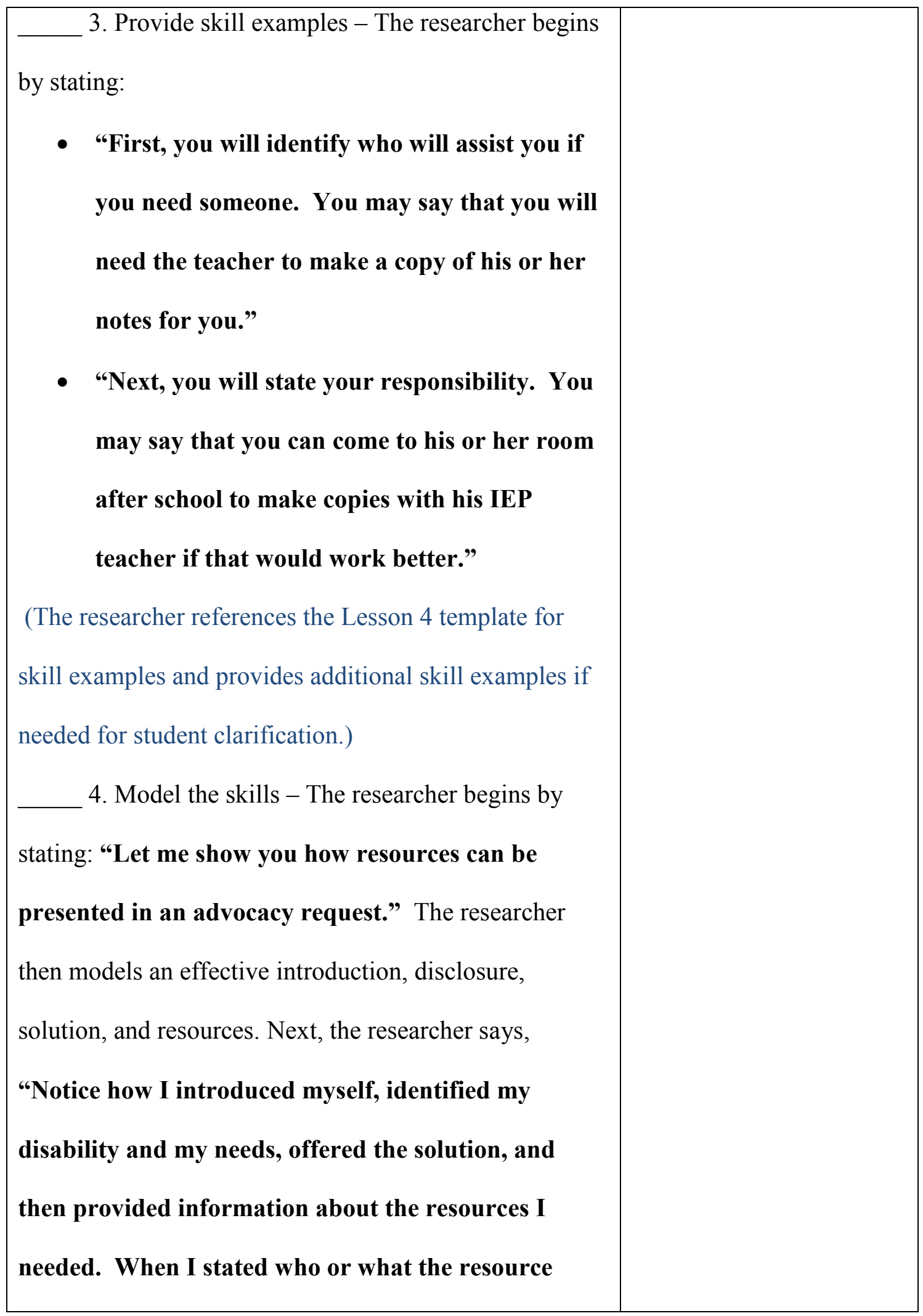




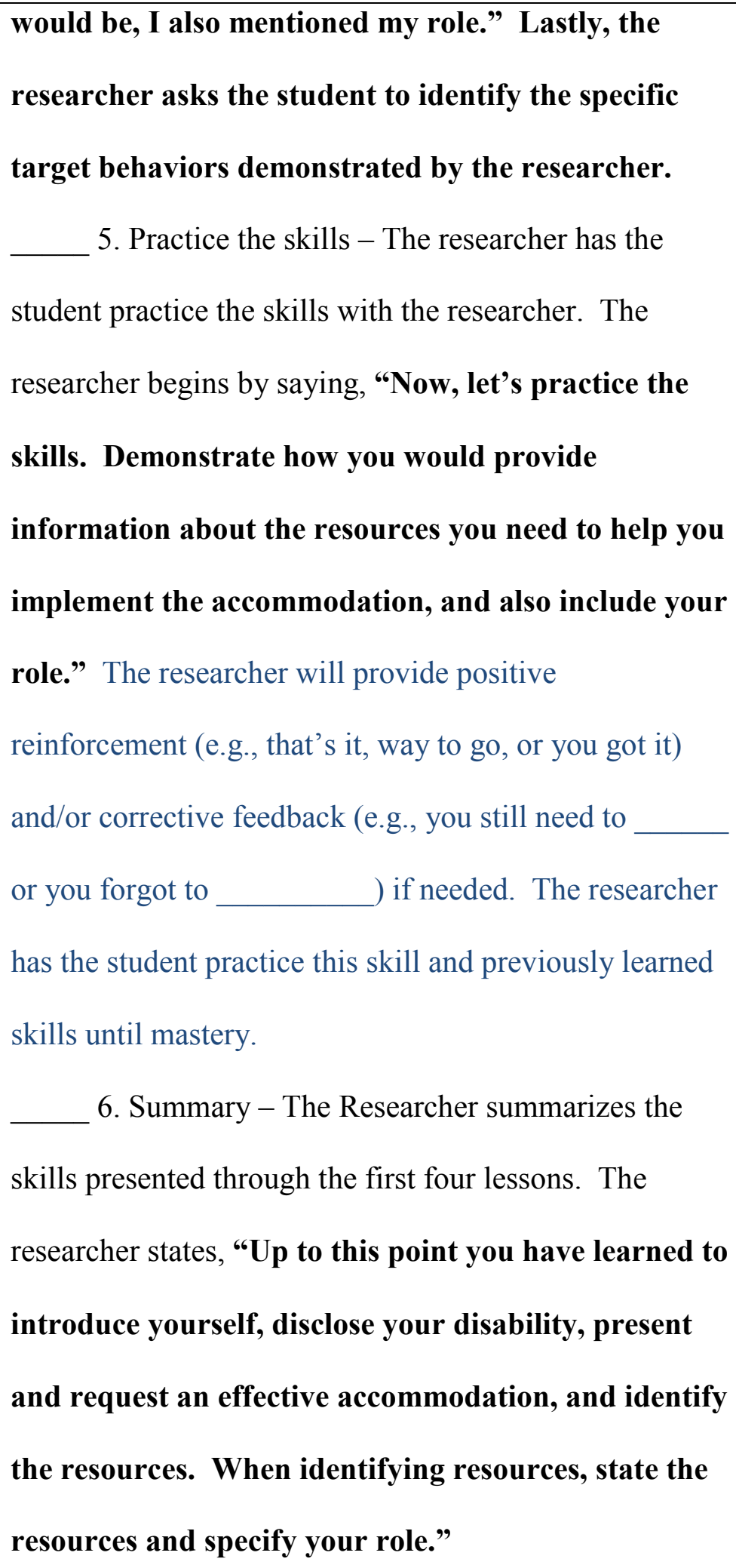


The researcher informs the student that they will be roleplaying this request for accommodations at the next session, and the role-play will be video recorded. 
Session 6

Lesson 5 Agreement

- SACR Review - This session begins with the researcher reviewing the target skills from Lessons 1-4 (i.e., Introduction, Disclosure, Solution, and Resources) on the SACR poster. The student may reference his or her binder during this review.

- Role-Play Probe - After the review, the researcher asks the student to role-play how he or she would request an accommodation from a teacher. The researcher reminds the student to include the targeted skills as well as any other skills he/she deems appropriate. The researcher states that the student will have an opportunity to view the role-play and write a reflection after the role-play has been completed. The student may use the Student Reflection Poster to assist him/her in generating ideas for the role-play reflection. After the student writes the reflection, the researcher and student discuss the role-play. The student may ask the researcher for clarification or 


\begin{tabular}{|c|c|}
\hline $\begin{array}{c}\text { support during this review. If a student does not } \\
\text { recognize or acknowledge a mistake, the } \\
\text { researcher will provide additional feedback. } \\
\text { Lesson } 5 \\
\text { - The researcher introduces Lesson } 5 \text { by stating the } \\
\text { student will now learn how to ask for agreement. } \\
\text { The researcher provides the student with a copy } \\
\text { of the Lesson } 5 \text { template that will include the } \\
\text { skill, the goal of the skill, skill examples, and a } \\
\text { summary. This template will be referenced during } \\
\text { the lesson. } \\
\text { 1. Describe the skill - The researcher identifies the } \\
\text { purpose of the lesson and explains the intent of the skill. } \\
\text { She states: "An agreement is the step when you ask the } \\
\text { teacher if the accommodation is acceptable to use in } \\
\text { class." } \\
\text { agreement with an affirming statement." (The } \\
\text { 2. State the goal of the lesson - The researcher }\end{array} \mid$ \\
\hline
\end{tabular}


by stating:

- "First, you will want to ask if the accommodation plan sounds agreeable. You might ask a question like: Does this plan work for you?"

- 'Next, you will respond to the teacher's agreement with an affirmative statement (e.g., Good, O.K., or Thanks)." (The researcher references the Lesson 5 template for skill examples or provides additional skill examples if needed for student clarification.)

4. Model the skills - The researcher begins by stating: "Let me show you how asking for an agreement is part of the self-advocacy process." The researcher then models an effective introduction, disclosure, solution, resources, and agreement. Next, the researcher says, "Notice how I introduced myself, identified my disability and my needs, offered the solution, identified resources, asked for agreement, and affirmed the agreement." Lastly, the researcher asks the student to identify the specific target behaviors 


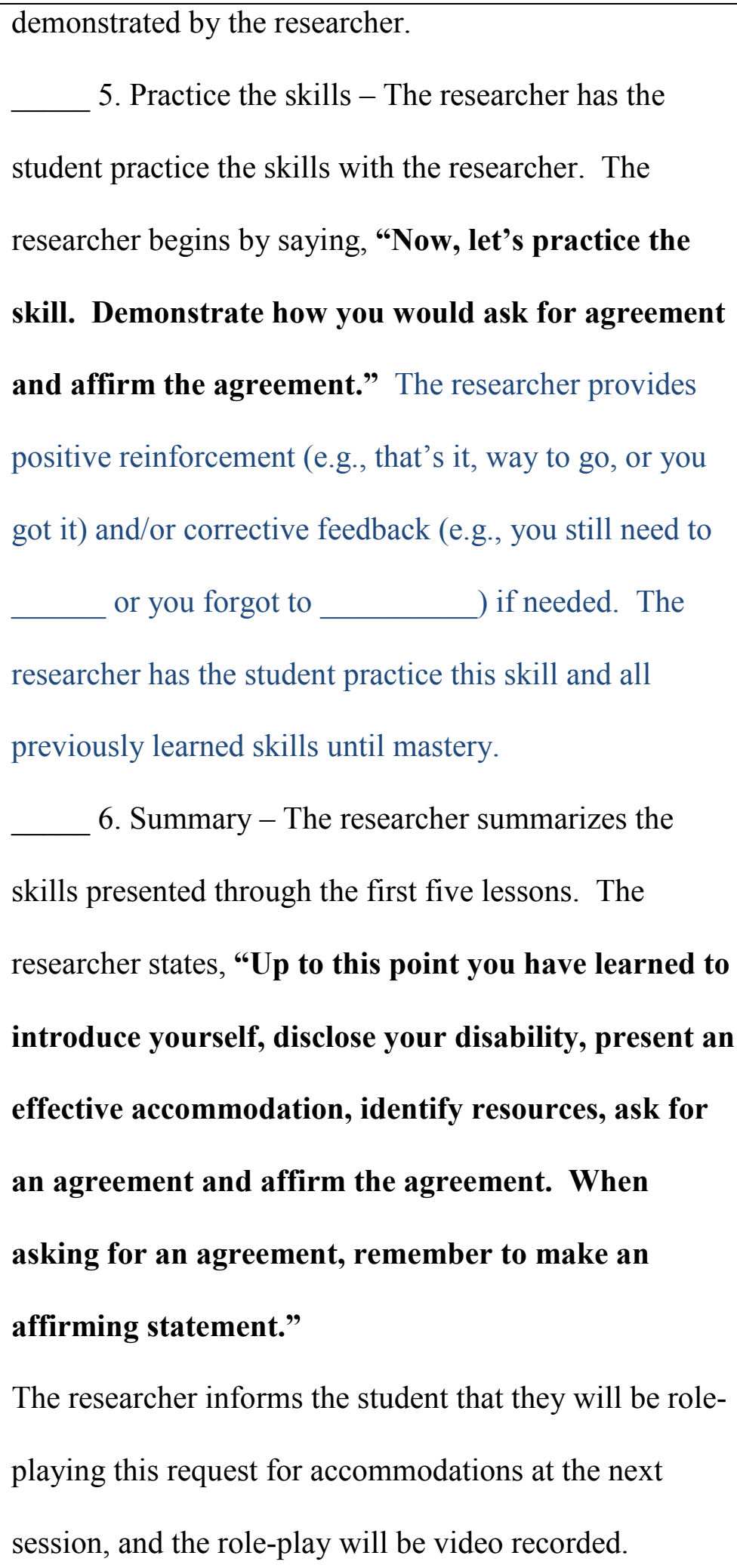


Session 7

Lesson 6 Summary

Date of Lesson

- SACR Review - This session begins with the researcher reviewing the target skills from

Lessons 1-5 (i.e., Introduction, Disclosure,

Completed yes or no

Solution, Resources, and Agreement) on the SACR poster. The student may reference his or her binder during this review.

- Role-Play Probe - After the review, the researcher asks the student to role-play how he or she would request an accommodation from a teacher. The researcher reminds the student to include the targeted skills as well as any other skills he/she deems appropriate. The researcher states that the student will have an opportunity to view the role-play and write a reflection after the role-play has been completed. The student may use the Student Reflection Poster to assist him/her in generating ideas for the role-play reflection. After the student writes the reflection, the researcher and student discuss the role-play. The student may ask the researcher for

If lesson was not completed, the researcher will begin with Step

Date lesson completed 


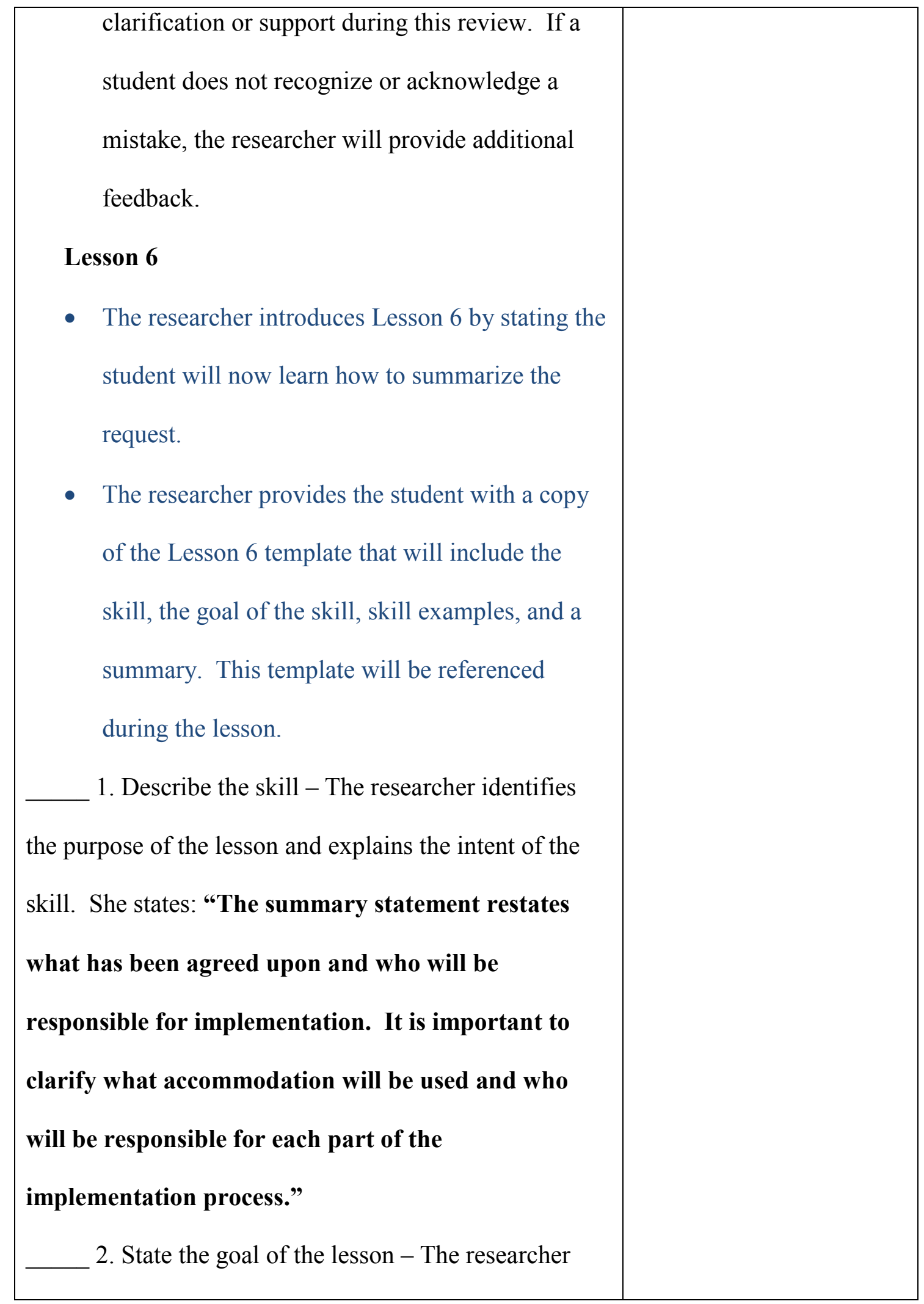


states: "The goal of the summary is to restate the
accommodation, state what you will do to implement
the accommodation, and state what the teacher's
involvement will be." (The researcher references the
Lesson 6 template)
3. Provide skill examples - The researcher begins

by stating:

- "First, you will restate the solution and resources. You might say: Good. I'll plan to use a preprinted copy of the class notes for each lesson that you present."

- "Next, you will state what you will do to arrange for the notes. You may say: I will make a copy of the notes the day before the lesson will be presented."

- "Then, specify what the teacher will need to do. You may say: You will help me by having an electronic copy of the notes on your web page so I can print them in the library."

- "If the teacher does not need to do anything, you may say: I will not need you to do anything. If I have any problems, I will let you 


$\begin{aligned} & \text { know." } \\ & \text { (The researcher references the Lesson } 6 \text { template for skill } \\ & \text { examples and provides additional skill examples if } \\ & \text { needed for student clarification.) } \\ & \text { 4. Model the skills - The researcher begins by } \\ & \text { stating: "Let me demonstrate a summary statement } \\ & \text { for you." The researcher then models an effective } \\ & \text { introduction, disclosure, solution, resources, agreement, } \\ & \text { and summary. Next, the researcher says, } \\ & \text { "Notice how I introduced myself, identified my } \\ & \text { disability and my needs, offered the solution, } \\ & \text { identified resources, asked for agreement, affirmed } \\ & \text { the agreement, and summarized the request. For the } \\ & \text { summary, I specifically summarized the } \\ & \text { accommodations and stated my role and the role of } \\ & \text { the teacher." Lastly, the researcher asks the student to } \\ & \text { identify the specific target behaviors demonstrated by the } \\ & \text { researcher. } \\ & \text { skill. Demonstrate how you would make a summary } \\ & \text { student practice the skills with the researcher. The }\end{aligned}$
researcher begins by saying, "Now, let's practice the




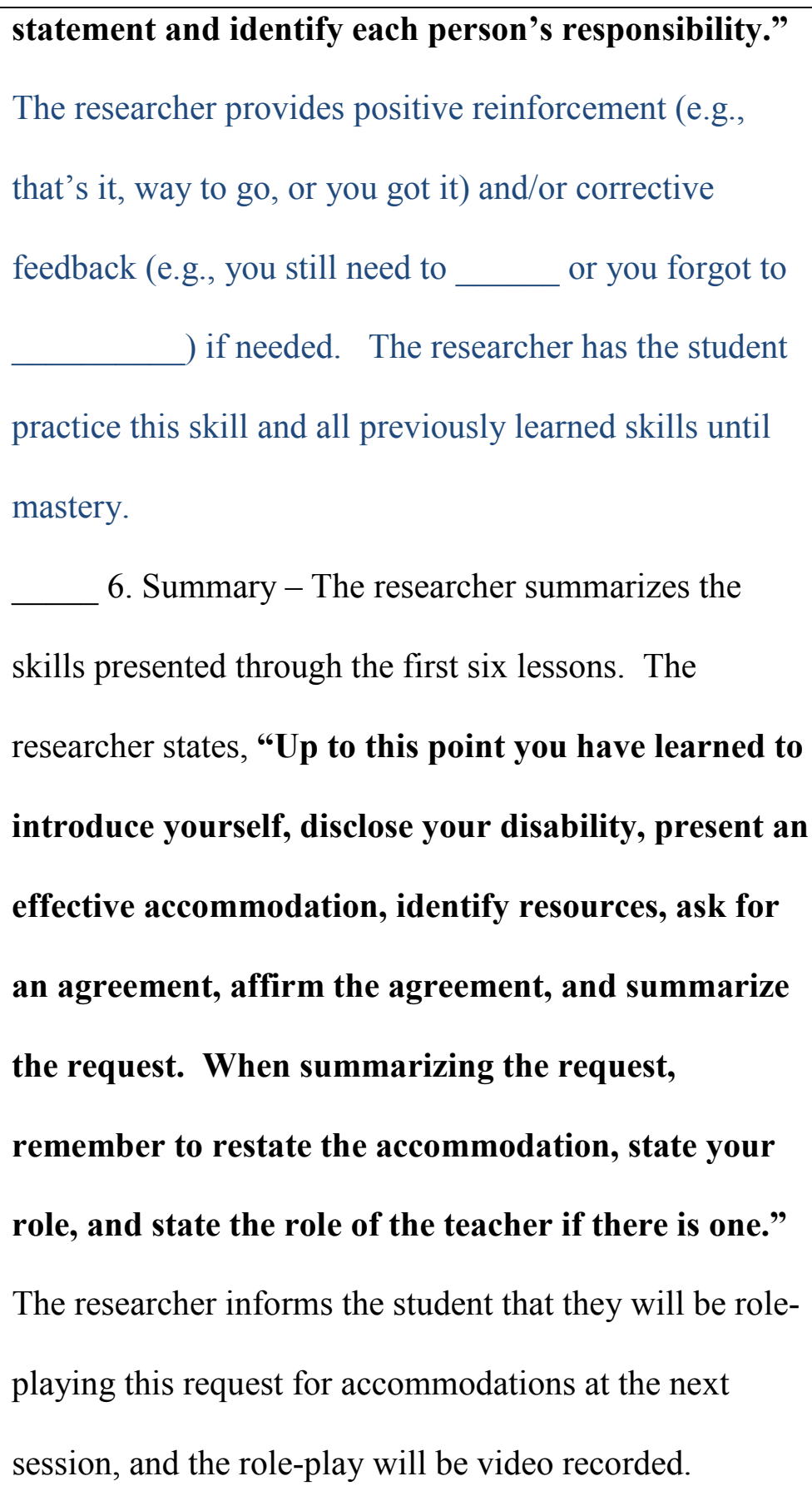




\section{Session 8}

Lesson 7 Closure

Date of Session

- SACR Review - This session begins with the researcher reviewing the target skills from

Lessons 1-6 (i.e., Introduction, Disclosure, Solution, Resources, Agreement, and Summary) on the SACR poster. The student may reference his or her binder during this review.

- Role-Play Probe - After the review, the researcher asks the student to role-play how he or she would request an accommodation from a teacher. The researcher reminds the student to include the targeted skills as well as any other skills he/she deems appropriate. The researcher states that the student will have an opportunity to view the role-play and write a reflection after the role-play has been completed. The student may use the Student Reflection Poster to assist him/her in generating ideas for the role-play reflection. After the student writes the reflection, the researcher and student discuss the role-play. The student may ask the researcher for 


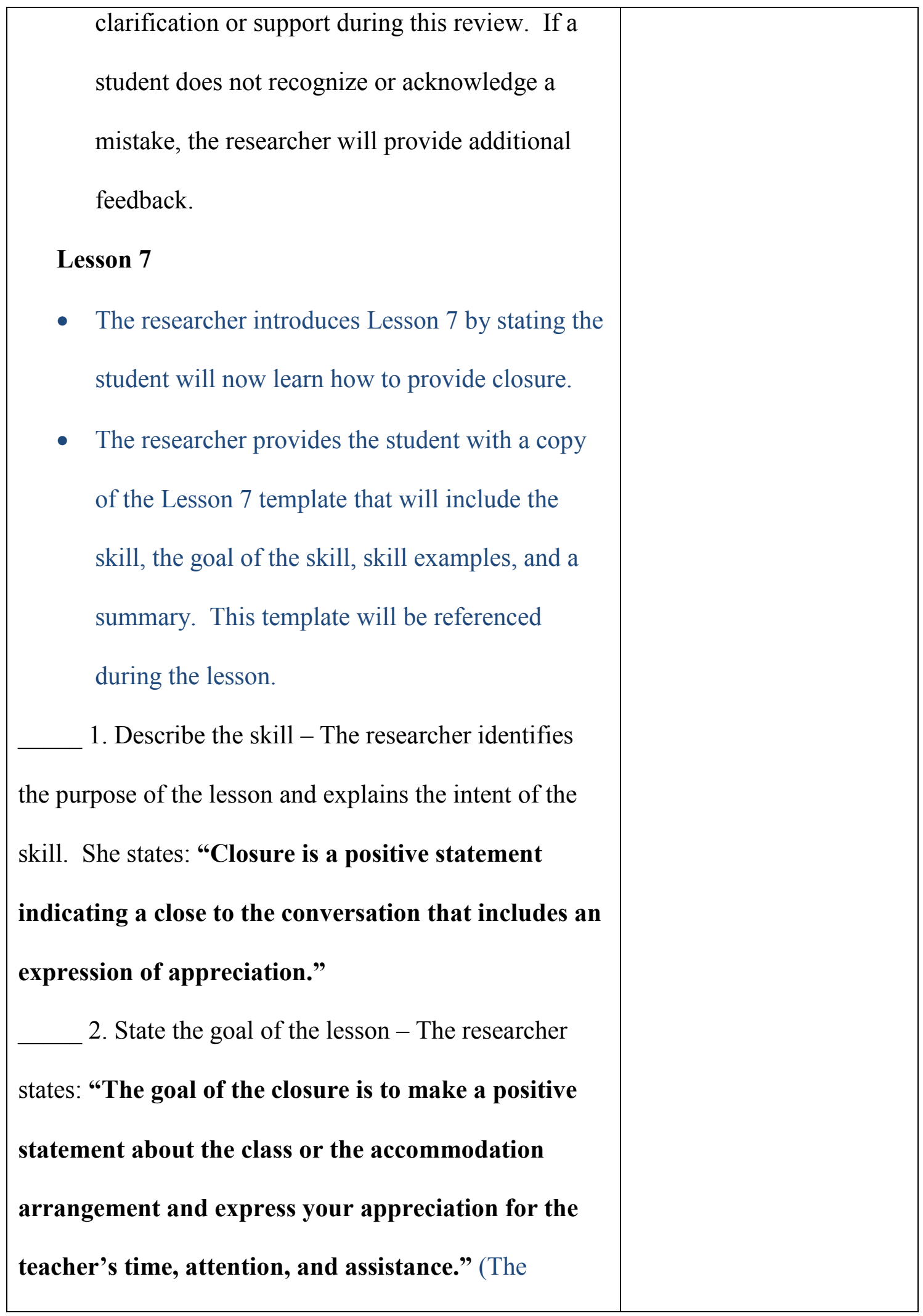


researcher references the Lesson 7 template)

3. Provide skill examples - The researcher begins

by stating:

- "First, you will make a general statement. You may say: I'm looking forward to your class."

- "Next, you will express your appreciation. You may say: Thanks for your help. "

(The researcher references the Lesson 7 template for skill examples and provides additional skill examples if needed for student clarification.)

4. Model the skills - The researcher begins by stating: "Let me demonstrate how closure works into the accommodation request process." The researcher then models an effective introduction, disclosure, solution, resources, agreement, summary, and closure. Next, the researcher says, "Notice how I introduced myself, identified my disability and my needs, offered the solution, identified resources, asked for agreement, affirmed the agreement, summarized the request, and provided closure. Notice I included a positive statement and an expression of 


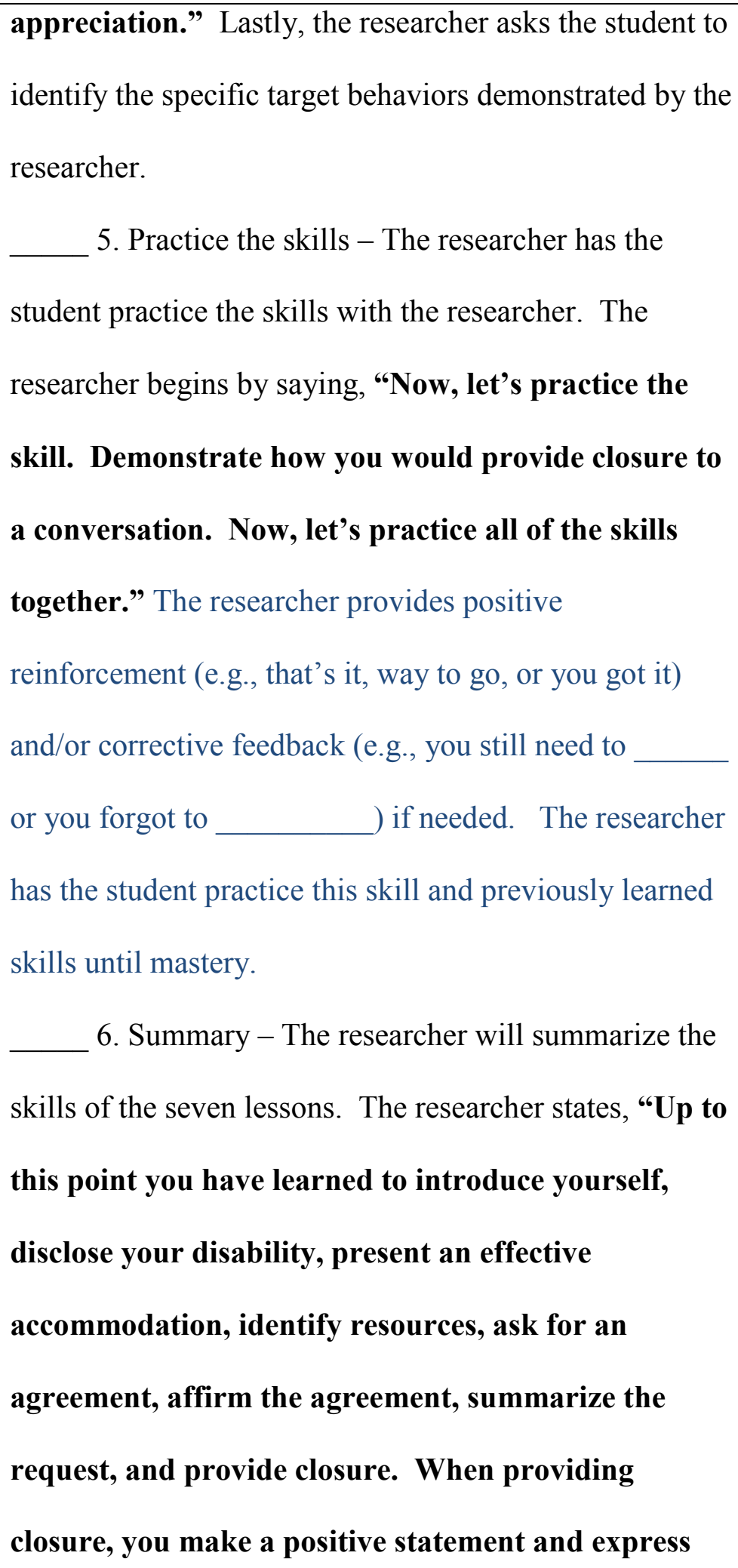

6. Summary - The researcher will summarize the skills of the seven lessons. The researcher states, "Up to this point you have learned to introduce yourself, disclose your disability, present an effective accommodation, identify resources, ask for an agreement, affirm the agreement, summarize the request, and provide closure. When providing closure, you make a positive statement and express 
your appreciation."

The researcher informs the student that they will be role-

playing this request for accommodations at the next

session, and the role-play will be video recorded. 
Sessions 9-10+

- SACR Review - These sessions begin with the

Date of Session

researcher reviewing the target skills from

Lessons 1-7 (i.e., Introduction, Disclosure,

Solution, Resources, Agreement, Summary, and

Lesson Completed

yes or no

Closure) on the SACR poster. The student may

reference his or her binder during this review.

- Role-Play Probe - After the review, the researcher asks the student to role-play how he or she would request an accommodation from a teacher. The researcher reminds the student to include the targeted skills as well as any other skills he/she deems appropriate. The researcher states that the student will have an opportunity to view the role-play and write a reflection after the role-play has been completed. The student may use the Student Reflection Poster to assist him/her in generating ideas for the role-play reflection. After the student writes the reflection, the researcher and student discuss the role-play. The student may ask the researcher for clarification or support during this review. If a 


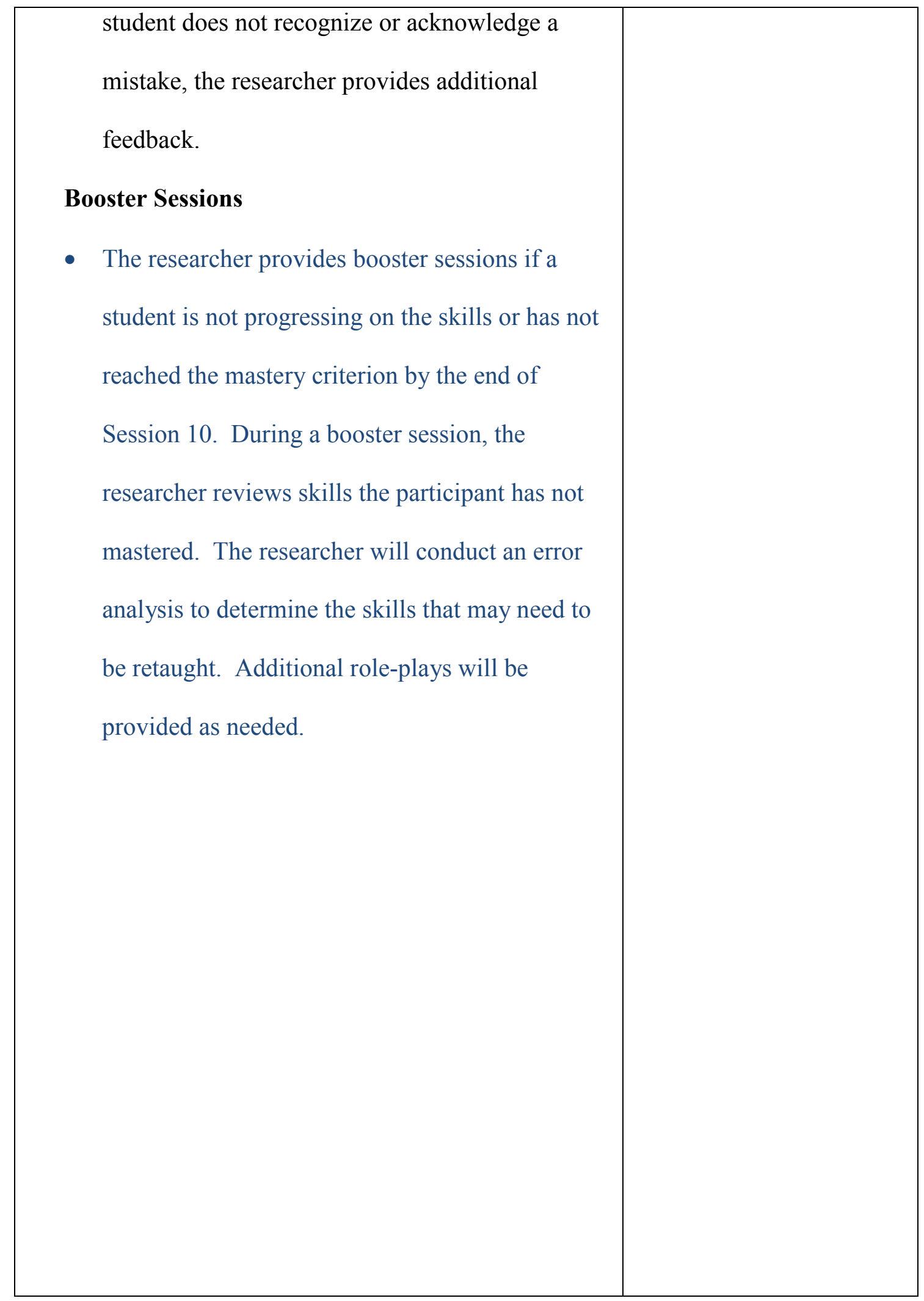




\section{APPENDIX N \\ DISABILITY AWARENESS LESSON PLAN}

\section{Session 1}

Date of Session

1. Researcher will state the objective.

Objective - As a result of this lesson, the students will be able to identify their disabilities, explain how their disabilities impact their ability to learn, and identify accommodations from their IEP that will enable them to be more successful in the classroom.

2. Researcher introduces and reviews vocabulary terms by defining the terms, clarifying the terms, and providing examples. Researcher provides students a copy of the chart that includes this information for each of the terms. A copy of this chart is located on page 2 of this lesson plan.

3. Researcher has the student complete the Disability Awareness Graphic Organizer. To accomplish this task, the student:

- Identifies his/her disability area from the IEP at a Glance report and writes the disability area on the graphic organizer.

- Identifies his/her strengths and needs that are included on Page 2 of his/her IEP and writes them on the graphic organizer. Student may add additional strengths and needs not listed on the IEP.

- Identifies his/her IEP accommodations from the IEP at a Glance report and writes them on the graphic organizer. Students may add accommodations that they have used in the past but are not listed on the IEP.

4. After the student has completed the Disability Awareness Graphic Organizer, the student orally identifies his or her disability area, learning needs, and an accommodation that he/she will eventually request from his/her general education content area teacher. 
5. Researcher provides the student with a notebook and explains that this notebook may be used as a resource during the intervention sessions. This notebook will contain the graphic organizer, lesson templates, and role-play reflections.

\begin{tabular}{|c|c|c|c|}
\hline Term & Definition & Clarification & Examples \\
\hline Disability Area & $\begin{array}{l}\text { The classification that } \\
\text { allows you to be } \\
\text { eligible for special } \\
\text { education supports } \\
\text { and services. }\end{array}$ & $\begin{array}{l}\text { The specific name } \\
\text { given for your } \\
\text { disability. }\end{array}$ & $\begin{aligned} \checkmark & \text { Learning } \\
& \text { Disability (LD) } \\
\checkmark & \text { Other Health } \\
& \text { Impairment } \\
& \text { (OHI) } \\
\checkmark & \text { Speech / } \\
& \text { Language } \\
& \text { Impairment } \\
& \text { (SPL) } \\
\checkmark & \text { Emotional } \\
& \text { Disturbance (ED) } \\
\checkmark & \text { Intellectual } \\
& \text { Disability (ID) }\end{aligned}$ \\
\hline Strengths & $\begin{array}{l}\text { Areas where you } \\
\text { excel. }\end{array}$ & $\begin{array}{l}\text { Things that you are } \\
\text { good at. }\end{array}$ & $\begin{array}{ll}\checkmark & \begin{array}{l}\text { Solving math } \\
\text { word problems }\end{array} \\
\checkmark & \text { Remembering } \\
& \text { what you hear } \\
\checkmark & \text { Working with } \\
\text { others }\end{array}$ \\
\hline Needs & $\begin{array}{l}\text { Areas where you } \\
\text { need extra support. }\end{array}$ & $\begin{array}{l}\text { Things you have } \\
\text { difficulty with. }\end{array}$ & $\begin{array}{ll}\checkmark & \text { Understanding } \\
& \text { what you read } \\
\checkmark & \text { Organizing your } \\
\text { thoughts for } & \\
\checkmark & \text { writing } \\
\checkmark & \text { Paying attention } \\
\text { in class }\end{array}$ \\
\hline Accommodations & $\begin{array}{l}\text { A support that } \\
\text { changes "the input } \\
\text { and/or output method } \\
\text { used by the teacher } \\
\text { and/or student related } \\
\text { to the intended } \\
\text { instructional } \\
\text { outcome" (King- } \\
\text { Sears, 2001, p. 73). }\end{array}$ & $\begin{array}{l}\text { A support that will } \\
\text { help you access, } \\
\text { learn, or } \\
\text { demonstrate } \\
\text { knowledge of the } \\
\text { course material. }\end{array}$ & $\begin{array}{ll}\checkmark & \text { Using electronic } \\
\text { books for } \\
\text { students who } \\
\text { have reading } \\
\text { difficulties } \\
\checkmark \quad \text { Having a graphic } \\
\text { organizer } \\
\text { available for } \\
\text { students who } \\
\text { have difficulties } \\
\text { organizing their } \\
\text { thoughts for } \\
\text { writing } \\
\text { assignments } \\
\checkmark \\
\text { Going to the } \\
\text { resource room to } \\
\text { receive testing } \\
\text { supports. }\end{array}$ \\
\hline
\end{tabular}

